San Jose State University

SJSU ScholarWorks

Master's Theses

Master's Theses and Graduate Research

1991

\title{
An historical and analytical study of Beethoven's fortepiano sonata in A Major, Opus 101 : a performance practice perspective
}

Marta Schermerhorn

San Jose State University

Follow this and additional works at: https://scholarworks.sjsu.edu/etd_theses

\section{Recommended Citation}

Schermerhorn, Marta, "An historical and analytical study of Beethoven's fortepiano sonata in A Major, Opus 101 : a performance practice perspective" (1991). Master's Theses. 212.

DOI: https://doi.org/10.31979/etd.rrj4-mpvp

https://scholarworks.sjsu.edu/etd_theses/212

This Thesis is brought to you for free and open access by the Master's Theses and Graduate Research at SJSU ScholarWorks. It has been accepted for inclusion in Master's Theses by an authorized administrator of SJSU ScholarWorks. For more information, please contact scholarworks@sjsu.edu. 


\section{INFORMATION TO USERS}

This manuscript has been reproduced from the microfilm master. UMI films the text directly from the original or copy submitted. Thus, some thesis and dissertation copies are in typewriter face, while others may be from any type of computer printer.

The quality of this reproduction is dependent upon the quality of the copy submitted. Broken or indistinct print, colored or poor quality illustrations and photographs, print bleedthrough, substandard margins, and improper alignment can adversely affect reproduction.

In the unlikely event that the author did not send UMI a complete manuscript and there are missing pages, these will be noted. Also, if unauthorized copyright material had to be removed, a note will indicate the deletion.

Oversize materials (e.g., maps, drawings, charts) are reproduced by sectioning the original, beginning at the upper left-hand corner and continuing from left to right in equal sections with small overlaps. Each original is also photographed in one exposure and is included in reduced form at the back of the book.

Photographs included in the original manuscript have been reproduced xerographically in this copy. Higher quality 6" $\times 9$ " black and white photographic prints are available for any photographs or illustrations appearing in this copy for an additional charge. Contact UMI directly to order.

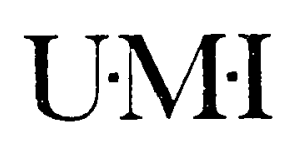

University Microfilms International

A Bell \& Howell information Company 300 North Zeeb Road. Ann Arbor. MI 48106-1346 USA

$313 / 761-4700 \quad 800 / 521-0600$ 

An historical and analytical study of Beethoven's Fortepiano Sonata in A Major, Opus 101: A performance practice perspective

Schermerhorn, Marta, M.A.

San Jose State University, 1991

Copyright (c)1992 by Schermerhorn, Marta. All rights reserved.

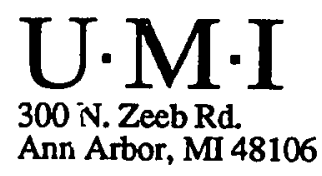





\title{
AN HISTORICAL AND ANALYTICAL STUDY OF BEETHOVEN'S FORTEPIANO SONATA IN A MAJOR, OPUS 101: \\ A PERFORMANCE PRACTICE PERSPECTIVE
}

\author{
A Thesis \\ Presented to \\ The Faculty of the Department of Music \\ San Jose State University \\ In Partial Fulfillment \\ of the Requirements for the Degree \\ Master of Arts
}

By

Marta Schermerhorn

August, 1991 
APPROVED FOR THE DEPARTMENT OF MUSIC

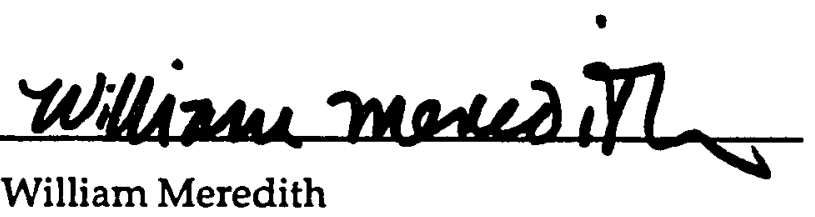

Dr. William Meredith
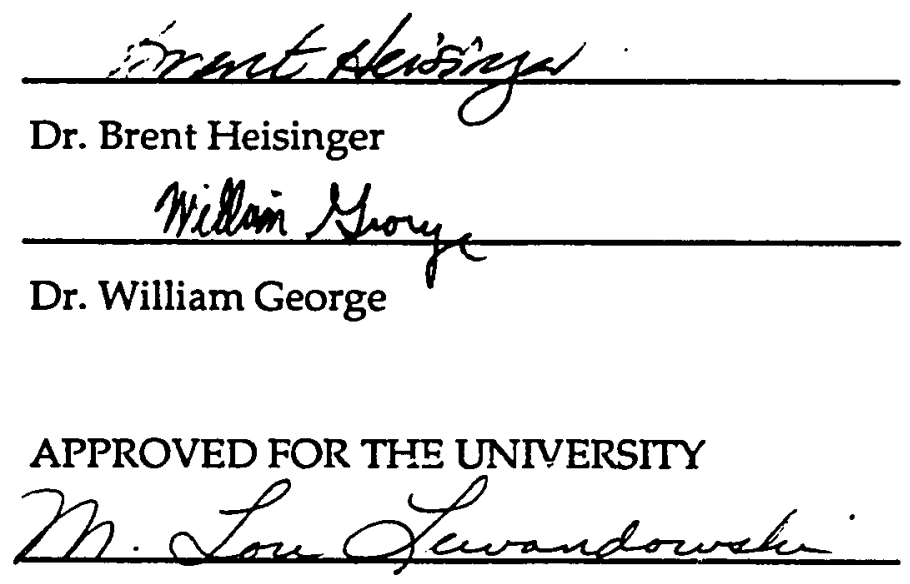


\begin{abstract}
This study examines historical and analytical aspects of Beethoven's Fortepiano Sonata in A Major, Opus 101, through the perspective of historically informed performance practices. The first part focuses on the biographical context of the sonata beginning with Beethoven's life and works from 1814-1816. The discussion of the chronological place and significance of Opus 101 illustrates Beethoven's emergence into his late period. The simultaneous developments of the fortepiano and Beethoven's late style are presented. Differences between the fortepiano and the modern piano are addressed. A detailed discussion of tempo indications and metronome markings for Opus 101 illustrates the importance Beethoven placed on selecting his intended tempos.

The second part of the study contains a formal analysis of the sonata with particular emphasis on the fantasy-sonata style. Beethoven's lyricism and interest in counterpoint are discussed as key expressive characteristics of his late style. The study concludes with be a philosophical exploration regarding an hermeneutic interpretation of Opus 101.
\end{abstract}




\section{TABLE OF CONTENTS}

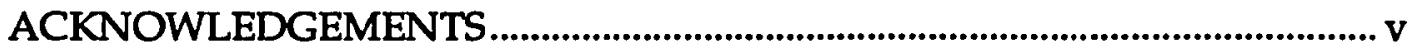

Chapter 1 Biographical Contexts-Beethoven's Middle and Late

Periods ........................................................................................................................ 1

Chapter 2 Chronological Place and Significance of Opus 101 ........................... 13

Chapter 3 The Role of the Fortepiano in Beethoven's Keyboard Works ........ 28

Chapter 4 Performance Practice Considerations for the Modern Piano ......... 42

Chapter 5 Dedication to Baroness Dorothea von Ertmann ..................................76

Chapter 6 Beethoven's Tempo Indications in Opus 101 ....................................... 82

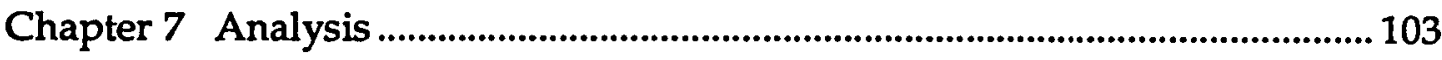

Chapter 8 Hermeneutic Interpretation of Opus 101 ............................................ 149

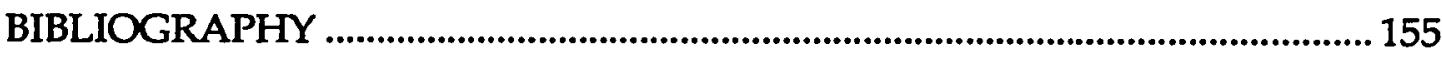




\section{ACKNOWLEDGEMENTS}

I would like to thank my thesis advisor, Dr. William Meredith, director of the Ira F. Brilliant Center for Beethoven Studies, for his assistance in the preparation of my master's thesis. I am very grateful to have had the privilege to work with him. His suggestions for sources of research material were invaluable to the completion of my thesis. Many thanks are also due to Pat Elliott, curator of the Beethoven Center, for her endless patience and helpful guidance in procuring research materials in the Beethoven Center. Her cheerful attitude and resourceful knowledge about Beethoven studies were always appreciated during the many hours I spent working in the Center.

I also wish to thank my graduate advisor, Dr. William George, for his constant encouragement and faith in my abilities to produce this academic research paper. I am particularly indebted to his careful attention to the bibliographical aspects of my thesis. To Dr. Brent Heisinger, I owe many heartfelt thanks for his thorough examination and suggestions regarding the musical analysis. His analytical viewpoints as a composer and scholar were extremely valuable.

I want to offer my special thanks to Christopher Schmidt for his computer wizardry. His patience and creative assistance with the technical formatting of my thesis are genuinely appreciated. I am also very grateful to my dear friend, Janice Rohn, for generously offering her valuable time to help me complete the final copies of my thesis at Apple Computer. My sincerest thanks are extended to my family for all of their love and support throughout the duration of researching and writing my thesis. 


\section{Chapter 1}

Biographical Contexts: Beethoven's Middle and Late Periods

After toiling for the twenty years from the mid-1790s to 1814, Beethoven had achieved considerable fame by the end of his middle period. The peak of Beethoven's glory came in 1814, due in part to the opening of the Congress of Vienna, an event which brought all of the crowned heads of Europe to Europe's musical capital. Beethoven composed a short chorus entitled Ihr weisen Gründer glückliche Staaten, WoO 95, which was performed at the beginning of the Congress to welcome the visiting rulers. To celebrate the occasion of the Congress itself, Beethoven's revised opera Fidelio was performed for the monarchs on November 26. Dr. Alois Weissenberg, who was a great admirer of Beethoven, attended the Congress and the opera performance. Weissenberg logged in his record book that "To-day [sic] I went to the Court Theatre and was carried to heaven-the opera Fidelio by L. v. Beethoven was given." 1 On November 29, a grand concert featuring Beethoven's cantata Der glorreiche Augenblick, Opus 136, "Wellington's Victory" for orchestra, Opus 91, and the Symphony No. 7 in A major, Opus 92, was performed in the Redoutensaal for the assembled royalty. Several foreign dignitaries, including the Tsarina of Russia and Prince Rasumovsky, flattered Beethoven with lavish compliments and expressed their respectful admiration for his musical contributions. Beethoven was "an object of general curiosity to all the foreign visitors, for it is the lot of genius, particularly when that genius is accompanied by an element of the

${ }^{1}$ Elliot Forbes, ed., Thayer's Life of Beethooen (Princeton: Princeton University Press, 1973), 594. Hereafter: Thayer-Forbes. 
heroic, to attract that attention of the nobility." 2 Besides enjoying his well deserved fame, Beethoven also reaped substantial financial profits. The investments in bank shares and the restoration of the annuities from the Kinsky family and Prince Lobkowitz yielded a significant income for Beethoven. Maynard Solomon speculates that Beethoven's musical contributions to the Congress of Vienna illustrate a pivotal change of direction in music history. Besides his political compositions for the Congress, Beethoven's only other works of great significance in 1814 were the Fortepiano Sonata in E minor, Opus 90, and the final revision of Fidelio. Solomon suggests that the "frenetic activity and meretricious productivity of the Congress period may temporarily have diverted Beethoven from the consciousness that he had no major creative projects in progress, no challenging musical issues at hand." ${ }^{3}$ At this time, Vienna was recovering from the Napoleonic Wars and shifting into the post-Enlightenment period. The essence of heroic endeavor and enthusiasm had subsided and a new phase of Austrian nationalism began to emerge. Although Beethoven's "Heroic period" had come to an end by 1814 , he was still somewhat unresolved about the issue of heroism. For the most part, Beethoven seemed uninspired by the musical works of his contemporaries. He continued to search for the answer to his more mature style of expression by reflecting back in time and observing the music of the old masters-Bach, Händel and Palestrina. Solomon contends that Beethoven proceeded to incorporate into his late works "the portrayal of heroism

2 Anton Felix Schindler, Beethooen As I Knew Him, edited by Donald MacArdle and translated by Constance Jolly (New York: W. W. Norton and Co.1972), 205.

3 Maynard Solomon, Beethooen (New York: Schirmer Books, 1977), 227. 
without heroics, without heroes." 4

The jubilation surrounding Beethoven's fame and fortune was abruptly altered toward the end of 1815. Caspar Carl, Beethoven's brother, died of tuberculosis on November 15, 1815. Beethoven had been especially fond of Caspar Carl and was genuinely concerned ahout the welfare of Caspar Carl's young son Karl. In his last will and testament, dated November 14, 1815, Caspar Carl appointed his brother, Ludwig van Beethoven, as Karl's guardian. Beethoven was overwhelmingly possessed with a feeling of paternal responsibility toward Karl. He was also obsessed with the notion of rescuing Karl from his mother, Johanna. According to Editha and Richard Sterba's psychological study of Beethoven's behavior, they conclude that Beethoven perceived Karl as a "suitable substitution for [his] brother as an object of maternal love. Hence the child must be wrested from his real mother." 5

On November 17, 1815, a codicil to the will (dated November 14, 1815) was relinquished to the Austrian Court. In the codicil, Caspar Carl cancelled Beethoven's primary custody of Karl and indicated "for the welfare of my child I recommend compliance to my wife and more moderation to my brother." 6 Beethoven was enraged over the loss of sole custody. Solomon interjects that, at this point in time, "Beethoven was beginning to have trouble distinguishing fantasy from reality."7 In Beethoven's distorted opinion, Johanna was an unfit

${ }^{4}$ Solomon, 230.

5 Editha and Richard Sterba, Beethoven and his Nephew: A Psychological Study of Their Relationship, translated by Willard R. Trask (New York: Schocken Books, 1971), 52.

6 Thayer-Forbes, 625. 
mother for Karl, in part, because she was a woman. In the Sterbas's analysis of Beethoven's attitude toward women, they contend that

in Ludwig's view, his brother Carl had been destroyed by Johanna; three years earlier, he had lost his brother Johann to a woman. But he still had a close male relative whom he could save from woman's fated claws. This was his nephew. The nine-year-old boy entered perfectly into the pattern of a continuation of Ludwig's struggle against Johanna for his brother Carl. 8

Neglecting his composing almost entirely, Beethoven time was completely consumed with numerous hours spent in litigation, correspondence, arguments, and personal torment to appeal for the custody of Karl. Beethoven agonizingly struggled for exclusive guardianship of Karl in the courts by denouncing Johanna's character with alleged claims of embezzlement and lurid sexual behavior (calling her the "Queen of the Night"). Many of Beethoven's accusations against Johanna were later discovered to be unfounded. According to the Sterbas's investigation of the truth behind Beethoven's appeal to the courts for custody of Karl:

We encounter almost insuperable difficulties when we attempt to obtain a picture of Johanna's personality. Beethoven, in his burning hatred of the woman, has represented her in his statements as abysmally evil, and the power and influence of his own personality have forced everyone to see her as he wished her to be seen. ${ }^{9}$

The death of Caspar Carl and the discrepancies of the will concerning Beethoven's guardianship of Karl was "one of the most important and at the

\footnotetext{
${ }^{7}$ Solomon, 235.

8 Sterbas, 51-2.

${ }^{9}$ Sterbas, 53.
} 
same time most melancholy events in Beethoven's life-an event which exerted the profoundest [sic] influence on the rest of his life."10

Another disappointment in Beethoven's life was his failed attempt to establish a family of his own. The custody of Karl represented Beethoven's only hope for an experience in parenthood. Beethoven enrolled Karl as a boarder and pupil in a private school directed by Cajetan Giannatasio del Rio. Because he was suspicious of Johanna's clandestine visits to the school against the strict contract of visitation rights, Beethoven withdrew Karl from the school. Beethoven hired a private tutor so Karl could live with him. Johanna continued to appeal to the court for custody of Karl and Beethoven fervently fought back. The four-year struggle for custody ended in July 1820 when the court's final decision named Beethoven as Karl's legal guardian.

In addition to the death of his brother and the self-assumed responsibility of his nephew, Beethoven experienced even more personal hardships, including his continually worsening health, the arrival of near total deafness, and an increase of his paranoia regarding money. Beethoven was suffering from the pains of his physical illness as well as emotional exhaustion both in his personal and creative life. Around 1815 Beethoven's suffering increased from the effects of abdominal malady. His excessive consumption of wine also contributed to the deterioration of his health; by 1820 the first signs of liver disease appeared with the symptoms of jaundice. 11 Unfortunately, Beethoven was probably carrying on the family tradition of alcohol addiction.

10 Thayer-Forbes, 623.

11 Solomon, 257. 
In a letter to his dear friend Ferdinand Ries, dated February 28, 1816, Beethoven admitted 'T have not been well for some time; my brother's death affected my spirit and my work."12 In the same letter to Ries, Beethoven expressed his feelings of responsibility in honoring his brother's original wishes for Karl's welfare: "Yet I have the sweet consolation of having saved a poor innocent child from the hands of an unworthy mother."13 Quite contrary to Beethoven's perception of Johanna's capabilities as a mother, the Sterbas's study clarifies the reality of Johanna's character, as follows:

It must be emphasized that there is no evidence that Johanna was a bad mother, that she neglected or mistreated her son; she was concerned for her child, and she suffered under the inhuman cruelty with which Beethoven kept him from her for many years. In addition, the surviving descriptions of the boy during the time succeeding his father's death indicate that he was well behaved and exhibited no pathological traits; this supports the assumption that Johanna was not a bad mother. ${ }^{14}$

Although Beethoven's physical health was deteriorating rapidly, he found great emotional strength and comfort in winning the lawsuit against Johanna.

Beethoven experienced a sense of assurance and fulfillment with the opportunity to be a loving paternal-and maternal-figure for Karl. Sterba deduces that:

A feeling of joy possessed him, such as nothing in his life before or after ever aroused in him. We may say that the acquisition of the boy was the most significant experience of which we have any knowledge throughout

12 Franz Wegeler and Ferdinand Ries, Beethoven Remembered: The Biographical Notes of Franz Wegeler and Ferdinand Ries (Arlington: Great Ocean Publishers, 1987), 123. Hereafter: Wegeler-Ries.

13 Wegeler-Ries, 123.

14 Sterbas, 54. 
his life. From then until his death, his relationship to his nephew remained his most important emotional experience. 15

Around 1798 Beethoven was afflicted with the first stages of deafness and by 1815 was almost completely deaf. On January 25,1815 , Beethoven gave what would be his last public performance as a pianist, accompanying the singer Franz Wild for a concert celebrating the Russian Tzarina's birthday. The grief Beethoven suffered over the deterioration of his hearing heightened his vulnerability as a composer and a member of society. This sense of vulnerability directly effected his pride and self-confidence and caused him to become even more suspicious and mistrusting of people and their intentions. Because of Beethoven's notoriety as being politically blasphemous and almost neurotically erratic, the general populace "considered Beethoven not merely deaf, but a misanthrope, a recluse, and an eccentric." 16

Although Beethoven was financially quite comfortable toward the end of his middle period, the expenses of court costs, plus the schooling and care of Karl, had decreased his income. Beethoven's reduction in income was also a result of his lack of musical output for publication. Only in Beethoven's mind had he convinced himself that he destined to poverty. The Sterbas's assessment of Beethoven's paranoia about being destitute follows:

These traits of petty economy, of exaggerated interest in figures and sums of money, and of heightened anxiety concerning the possession of objects scarcely important or even svorthless, are familiar to psychologists. It is well known that persons who have reached the age at which their sexual interest slackens exhibit the ahove-described attitude toward poverty to a

\footnotetext{
15 Sterbas, 55.

16 Solomon, 257.
} 
far greater degree than formerly. It corresponds to a psychological regression, and often goes hand in hand with an increase of interest in their own digestive processes. If Ludwig, after the death of his brother [C]arl, showed a markedly heightened and petty interest in money and possession, if his defensive attitude toward all possible losses increased, while at the same time his complaints of intestinal upsets became more and more frequent, we cannot but conclude that, though biologically still in full possession of his virility, psychologically he was regressing. 17

Even though, in reality, he was financially secure, Beethoven eagerly accepted commissions of lesser musical significance to help increase his income. Beethoven agreed to arrange the instrumental and vocal settings of approximately 180 Scottish airs for an amateur musician named George Thomson of Edinburgh ${ }^{18}$. One of the practical reasons Beethoven undertook this commission was because he needed the added income. In a letter to Ries dated 8 March 1816, Beethoven explained the circumstances of his financial situation as follows:

My answer comes somewhat late-However, I was ill and have had a lot to do.....Not a penny of the 10 ducats in gold has arrived so far, and I am beginning to believe that the English, too, are only generous when abroad; the same applies to the Prince Regent, from whom I did not even receive the copying costs for my Battle [Battle of Vittoria] which I sent him, indeed not even a word or note of thanks....My salary amounts to 3400 florins in paper money. I pay 1100 rent; my servant and his wife $900 \mathrm{fl}$; you can work out what remains. At the same time I have to support my little nephew completely; until now he has been at boarding school; this costs up to $1100 \mathrm{fl}$. and is still not satisfactory, so that I have to establish a regular household before I can bring him to live with me. How much one has to earn merely to be able to live here; and yet there is no end to it, because-because-because-you know what I mean.19

17 Sterbas, 121.

18 Solomon, 297.

${ }^{19}$ Wegeler-Ries, 123-4. 
In 1816, Beethoven employed Anton Schindler to be his private secretary and servant, but virtually without pay. 20 Schindler was entrusted with all of Beethoven's demanding correspondence affairs with publishers and lawyers. Schindler commented on Beethoven's multiple conflicts as having

a debilitating effect on his morale-such were the fateful occurrences that followed one another in almost uninterrupted succession, and many of them gave rise to long periods of depression. ${ }^{21}$

Schindler's biography of Beethoven is not considered to be the most reliable source of information on Beethoven, even though he was Beethoven's first biographer. The biography contains many of Schindler's fabrications about Beethoven's life and works; there are significant omissions of important information about Beethoven-especially his late: life-due to the fact that Schindler destroyed two-thirds of the Conversation Books.22 According to Solomon, Schindler's "attitude toward Beethoven himself was compounded of servility, worship, and hatred in more or less equal parts, all of which alternate freely in his unreliable biographical studies of the composer."23

Given these circumstances, it is a wonder that Beethoven continued to compose at all. But as he became more isolated from society, Beethoven explored deeper within himself to find a more intimately passionate expression in his music. As Dannreuter eloquently states:

20 Joseph Kerman and Alan Tyson, The New Grove: Beethooen (New York: W.W. Norton and Co., 1986), 60. Hereafter: Kerman-Tyson.

21 Schindler, 200.

22 Solomon, $x$.

23 Solomon, 260. 
He passes beyond the horizon of a mere singer and poet, and touches upon the domain of the seer and the prophet; where, in unison with all genuine mystics and ethical teachers, he delivers a message of religious love and resignation, identification with the suffering of all living creatures. 24

Between 1813 and 1815, Beethoven's production of musical works diminished considerably. The compositions for the Congress of Vienna, including Wellington's Victory and the two Cello Sonatas, Opus 102, represent the major works during this transition into Beethoven's late period. One explanation for Beethoven's pattern of lean productivity from the end of 1815 to 1818 could have been his excessive preoccupation with the custody and welfare of Karl. But in 1816 Beethoven's focus of creative powers was restored. Two important works were composed in 1816. In April Beethoven set the song cycle An die Ferne Geliebte, Opus 98, to music, inspired in part by the poetry of Alois Jeitteles. Beethoven was grateful to the young poet (and medical student) for the uplifting inspiration it brought to his music during such an unhappy time in his life.

In November Beethoven completed the Fortepiano Sonata in A major, Opus 101, which was "the first of the great set of late pianoforte sonatas for which, as we shall see, Beethoven was to ponder as to the best word for Hammer-action when printing the title."25 Rough sketches of the sonatas were composed the previous year about the same time as the two Cello Sonatas, Opus 102. But during the summer of 1816 Beethoven devoted his attention to thoroughly working out the final composition of the sonata. 1951), 106.

24 George Grove, Beethoven, Schubert, Mendelssohn (London: MacMillan and Co. Ltd.,

25 Thayer-Forbes, 655. 
During his late period Beethoven's circle of friends and patrons also went through a transitional phase dictated by "death, emigration, or personal estrangement." 26 Toward the end of 1812 one of Beethoven's patrons, Prince Kinsky, suddenly died. Prince Lichnowsky died in 1814, ending the patronage of a twenty-year association of unfailing support and admiration for Beethoven. Besides Schindler, old friends such as Count Moritz Lichnowsky, Baron Pasqualati, Stephan von Breuning, Domanovecz von Zmeskall, Johann Streicher, Ignaz Schuppanzigh, and new friends including Johann Mälzel, Franz Oliva and Karl Bernard comprised the variety of Beethoven's friendships. Count Brunsvik, Count Razumovsky and Baron Gleichenstein left the intimate circle of Beethoven's friends due to their various travels away from Vienna. One of Beethoven's only remaining friends of the aristocracy was Archduke Rudolf. In addition to his quarrel with Breuning which temporarily ended their relationship in 1817, Beethoven also felt the loss of Schuppanzigh, who had taken a conducting position in a court orchestra in Russia. Oliva also left Vienna in 1817 to teach German literature in St. Petersburg. The deprivation Beethoven experienced over the lost friendships of Breuning, Schuppanzigh and Oliva was deeply painful. Schindler suggests that

If Schuppanzigh was the frequent stimulus (sometimes even the coercer, and in his own interests) to Beethoven's composing or conducting, Breuning was the constant, thoughtful, selfless guide and helper in moments of trouble. He and Beethoven did not meet again until 1826, after both men had aged by nine years. ${ }^{27}$

26 Solomon, 228.

27 Schindler, 202. 
The many conflicts and disappointments leading up to his late period caused Beethoven to retreat into his own private world, devoid of the possibility of a wife and family. Isolated from the outside world with little remaining except his creative powers, Martin Cooper intimates that Beethoven's

rages and hates were the rages and hates of frustration, of resentment at the unreal world of everyday needs impinging on his creative activities, and at human beings who seemed to conspire to ignore or misunderstand the purity and nobility of his intentions." 28

In a letter addressed to Archduke Rudolf, Beethoven expressed the resolution of his faith in humanity, God and nature as validating his self-worth. Solomon concludes that "Humanity, God, and Nature' were Beethoven's spiritual Trinity, which stood as the foundation of an ever-ascending superstructure of faith and expectation, and which would not fail to leave its impress upon his last works." 29

28 Martin Cooper, Beethoven: The Last Decade, 1817-1827 (London: Oxford University Press, 1970), 130.

29 Solomon, 264. 


\section{Chapter 2}

Chronological Place and Significance of Opus 101

By 1815 Beethoven had composed twenty-seven fortepiano sonatas with opus numbers in which he displayed his familiarity with the general parameters of the Classical sonata forms. Beethoven's fortepiano sonatas (including WoO and Opus numbers) span almost the entire length of his career and life, beginning in 1782 with $\mathrm{WoO}$ and continuing until Opus 111 in 1822. The sonatas composed during Beethoven's first period (1782 to 1802) reflect the composer's essentially imitative style of Classical design based on his studies of Mozart and Haydn. But even in his early sonatas Beethoven began to experiment and expand beyond the structure of the well-established three-movement sonata form. With the exception of the two-movement sonatas (WoO 5; WoO 51; and Opus 49, Nos. 1 and 2), nine of the sonatas have four movements while the remaining twelve sonatas maintain the traditional three-movement structure. Toward the end of the first period, it is noteworthy that Beethoven labeled the two sonatas of Opus 27 "quasi una fantasia," representing his desire to create greater freedom of expression by loosening the restrictions of form within and between the movements. Freedom of expression and form are masterfully demonstrated in Beethoven's last five sonatas in which he fully manifested the quasi una fantasia style without actually labeling the sonatas as such.

The six sonatas (Opuses 53, 54, 57, 78, 79 and 81a) composed between 1803 to 1812 exemplify Beethoven's "Heroic period" (1802-1812). ${ }^{30}$ Beethoven's 
"Heroic period" was initially inspired by the new ideals of the Enlightenment, which ultimately led to the French Revolution. For Beethoven, Napoleon represented the hero who was destined to rescue humanity from the servile bonds imposed by the nobility. By encouraging freedom for individual achievement, Napoleon symbolized the embodiment of the Age of Revolution. The three highly significant sonatas of the "Heroic period" are the "Waldstein," Opus 53, the "Appassionata," Opus 57 and the Les Adieux, Opus 81a. Although the magnificent scope and breadth of these sonatas are awesome in expression and design, Beethoven steadfastly maintains the three-movement architecture of the Classical sonata. Beethoven's musical expression in these three sonatas demonstrate a more personal and direct emotional response than his earlier sonatas.

In the spirit of Beethoven's "Heroic period," Donald Tovey exclaims that "in the Waldstein Sonata Beethoven crossed the Rubicon ... [suggesting] an irrevocable act of war." 31 In the "Appassionata" Beethoven bases the first movement on a fate motive which conveys a tragic sense of doom throughout the sonata. The dramatic effect of the extreme dynamic contrasts demonstrates Beethoven's intensely emotional style of expression. For example, the three movements of Les Adieux depict the emotions of the parting, absence and reunion of a great friendship. More specifically, the sonata narrates Beethoven's emotions of the parting, absence and reunion with Archduke Rudolf. Tovey ascertains that "the music is a monument to the friendship of two men, deep as

30 Maynard Solomon, Beethoven (New York: Schirmer Books, 1977), 126.

31 Donald Tovey, A Companion to Beethoven's Pianoforte Sonatas: Bar to Bar Analysis (London: Associated Board of Royal Schools of Music, 1931), 156. 
any friendship formed in school days or in the full stress of life, and manly as Beethoven's ripest art."32 Beethoven reverently inscribed the dedication the sonata to Archduke Rudolf as "written from the heart and dedicated to H.R.H." 33 For the first time Beethoven entitled the three movements with German superscriptions; the first movement, Das Lebewohl (Les Adieux), the second movement, Abwesenheit (L'Absence), and the third movement, Das Wiedersehen (Le Retour). The most prominent characteristic in the sonatas of the "Heroic period" is Beethoven's expansion of Classical proportions. Beethoven expanded the length, tonal and emotional intensity of the individual movements without destroying the Classical foundations of sonata forms. The stronger fortitude and construction of the fortepiano's design during the "Heroic period" offered Beethoven greater capabilities in dynamic range, control of keyboard touch, expanded keyboard registers and the foot damper pedal which he masterfully utilized in the sonatas.

The Fortepiano Sonata in E minor, Opus 90, was composed in 1814 at the end of his "Heroic period" and represents his first serious keyboard work since 1810. During the four-year period between the Sonatas, Opus $81 \mathrm{a}$ and 90 , Beethoven composed the Seventh and Eighth symphonies and occasional music for the Congress of Vienna. With regard to the Opus 90 sonata, Schindler comments that:

we are seized with amazement at the deep tenderness and intimacy of this newest composition in contrast to its predecessors' energy and power.

32 Tovey, 197.

33 Tovey, 197. 
Such intimacy as we hear developed in the second movement would be hard to find in any work preceding it. ${ }^{34}$

The two-movement sonata illustrates Beethoven's shift away from the triumphant, expansive nature of the "Heroic period" toward the more reflective, transcendent manner of his late period. The most representative characteristic of Opus 90 is Beethoven's economy of means; as Mellars notes, "within its modest dimensions it generates extreme dramatic intensity; yet the music's reticence, its 'controlling power,' safeguards it against rhetoric, let alone grandiloquence."35

A significant feature of Opus 90 is Beethoven's exclusive application of German tempo markings at the beginning of each movement. Beethoven's German tempo indications are highly descriptive and also suggest his expressive intentions. The first movement is marked Mit Lebhaftigkeit und durchaus mit Empfindung and Ausdruck, (with vivacity or sprightliness and throughout with feeling or sentiment and with expression). The second movement is marked Nicht zu geschwind und sehr singbar vorgetragen, (not too fast and very songfully [sic]). According to Tovey, Beethoven defiantly chose the German language over the Italian because "Italian was a Bonapartist language, and Napoleon's day was over."36 In the Sonata, Opus 81a, Beethoven used German superscriptions for each movement with Italian tempo marks; but in Opus 90 , he specified the German language exclusively to express his political shift toward German nationalism, in addition to the naturalness of his native language to indicate

\footnotetext{
34 Anton Felix Schindler, Beethoven As I Knew Him, edited by Donald MacArdle and translated by Constance Jolly (New York: W. W. Norton and Co., 1972), 209.

35 Wilfred Mellers, Beethoven and the Voice of God (London: Farber and Farber Ltd., 1983), 130.

36 Tovey, 208.
} 
tempo and expression.

Beethoven's dedication of Opus 90 to Lichnowsky, in honor of the Count's engagement, was somewhat humorous in intention. According to Schindler, Beethoven unofficially titled the passionately energetic first movement, "Conflict Between Head and Heart" and the lyrically tuneful rondo movement, "Happy Conversations with the Beloved." 37 Beethoven artistically succeeded in combining two contrasting emotional levels between the two movements. The elements of humor are portrayed in the boisterously, laughing quality of the first movement; while the essence of intimacy is lyrically displayed in the folk-like melodies of the second movement. Beethoven's Opus 90 hangs in the balance between the decline of the Enlightenment era and emerging ideals of Romanticism, both in intellectual and emotional content. According to Lawrence Kramer, Beethoven was destined to change the focus of his music based on "the heady mix of Enlightenment and Romantic concepts that made up his intellectual milieu."38

One possible explanation for Beethoven's shift away from the typically Classical, three-movement sonata design, may be his exposure to the late eighteenth-century literary style and structure of depicting the polarity of a single subject. Kramer explains that the practice of "expressive doubling is a form of repetition in which alternative versions of the same pattern define a cardinal difference in perspective." ${ }^{39}$ The definition of expressive doubling

37 Schindler, 210.

38 Lawrence Kramer, Music as Cultural Practice, 1800-1900 (Berkeley: University of California Press, 1990), 25-6. 
seems to suit Beethoven's intention for the two movements of Opus 90; the movements suggest two contrasting aspects of love with the "Conflict Between Head and Heart' and "Happy Conversation with the Beloved." The feature of expressive doubling in Opus 90 does not assume a programmatic role, but instead, implies an intellectual and emotional quest toward the aesthetics of Romanticism.

Beethoven progressed from the magnificent force and masterful productivity of his "Heroic period" to the intensely personal expression and transcendental resolution of his late period (1815-1827)40. In all of Beethoven's transitional periods, "the exhaustion of the prior style was an opportunity and a liberation for Beethoven, although it subjected him to painful reformulations of his musical ideas and vocabulary." 41 The Fortepiano Sonata in A major, Opus 101 , represents a transition and change in Beethoven's creative career into his late period.

Even though he was nearly totally deaf during his late period, Beethoven was always drawn back to his favorite instrument, the fortepiano, to express his boldest ideas and most intimate thoughts; "even at the end, the piano remained Beethoven's most intimate means of self-communion." 42 The last five fortepiano sonatas were composed during a six-year period from late 1816 to early 1822. Carl Czerny's recollection of Beethoven's passion for composing at the fortepiano

\footnotetext{
${ }^{39}$ Kramer, 22.

40 Solomon, 229.

41 Solomon, 229.

42 Solomon, 305.
} 
in his late period follows:

Beethoven was accustomed to composing everything with the aid of the piano, and would try out a given passage countless times; one can imagine, then, what a difference it made when his deafness made that impossible. Therefore the uncomfortable keyboard writing in his last sonatas, therefore the harshness of the harmony; and as Beethoven himself admitted in confidence, therefore the lack of easy continuity and the departure from the older form. 43

Paul Badura-Skoda questions Czerny's conclusions about Beethoven's late sonatas; Czerny revealed in his memoirs "that he did not quite know what to make of them [the late sonatas]."44 Even though Czerny supposedly studied Opus 101 with Beethoven, that does not soften his judgements regarding the "harshness of the harmony" and the "lack of easy continuity." Beethoven's deafness certainly infringed upon his ability to hear the music he was composing; his deafness did not, however, impede his inner musical ear, which dictated how harmonies and musical continuity should be expressed.

Beethoven did not label these last five sonatas "quasi una fantasia," but simply took the genre of the fantasy-sonata as premise. The form and content of the late sonatas amply demonstrate the rhapsodic elements of the fantasy-sonata. In the Sonata, Opus 101, Beethoven manifests a freer treatment of form and expression within the general parameters of traditional sonata form, similar to his Sonatas, "quasi una fantasia,"Opus 27. Paul Bekker believed that Beethoven composed Opus 101 in the fantasy-sonata style, even though the words quasi una

43 Carl Czerny, On the Proper Performance of all Beethooen's Works for Piano, edited and with a commentary by Paul Badura-Skoda (Wien: Universal Edition, 1970), 13. Hereafter: Czerny, Proper Performance.

44 Czerny, Proper Performance, 2. 
fantasia do not appear on the score. Bekker accepts the substitute of Beethoven's "marks of expression in German which render any further attempt at elucidating the work superfluous." 45 Solomon contends that Opus 101 "is similar in design to the fantasy sonatas of earlier years, with its climax reserved for the finale and an expressive 'Langsam und sehnsuchtsvoll' introduction leading to a dramatic, contrapuntally conceived sonata-form movement, the development section of which is a four-part fugue." 46

In the last five sonatas, beginning with Opus 101, Beethoven's artistic focus is almost solely directed toward the expression in his music. Eric Blom notes that the seemingly spiritual depth of Beethoven's

writing has the ingenuity of the completely self-possessed master; but it is due precisely to this self-possession that Beethoven is now able to concentrate his whole creative mind on emotional expression in the most poetical terms of which music is capable. 47

Beethoven's heightened sense of lyricism and renewed interest in the contrapuntal techniques of the Baroque masters established his distinctive style of expression in the late sonatas. Blom elucidates the Romantic elements of Beethoven's last five fortepiano sonatas as follows,

All the sentiment and earnestness of Schumann, all the grace and individuality of Schubert, are there; with an intensity, breadth, and completeness, which those masters might perhaps have attained if they 1932), 131.

45 Paul Bekker, Beethoven, translated by M. M. Bozman (London: Dent and Sons Ltd.,

46 Solomon, 299.

47 Eric Blom, Beethooen's Pianoforte Sonatas Discussed (New York: E. P. Dutton and Co. Inc., 1938; reprint, New York: Da Capo Press, 1968), 195. 
had bestowed the time and pains on their work which Beethoven did. 48 Regardless of the fact that Beethoven's late period coincided with the early Romantic era,

he [Beethoven] resisted the impending Romantic fragmentation of the architecturally concentrated and controlled cyclic forms of the Classic era into small forms and lyric mood pieces; for this was a kind of music in which fantasy images were given free play but were essentially rendered harmless through an avoidance of conflict. 49

A significant development in the late sonatas is Beethoven's expanded use of contrapuntal writing. Fugal material appears in the development sections of Opuses 101, 106 and 111, and less apparently in Opus 110. Beethoven creatively molded or fused the elements of the fugue and aspects of lyricism into the matrix of the well-established sonata structure. Cooper comments on the Romantic characteristics in Beethoven's late sonatas:

It is in his last piano works that Beethoven most clearly anticipates the aesthetics of the nineteenth century; for even when he continues to use traditional forms, he uses them in so personal a manner and in such unusual combinations that the effect is entirely new. .0

In his late sonatas, Beethoven was able to nurture his personal musical expression, in part, by modifying Classical sonata forms.

Beethoven composed a majority of the Fortepiano Sonata in A major, Opus 101, during the summer months he spent in Baden; he completed the work in November 1816 (according to the date on the autograph). During 1816,

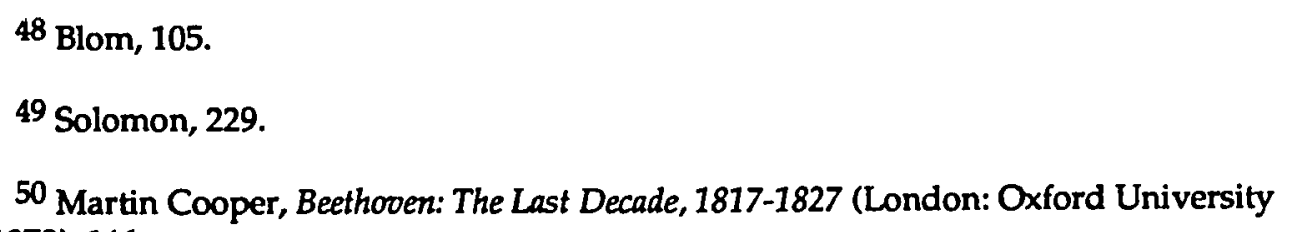
Press, 1970), 146. 
Beethoven continued to agonize over his personal problems and debilitating health. Beethoven seemed to find hopeful refuge from his personal despair while composing the sonata. Cooper intimates that Beethoven possibly equated the sonata as "an oasis in this wilderness, the escape into an ideal world from the cares that only find, perhaps, an occasional echo in the finale's fugato." 51 It was as if Beethoven had resigned his soul and being to music to express his unfulfilled emotional yearnings.

The first mention of the sonata may appear in a letter written by Beethoven on July 19, 1816, to Breitkopf and Härtel of Leipzig, where he offers the sonata for publication.52 Although Opus 101 is not specifically mentioned in the letter, it is only Emily Anderson's speculation that the "new sonata for pianoforte solo" actually refers to Opus 101.53 According to the date written in Beethoven's own hand on the cover page of the autograph-"1816 im Monath November"-he completed the sonata in November of 1816 (Example 1).

51 Cooper, 147.

52 Emily Anderson, ed. and trans., The Letters of Beethoven, vol. II (London: MacMillan and Co. Ltd., 1961), 586-7, L. 642.

53 Many Beethoven scholars doubt the credibility of Anderson's knowledge regarding Beethoven's works. 


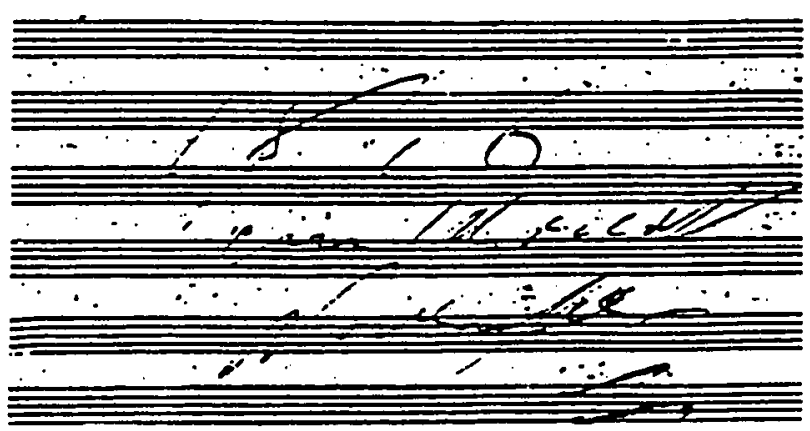

Example 1: Ilustration of Opus 101 autograph, cover page.

Beethoven then solicited Opus 101 to the London publisher, Robert Birchall. Since Beethoven could not write in English, "Beethoven's letter to Birchall was probably written by Joseph Baptist von Häring, a Viennese businessman who was relatively fluent in English."54 In the letter to Birchall dated October 1, 1816,-among other items of business-Beethoven offered Opus 101 and a trio as separate works with individual fees; "I offer you of my works the following new ones. A Grand Sonata for the pianoforte alone $£ 40$. A Trio for the piano with accompt. of violin and violincello for $£ 50 . " 55$ Unlike his proposal to Härtel, Beethoven presented Opus 101 as a new work in his offer to Birchall. It is William Meredith's opinion that

Beethoven's letter to Birchall of October 1, 1816, is a fascinating document on two counts: first, because, even in its admittedly clumsy English, the force and flavor of Beethoven's personality speaks through Häring's (?) translation with a directness familiar to readers of the German originals of Beethoven's letters, and second, because of the insight it gives into his

54 William Meredith, "Robert Birchall and Ludwig van Beethoven: Beethoven's Letter of October 1, 1816, Reappears," The Beethooen Newsletter 1 (1986): 4.

55 Anderson, vol. ПI, 603, L. 662. 
often troubled dealings with his English publishers. ${ }^{56}$

Dissatisfied and impatient with the slow responses from Härtel and Birchall, Beethoven approached the Viennese publisher, Sigmund Anton Steiner, with his proposal for publication of Opus 101. In a letter to Steiner dated November 1816, Beethoven poetically requested his payment terms as follows: "As for a new sonata for pianoforte solo, well then, as soon as 60 fully armed men present themselves, it can be produced immediately," -humorously meaning 60 gold ducats in payment. 57 Elliot Forbes contends that Beethoven had accrued a sizeable debt to Steiner at this time and frequently corresponded with Steiner in a "playful character."58

Beethoven's Sonata, Opus 101, was finally published by Steiner in February 1817.59 The timing and content of his proposals, which were distributed to the various publishers, displays Beethoven's individual marketing strategies as a composer struggling to be a shrewd business man. Meredith concludes that starting "in 1807 he had begun the financially advantageous practice of trying to arrange for simultaneous publication of all of his works on the continent and in England, and he continued this practice over the next decades." 60

Beethoven's autograph of Opus 101 presently exists in a private collection

56 Meredith, 6.

57 Anderson, vol. II, 614, L. 674.

58 Elliot Forbes, ed., Thayer's Life of Beethoven (Princeton: Princeton University Press, 1973), 654-5. Hereafter: Thayer-Forbes.

59 Thayer-Forbes, 692.

60 Meredith, 4. 
in Germany. 61 Sketches of the development and recapitulation from the first movement (without mm. 149-199) are located in the desk sketchbooks of Autograph 11, Bundle I ( dated "mid-1816 to ?"), in the Staatsbibliothek Preussischer Kulturbesitz in Berlin.62 Various measures of the second, third and fourth movements can be found in the Scheide Sketchbook (dated ca. March 1815 to ca. May 1816) which is located in the private library of Mr. William Scheide in Princeton, New Jersey. 63 Portions of the sketches for the second movement and the coda of the fourth movement can be found in the Paris Ms 78 and Ms 103 Sketchbooks (dated 1816) located in the Bibliothèque Nationale in Paris. 64 Although the original autograph is inaccessible to the general public, Beethoven scholars and enthusiasts should be aware that a facsimile of the autograph can be viewed and studied at the Ira F. Brilliant Center for Beethoven Studies (San Jose State University, San Jose, California 95192-0171).

Yet another confusing aspect surrounding Beethoven's completion date of Opus 101 still remains. According to Schindler, the first performance of Opus 101 -in fact, by Schindler's recollection, the only performance of any of Beethoven's fortepiano sonatas during the composer's lifetime-took place in

61 Kurt Dorfmüller, ed. "Supplement zum Thematisch-bibliographischen Verzeichnis von Kinsky-Halm," in Beitrage zur Beethoven-Bibliographie: Studien und Materialien zum Werkverzeichnis von Kinsky-Halm edited by Kurt Dorfmüller (München: G. Henle Verlag, 1978), 336.

62 Douglas Johnson, Alan Tyson, and Robert Winter, The Beethoven Sketchbooks: History, Reconstruction, Inventory (Berkeley: University of California Press, 1985), 247. Hereafter: JohnsonTyson-Winter.

63 Johnson-Tyson-Winter, 245.

64 Johnson-Tyson-Winter, 346. 
February of 1816 in a public concert organized by Schuppanzigh. 65 Schindler claimed that the composer attended the concert, even though Beethoven was not the performer of the sonata. Apparently Beethoven "had entrusted the performance to an artistic and cultivated amateur, Stainer von Felsburg, having first initiated him in the poetic elements of the work and the extraordinarily difficult first and third movements."66

Several notable contemporary Beethoven scholars have attempted to untangle the dates and facts regarding the first-if, any-documented performance of Opus 101 during Beethoven's lifetime. According to Donald MacArdle, it was not fashionable in the late-Classical period to program fortepiano sonatas on public concerts, but rather, they "were considered suitable only for performances in the home."67 Solomon challenges Schindler's claim that the performance in February 1816 of Opus 101 was the only performance of any Beethoven sonata (during the composer's lifetime):

Thus it is not really surprising that there were only two known public performances of Beethoven's piano sonatas during his lifetime-of opus 90 or opus 101 in Vienna in 1816 and of the Funeral March Sonata, op. 26, in Boston in 1819.68

Even though Schindler only remarked about the first and third movements of the "new sonata" featured on the February 1816 concert, it was quite possible that

65 Schindler, 209.

66 Schindler, 209.

67 Schindler, 340.

68 Solomon, 128. 
the "new sonata" was actually Opus 90-"which had been published in June 1815 , and which could legitimately be described as a 'new sonata." 69 Thayer's documented account of the concert varies slightly from Schindler's:

Linke's concert took place on the 18th of February in the hall of 'Zum Römischen Kaiser,' the programme [sic] except a Rondoletto for the Violincello by Romberg, being also entirely Beethoven. Stainer von Felsburg played 'a new pianoforte Sonata,' and Czerny the pianoforte part of the Violincello Sonata, Op. 69, on which the composer 'made amends publicly'.70

Again, the identity of the "new sonata" in undetermined, although it would be reasonable to assume that the sonata performed on the concert of February 1816 was Opus 90.

${ }^{69}$ Schindler, 340 .

70 Thayer-Forbes, 641. 


\section{Chapter 3}

The Role of the Fortepiano in Beethoven's Keyboard Works

In examining the role of the fortepiano in Beethoven's late period, an overview of the fortepiano's role in the composer's early and middle period is warranted in order to trace the developments in fortepiano building. The history and development of the Classical fortepiano and the keyboard music of Beethoven are almost synonymous from approximately 1775 to 1825 . Haydn and Mozart were accustomed to the five-octave range of the early fortepianos, but it was this instrument which Beethoven inherited. However, he soon desired a wider range, better tone quality and more durability from the fortepiano to accommodate the expressive requirements in his music. William S. Newman concludes that "in his piano writing Beethoven was both more enterprising and more challenging than any of the three other greatest masters of piano composition who were his near contemporaries in Vienna and London (Haydn, Mozart and Schubert)."71 The music of Beethoven represents a link between the Classical and Romantic periods in the same way that the fortepiano is the link to the modern grand piano. Regarding Beethoven's role as a transitional pivot from the Classical to the early Romantic period, David Grover proposes that:

Some commentators stress Beethoven's position as the last of the great classicists continuing along paths trodden by Haydn and Mozart, while others view him as the first romantic establishing guidelines which can be

71 William S. Newman, Beethoven on Beethoven: Playing His Piano Music His Way (New York: W. W. Norton and Co., 1988), 46. Hereafter: Newman, Beethoven on Beethoven. 
traced through to Wagner. This diversity of opinion indicates that form and harmony were assuming new complexity during Beethoven's lifetime. Normally adhering to the framework of sonata form, his later works stretched it to its limits and show that his imagination was ranging increasingly outside its restrictions. ${ }^{72}$

The difference between Beethoven's demands of the fortepiano and those of Haydn and Mozart is, in part, due to Beethoven's powerful force and intensity as a fortepianist. Newman describes Beethoven's individual characteristics:

At his best Beethoven played with great technical facility, though revealing some impatience with the perfection of technical details; he often exhibited a certain excess of animal spirits; he excelled in legato playing; and he commanded special attention for the depth of his expressive playing, particularly in slow movements. With a true creator's tendency to live chiefly in the present, he did some of his most inspired playing in his extraordinary improvisations. ${ }^{73}$

Although Beethoven was renowned for his beautiful legato playing-quite different from Mozart's detached style of playing - he also unabashedly exercised the tremendous physical strength of his keyboard technique. A direct result of Beethoven's indifference to the limitations of the fortepiano was his habit of damaging many fortepianos. ${ }^{74}$ The gradual deterioration of Beethoven's hearing could also account for his heavy-handed manner of the fortepiano.

Beethoven desired a more durable fortepiano to fully express his penetratingly deep level of artistic utterance. Hubert Kennemer believes that Beethoven was a significant impetus for the development of the fortepiano,

72 David Grover, The Piano (New York: Charles Scribner's Sons, 1978), 99-100.

73 Newman, Beethoven on Beethoven, 46.

${ }^{74}$ Kenneth Drake, "A Study of the Beethoven Piano Sonatas in the Light of Evidence Provided by Beethoven's Pupils" (Ph.D. diss., University of Illinois, 1970), 22. Hereafter: Drake, diss.. 
Although several composers produced works which appeared within the transition period between 1775 and 1825, one sees in Ludwig van Beethoven a special opportunity to trace the expansion of the keyboard range within a large body of works which spans nearly the entire compositional career of the composer-in this case the thirty-two solo piano sonatas with opus numbers. ${ }^{75}$

Beethoven did not insist that fortepiano-builders make changes in the instrument; but instead, he made suggestions on how to adapt and refine the mechanics of the fortepiano. Edwin Good proclaims that "Beethoven's piano music reflects the instrument of his day, and the extensions of range in it exactly parallel the extensions of range in the pianos that he-and his potential customers [purchasing his published works]-possessed."76 In line with Good's statement, Newman affirms that "Beethoven extended the range of his piano music as the need arose and his preferred pianos permitted."77 Not until 1816, starting with Opus 101, did Beethoven utilize the extended bass range. It is interesting to note that despite the gradual expansion of the fortepiano's range, Beethoven "never attempted to alter any of his earlier works."78

It is unclear as to whether Beethoven actually owned any of his fortepianos. Ownership may not have been necessary, for Beethoven was able to persuade the fortepiano builders to loan out their instruments to him. This

75 Hubert Clarence Kennemer, "The Expansion of the Keyboard Range in the Solo Piano Sonatas of Beethoven" (Ph.D. diss., The University of Texas at Austin, 1970), vi-viii.

76 Edwin M. Good, Giraffes, Black Dragons, and other Pianos: A Technological History from Cristofori to the Modern Concert Grand (Stanford: Stanford University Press, 1982), 70.

77 Newman, Beethoven on Beethoven, 60.

78 Derek Melville, "Beethoven's Pianos," in The Beethoven Reader, edited by Denis Arnold and Nigel Fortune (New York: W. W. Norton and Co., 1971), 47. 
assessment is validated in a portion of one of Beethoven's letters written in 1802: "the whole tribe of pianoforte manufacturers have been swarming around me in their anxiety to serve me.... Each of them wants to make me a pianoforte exactly as I should like it."79

The following brief history of the development of the fortepianos during Beethoven's lifetime not only demonstrates the evolution of the instrument, but also the progression and elaborations of Beethoven's keyboard music. For the purpose of this study, the following discussion of the fortepiano will be limited to the years preceding 1816. Comments on Beethoven's Broadwood and Graf fortepianos are mentioned for comparative purposes only, since those particular fortepianos were acquired after 1817. Beethoven used approximately fourteen different styles of fortepianos during his lifetime. The general understanding that Beethoven's Érard, Broadwood and Graf fortepianos have been historically considered his favorite instruments is based primarily on the fact that they are extant.

Beethoven acquired the Érard and Broadwood fortepianos as gifts from the highly respected fortepiano builders of France and England, respectively. From 1825 until his death, the Graf fortepiano was on permanent loan to Beethoven from Conrad Graf of Vienna. It is Newman's opinion that the Érard and Broadwood fortepianos "proved to be important to Beethoven almost solely for the honor and prestige they betokened, and the Graf ... could have had no special meaning in any case, since by 1825 Beethoven could not hear it at all and

79 Emily Anderson, ed. and trans., The Letters of Beethoven, vol. I (London: MacMillan and Co. Ltd., 1961), 82, L. 66. 
would be writing little further piano music, anyway." 80 Recent research indicates that "Beethoven started with a distinct preference for certain Viennese pianos and, especially through his lifelong association with the Stein and Streicher families, maintained that allegiance to the end of his life." 81

During his early years, Beethoven played and composed on a five-octave Stein fortepiano (replacing his unfavorable Späth fortepiano) not unlike the fortepianos used by Haydn and Mozart. It is Newman's conjecture that Beethoven quite possibly received a Stein fortepiano as a gift from Count von Waldstein in 1788.82 Beethoven expressed his preference for the light action and clear tone of the Stein and Streicher fortepianos in numerous correspondence with Johann Andreas Stein of Augsburg and Johann Andreas and Nanette Streicher of Vienna. With the death of Andreas Stein in 1792, and the marriage of his daughter, Nanette, to Andreas Streicher, the husband and wife team established the Streicher firm in 1794; "scon [to be] the leading Viennese pianomaking firm, its renown upheld into the middle years of the nineteenth century by their son, J.B. Streicher." 83

Late in 1790, Beethoven acquired a Walter fortepiano from the Viennese fortepiano-maker, Anton Walter. Beethoven was apparently quite pleased with the tone and action of the Walter fortepiano, but he was disappointed that it was incapable of possessing a true una corda due to technical problems related to the

\footnotetext{
80 Newman, Beethoven on Beethoven, 55.

81 Newman, Beethoven on Beethoven, 43.

82 Newman, Beethoven on Beethoven, 50.

83 Grover, 98.
} 
Viennese action.84 In 1801, at age ten, Czerny played Beethoven's Walter fortepiano when he auditioned for lessons with the composer. In his memoirs, Czerny recounted that Beethoven's Walter fortepiano was "then the best" instrument of the time. ${ }^{85}$ Beethoven was initially limited to the fortepiano's fiveoctave range when composing his first twenty fortepiano sonatas with opus numbers. With the exception of Beethoven's extension upward beyond the FF- $f 3$ range in the Sonata, Opus 14, No. 1, it is quite probable that his Walter fortepiano had a five-octave plus two note range extending from $\mathrm{FF}$ to $\mathrm{g}^{3.86}$

In 1803 Beethoven received an Érard fortepiano as a gift from the renowned Paris fortepiano-maker, Sebastien Érard. Beethoven was honored by the unsolicited gift, but he disliked the heavy touch and darker tone quality of the Érard fortepiano. In a letter to Streicher in 1810, Beethoven not only requested another Streicher fortepiano, but also expressed his dissatisfaction with the Érard:

You promised to let me have a piano by the end of October; and now we are already half through November and as yet I haven't received one-My motto is either play on a good instrument or not at all-As for my French piano, which is certainly quite useless now, I still have misgivings about selling it, for it really is a souvenir such as no one here has so far honored me with .... All good wishes, if you send me a pianoforte; if not, then all bad wishes. ${ }^{87}$

84 Melville, 57.

85 Carl Czerny, On the Proper Performance of all Beethoven's Works for Piano, edited and with a commentary by Paul Badura-Skoda (Wien: Universal Edition, 1970), 4. Hereafter: Czerny, Proper Performance.

86 Good, 70.

87 Anderson, vol. I, 300, L. 283. 
Is there a slight hint of manipulation in Beethoven tone of writing to suggest that Streicher "honor" him with the gift of a Streicher fortepiano? Perhaps, but this is only speculation. Even so, the French Érard fortepiano remained in Beethoven's possession until around 1825.

Beethoven appreciated the expanded range of the Érard, which was extended upwards by a fifth, thus spanning FF- $c^{4}$. Besides the advantage of the Érard's expanded range, Beethoven could find no other redeeming attributes of the French fortepiano regarding its tone and touch. After comparing the Érard and the Walter fortepianos, Derek Melville agrees with Beethoven that the Walter fortepiano "has an outstandingly beautiful tone, far superior to that of the Érard, although it is a smaller instrument: it is instruments such as this that persuade some discerning people that pianos of this type and period represent the highest peak that the piano has ever reached." 88

Beethoven was accustomed to the quick, responsive action and the clear, songful tone quality of the Viennese fortepianos. The internal construction of the Viennese fortepianos was identified 'by its individually hinged keys, each with a separate hammer and escapement mechanism." 89 The Érard's construction reflected the similar design and action of the English fortepianos. The basic difference in construction between the Viennese and English fortepianos was that the "English system was distinguished by the suspension of its keys from a common rail; by its heavier, deeper, more sluggish touch; and consequently by a

88 Melville, 45.

${ }^{89}$ Newman, Beethoven on Beethoven, 62. 
rounder, fuller, yet somewhat muffled tone of wider dynamic range." 90

Beethoven was disenchanted with the overall evenness of the Érard's tone, which was less colorful than the Viennese fortepiano. According to Good, the Érard "is triple strung throughout, without wound strings, and it carries the English type of arched iron gap-stretchers between the pin block and the belly rail." 91

The adaptation of foot-activated pedals first appeared on most of the English and French fortepianos between 1780 and 1790.92 The primary function of the pedals made it possible to sustain or mute the tones creating a variety of sound effects. According to Newman, there were three basic types of pedals available to Beethoven:

damper raising, whether divided into separate bass and treble controls or combined in a single control; action-shifting, permitting the striking of but one or two strings of triple-strung keys, and of but one string of doublestrung keys; and dampening, achieved through a piece of cloth, leather, or other material interposed between hammers and strings or laid on the strings, either to make the tone softer or to give it a special color such as 'flute' or 'bassoon'. 93

Beethoven's Érard fortepiano had four pedals including-from left to right-the lute-stop, sustaining pedal, sourdine (mute-stop) and una corda pedals. The Érard probably provided Beethoven with his first experience of controlling foot pedals, since his Viennese fortepianos had knee-lever mechanisms.

90 Newman, Beethoven on Beethoven, 63.

91 Good, 74.

92 Sandra Rosenblum, Performance Practices in Classical Piano Music: Their Principles and Applications (Bloomington: Indiana University Press, 1988), 40. Hereafter: Rosenblum, Performance Practice.

${ }^{93}$ Newman, Beethoven on Beethoven, 65. 
Although he was already familiar with the sourdine and una corda functions on his earlier fortepianos, Beethoven was particularly intrigued with the improved quality and capability of the Érard's true una corda. Unlike the una corda on today's modern grand piano (actually a due corde), the true una corda on Beethoven's Érard was capable of mechanizing an una, due and tre corde which created three different audible levels of dynamics. ${ }^{94}$ With the exception of the expanded range and true una corda pedal, the Érard's remaining innovative advancements in internal design could neither satisfy Beethoven's artistic criterion for tone quality and touch responsiveness, nor survive his intensely forceful technique of playing.

The expansion of the range of the keyboard became the mest important structural change of the fortepiano around the turn of the nineteenth-century. The first expansions of the fortepiano's keyboard was upwards by the interval of a second, as seen in the Walter fortepiano around 1785 and the Stein/Streicher fortepiano in 1797, which both ranged from FF-g3. Specific Beethoven sonatas can be recognized as landmarks in the expansion of the fortepiano's range after the turn of the nineteenth-century, as Grover discusses:

The sonatas from the Waldstein onwards demand at least six octaves range and the Hammerklavier Sonata the six-and-a-half-octaves of the Viennese Conrad Graf, Beethoven's last piano, as strong as his six-octave Broadwood.95

With the expansion from five to six octaves, the structural character of the fortepiano enlarged in weight and size, allowing the "tone quality [to become]

94 Arthur Loesser, Men,Women and Pianos (New York: Simon and Schuster, 1954), 173.

95 Grover, 99. 
increasingly sonorous and longer-lasting, characteristics that in turn enhanced legato playing and the 'singing' sound."96 Contemporaries of Beethoven advocated the importance of extending the range upwards. Besides the fortepiano's expansion upwards, Beethoven also wanted an extension of the bass register downwards for purposes of greater sonority, rather than solely "maintaining or fulfilling the integrity of a theme."97 Because the demand for the expansion downward was less popular, and the implementation also more difficult for the fortepiano-makers, the bass was only extended down a fourth to CC during Beethoven's lifetime.

Beethoven's Sonata, Opus 101, demonstrates several features of the fortepiano's evolutionary changes leading up to the year of 1816. In his last five sonatas Beethoven utilizes the fortepiano's continually expanding range. Opus 101 is particularly significant because there Beethoven "includes for the first time an extension in the keyboard range below FF in the bass." 98 In the last movement Beethoven uses the EE in measures 223-231. The widest extension in the movement-and the entire sonata-occurs between the EE in measure 223 to the $\mathrm{e}^{4}$ in measure 231, followed by the combination of the "notes on the second beat of measure 231 and creates a sonority which spans a compass of six octaves." 99 What fortepiano did Beethoven use to compose the sonata, considering that the lowest notes on both his Érard and Streicher was FF?

\footnotetext{
96 Rosenblum, Performance Practice, 37.

97 Newman, Beethoven on Beethoven, 59.

98 Kennemer, 54.

${ }^{99}$ Kennemer, 55.
} 
Beethoven must have had access to a fortepiano with the extended bass range before the year of 1818-which was the year he received the Broadwood fortepiano as a gift. At present, there is no documented evidence of which type of fortepiano Beethoven used to implement the EE in the sonata. ${ }^{100}$

Beethoven placed such great importance on the $\mathrm{EE}$ inclusion that he inscribed the words, Contra $E$, under its first appearance in measure 223. In a letter written to Haslinger in January of 1817-one month before the publication date of the sonata-Beethoven specifically stated the importance of publishing the sonata with the Contra $E$ labeled under the new note, as follows:

The worthy A[djutant] must still see that the few mistakes are corrected in the last movement [of Opus 101] where low E occurs. Meanwhile I should like the letter to be put under the first note, as I have indicated. ${ }^{101}$

Another example of Beethoven's exploration of the expansive range is illustrated in the extreme spacing between the hands in the last fifteen measures of the finale movement (Example 2).

100 Good, 91.

101 Anderson, vol. II, 660-1, L. 748. 

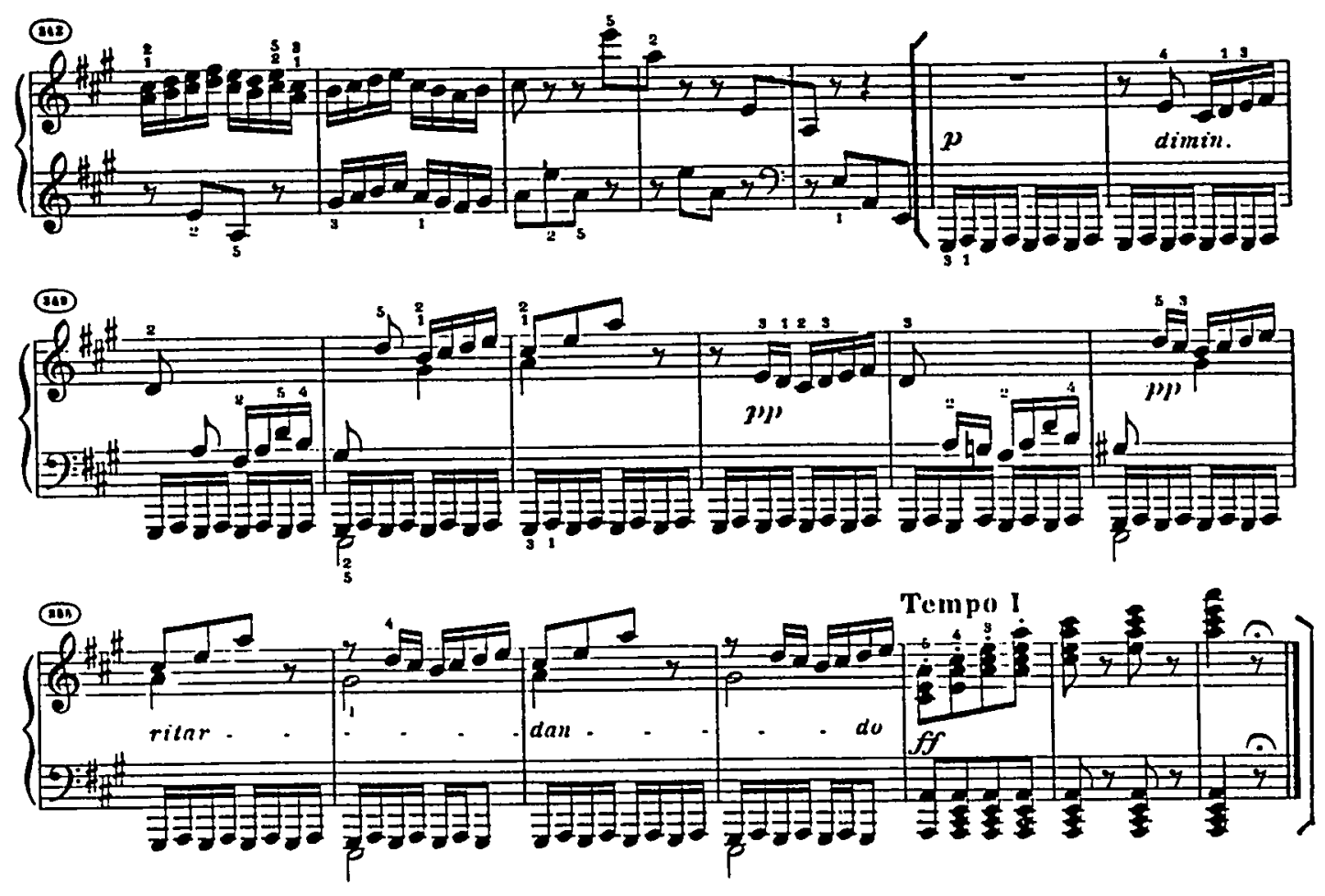

Example 2: Allegro, mm. 347-361.

A question of aesthetic judgement arises as to whether Beethoven could actually hear the balance of sonorities between the wide spacing of the hands and density of the final chords (Example 2). On the modern grand piano, the performer must battle with the "continuing problems of balance, projection, and clear sonority" when attempting to execute the wide spacing between the hands. ${ }^{102}$ Even though Beethoven was almost completely deaf by 1816, he was still aware of the tone color capabilities of the Viennese fortepiano. From a performance practice standpoint, it is more important to understand what Beethoven knew about the characteristics of the fortepiano's tone qualities, rather

102 William Newman, Performance Practices in Beethooen's Piano Sonatas: An Introduction (New York: W. W. Norton and Co., 1971), 46. 
than what he could or could not hear from the fortepiano. After playing Beethoven's Érard, Alfred Brendel commented on the noticeable tonal differences of the fortepiano compared to that of the modern grand piano:

its sound, dynamics and action have surprising little in common with the pianos of today. The tone of each single note has a distinct 'onset'; within its intimate confines, it is livelier and more flexible, and also more subject to change while it lasts. ${ }^{103}$

The significant difference in timbre between the Viennese fortepiano and the modern grand piano is the distinction in tone color between the low, middle and high registers. Brendel refers to the different timbre distinctions as "polyphonic playing" in character. ${ }^{104}$ The one-piece, cast-iron frame of the modern grand piano constitutes an almost exclusive uniformity of tone color throughout the compass of the registers. In contrast, the wooden frame design of the Viennese fortepiano creates three distinct tone color qualities, as described by Sandra Rosenblum:

The bass is sonorous and dark but remains clear, avoiding the woolly quality of the pianoforte [modern grand]. Low trills and closely spaced bass chords sound well on the fortepiano. When pushed, the bass can also growl. The middle register produces a warm singing tone. The treble, which begins at $c^{2}$ or a little higher, tends toward dryness and, in my experience, varies more among instruments in its effects than do the other registers. It is sometimes flutelike but it can also sound metallic and very penetrating. 105

103 Alfred Brendel, Musical Thoughts and Afterthoughts (Princeton: Princeton University Press, 1976), 15.

104 Brendel, 15.

105 Rosenblum, Performance Practices, 38. 
In the coda of the finale movement of Opus 101, Beethoven wrote a low measured trill from measures 347-358, in which he intermittently added the fortepiano's new EE in the bass voice (mm. 350, 354, 356 and 358). Based on Rosenblum's description of the fortepiano's tone color characteristics, it would be reasonable to ascertain that in Beethoven's mind he heard the unmuffled effect of the low bass trill—combined with the EE pedal point—and a "flute-like" clarity in the densely-voiced treble chords. Melville aptly suggests to the performer that "the lesson that the old pianos can teach us is that we should treat our modern instruments more in accordance with an earlier style of playing."106

106 Melville, 44. 


\section{Chapter 4}

Performance Practice Considerations for the Modern Piano

Beethoven was searching for more than the expanded range and durability of the fortepiano. According to Melville,

it is only contrast that Beethoven wanted, nor sheer volume of sound or exploitation of the instrument for its own sake ( $p p p$ is much the same on all pianos-rather better on some of Beethoven's, though of a different quality). ${ }^{107}$

A deduction can be made that Beethoven desired a wider range of expressive capabilities from the fortepiano as a result of its evolutionary changes of expansion and dynamic ranges. Even in his early years, Beethoven predicated that beautiful tone production was a combined effort of good legato playing and the fortepiano's ability to sing. 108 Beethoven preferred the tonal projection and sustaining power of the Viennese fortepianos to help create his desired singing tone.

Beethoven's conception of tonal aspects and dynamic range in his keyboard writing was directly influenced by the fortepianos he was using. Playing Beethoven's music on the modern grand piano requires some understanding - and listening - to Beethoven's different fortepianos to adapt a more authentic interpretation of his music. Kenneth Drake proposes the analogy that

107 Derek Melville, "Beethoven's Pianos," in The Beethoven Reader, edited by Denis Arnold and Nigel Fortune (New York: W. W. Norton and Co., 1971), 43.

108 William Newman, Performance Practices in Beethoven's Piano Sonatas: An Introduction (New York: W. W. Norton and Co., 1971), 60. 
to say that Beethoven was writing for the modern piano is as relevant to an understanding of his treatment of the piano as it would be to speculate on the outcome of the Revolutionary War had it been fought with modern instruments of warfare. 109

Of a majority of instruments, the piano has gone through the most evolutionary phases of construction, expansion, tone quality, mutations and action mechanisms. Since the late eighteenth-century, the three primary differences in design between Beethoven's fortepiano and the modern grand are the compass, the strength of the frame and the action-all of which ultimately affect the tone quality. ${ }^{110}$ From a performance practice standpoint, the performer should be cognizant of the musical effects produced by the differences between the two keyboards. Drake succinctly states that "since the Beethoven period, the piano has lost in intimacy what it has gained in power, brilliance and durability of structure." 111

Two significant innovations of the fortepiano, which Beethoven most likely did not experience, were the double-escapement action (developed by Érard and nearly perfected by 1821) and the one-piece, cast-iron frame (invented and patented by an American, John Isaac Hopkins, in 1825). ${ }^{112}$ The advantage of

109 Kenneth Drake, The Sonatas of Beethoven: As He Played and Taught Them (Cincinnati: MTNA, 1972; reprint, Bloomington: Indiana University Press, 1981), 7. Hereafter: Drake, Sonatas of Beethoven.

110 Kenneth Drake, "A Study of the Beethoven Piano Sonatas in the Light of Evidence Provided by Beethoven's Pupil's" (Ph.D. diss., University of Illinois, 1970), 15. Hereafter: Drake, diss..

111 Drake, diss., 27.

112 William S. Newman, Beethoven on Beethoven: Playing His Piano Music His Way (New York: W. W. Norton and Co., 1988), 62. Hereafter: Newman, Beethoven on Beethoven. 
the double-escapement action allowed an easier and more rapid execution of repeated notes, which Beethoven would have undoubtedly appreciated. The addition of the cast-iron frame provided a stronger foundation to support the increased tension of the strings and dramatically changed the tone quality of the fortepiano. An understanding of Beethoven's fortepianos enlightens and encourages the performer to return "to the modern piano with a keener awareness of shading and contrast" for a more comprehensive interpretation of Beethoven's fortepiano music. ${ }^{113}$

Just as the performer takes the fortepiano into consideration when adapting Beethoven's music to the modern grand piano, so should the performer observe Beethoven's autographs and first editions to compare his notation and markings to the modern music editions. Even though Beethoven's autographs are sometimes difficult to decipher, Brendel encourages the performer to examine the autographs to fully understand Beethoven's final product:

Beethoven's autographs are often difficult to read, but it would be wrong to conclude from this that his notation, let alone his composition, was imprecise. The chaotic side of Beethoven's nature, so startlingly apparent from the scrawl of his handwriting, is brought to order in the finished compositions. 114

Since many modern editions have been mercilessly over-edited and revised, performers are often unaware of the musical and spiritual implications of Beethoven's music. By studying Beethoven's autographs and first editions, performers can come closer to the musical perspective that Beethoven originally

113 Drake, diss., 28.

114 Alfred Brendel, Musical Thoughts and Afterthoughts (Princeton: Princeton University Press, 1976), 28. 
intended. Brendel's assessment of the interpretive benefits gained by observing Beethoven's marking in his autographs, follows:

It is therefore all the more important to observe every sign written down by Beethoven. His ability to notate the essential without overloading the text with instructions has been equalled by few later composers, and bettered by none .... Among the most important gifts a Beethoven player can have is the power to visualize, in an almost geographical sense, the entire panorama of varying dynamic levels embodied in a work-like looking at a landscape and taking in at a single glance its valleys and mountain-tops. 115

Of all the various pedals available to Beethoven throughout the evolution of the fortepiano, he preferred the sound effects of the damper-raising controlknee-levers, and eventually the foot-pedal-and the true una corda pedal.

According to Newman, Beethoven utilized the damper pedal in his own playing and in his compositions for seven specific purposes:

these include sustaining the bass, improving the legato, creating a collective or composite sound, implementing dynamic contrasts, interconnecting sections or movements, blurring the sound through harmonic clashes, and even contributing to the thematic structure. 116

In his memoirs, Czerny recounted that Beethoven "used a lot of pedal, much more than indicated in his works."117 Beethoven's first damper pedal indications in his fortepiano sonatas appeared in his Sonata, Opus 26, completed in 1800. Grover comments that Beethoven was "one of the earliest composers to mark

115 Brendel, 30.

116 Newman, Beethoven on Beethoven, 236.

117 Carl Czerny, On the Proper Performance of all Beethoven's Works for Piano, edited and with a commentary by Paul Badura Skoda (Wien: Universal Edition, 1970), 16. Hereafter: Czerny, Proper Performance. 
down pedalling instructions."118 When using the knee-lever damper control, Beethoven indicated the term "senza sordino" to raise the dampers and "con sordino" to restored the dampers. With the invention of the foot damper pedal, Beethoven prescribed the abbreviations "Ped." and " $O$ " for raising and lowering the dampers, respectively. 119 From a structural viewpoint, Rosenblum believes that:

Beethoven used pedal to highlight or relate to form in more ways than did his contemporaries. His effects include enhancing a pivotal point, bridging sections within a form or between movements, coloring an important section or theme, signaling the return of a theme or a section, and incorporating pedaling as an element of structure. 120

According to the autograph and first edition, Beethoven only indicated damper pedal marks toward the end of the coda in the first movement of Opus 101. The first pedal mark appears on the last beat of measure 95 , followed by a release mark after the tied quarter note chord in measure 96. Beethoven continues this same pedaling procedure-with the same rhythmically suspended chords over the bar lines-for two more measures. Beethoven's infrequency of pedal marking does not suggest that the performer refrain from using the pedal; on the contrary, "Beethoven notates the pedal only when he wishes to obviate misunderstandings, or when aiming at unusual effects."121

118 David Grover, The Piano (New York: Charles Scribner's Sons, 1978), 100.

119 Newman, Beethoven on Beethoven, 67.

120 Sandra Rosenblum, Performance Practices in Classical Piano Music: Their Principles and Applications (Bloomington: Indiana University Press, 1988), 127. Hereafter: Rosenblum, Performance Practices.

121 Brendel, 34. 
In the second movement of Opus 101, Beethoven indicates a extended pedal marking from measures 30 to 34 (Example 3). The blurred pedal effect demonstrates Beethoven's colorful usage of the pedal

at a crux in the form of the Vivace alla Marcia. At the arrival of the key of D-flat major, the Neapolitan of the dominant C, the composer created a unique sound by sustaining a bass pedal point for four measures under the stepwise chord changes of the delicate, imitative upper voices. From this precipice we are led back to a long dominant preparation for the return of the tonic key and the final section of the alla Marcia. ${ }^{122}$

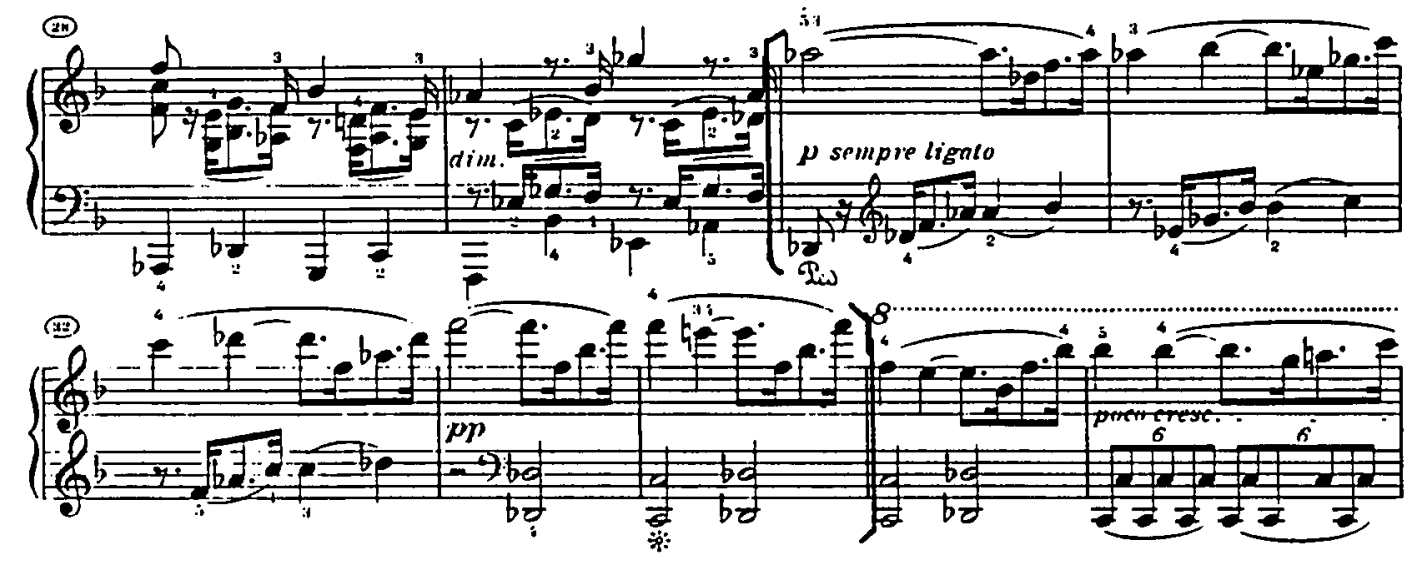

Example 3: Vivace alla Marcia, mm. 30-34.

Beethoven inscribed the words "sempre ligato" - as Beethoven spelled it in the autograph-to accompany the pedal marking. In Drake's opinion, the function of Beethoven's long pedal marking is to encourage a more legato touch. ${ }^{123}$ From an aesthetic point of view, the sound effect created by the blurred pedaling in this passage depicts a radical departure from the driving force of the

122 Rosenblum, Performance Practices, 128.

123 Drake, Sonatas of Beethooen, 142. 
syncopated rhythms in the previous theme. Besides Beethoven's one distinctively long pedal marking in the middle of the second movement, no other pedal markings can be found in the autograph or the first edition of the second movement.

In the third movement of Opus 101, Beethoven indicates damper pedal markings which quite possibly were intended to have two purposes. Beethoven was aware that the duration of the treble register notes was less than that of the bass register notes. From measures 14 to 17 , Beethoven marks the pedaling at the end of the measure over the bar line, with a release on the downbeat of the next measure (Example 4). This pedaling procedure would sustain the tones over the bar line while the performer prepares for the new hand position in the next measure. Newman questions Beethoven's reason for creating a resting period between the end of the damper pedal release and the beginning of the next damper pedal down:

That rest is partly psychological, in a syntactic sense (rounding off each one-measure incise) and partly actual, in that the register an octave higher than the tenor would die away more quickly on Beethoven's instruments, especially during the application of the una corda pedal throughout this movement. ${ }^{124}$

124 Newman, Beethoven on Beethoven, 238. 


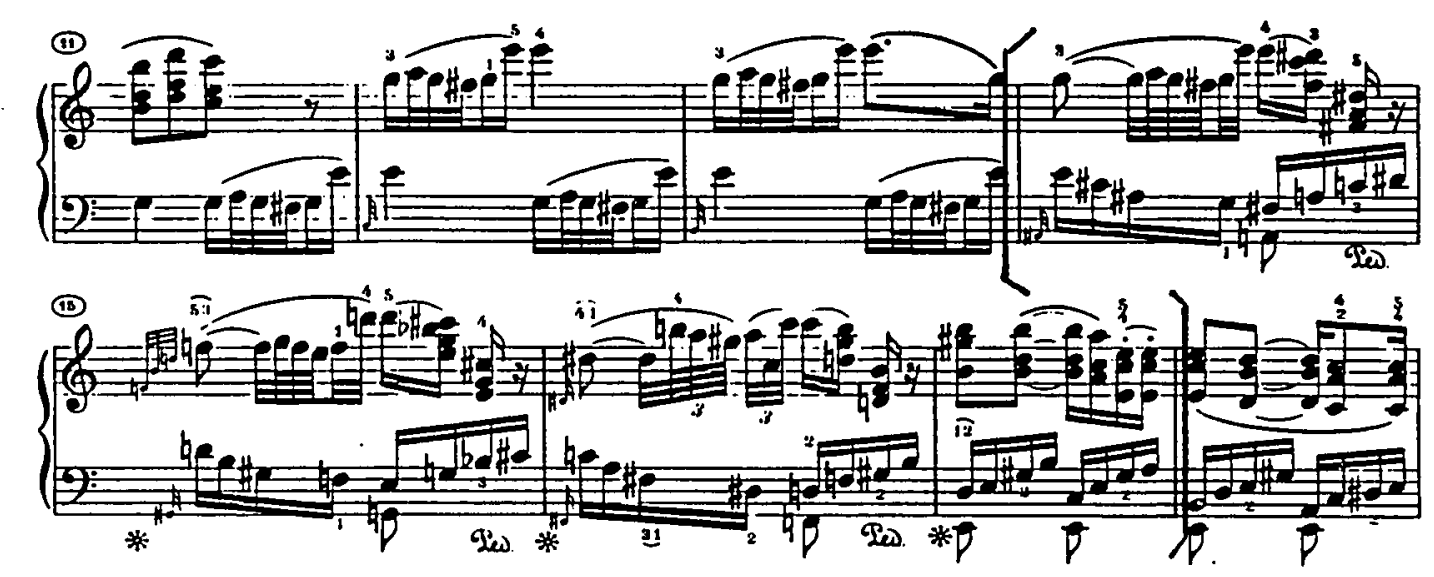

Example 4: Adagio, ma non troppo, con affetto, mm. 14-17.

The second implication for Beethoven's choice of pedal markings in the third movement is to facilitate a finer legato touch. Notice that Beethoven intends for the performer to hold the down-stem bass notes while continuing with the ascending tenor line. Without the aid of the damper pedal, neither the bass nor the tenor could be played legato. Newman suggests that the reason Beethoven did not indicate pedal markings in measures 17 and 18 is that the

heavy action and greater distance from the floor made the pedals clumsier to manipulate then, even at the 'Adagio' tempo, and would have proved generally impractical with the faster changes that would have to have been made. 125

Although Beethoven supposedly used the una corda control frequently in his playing, his first indication for the una corda in a score did not appear until the publication of the Fortepiano Concerto No. 4 in G major, Op. 58, in 1808.

Beethoven's request for the una corda does not appear in print again until his last five fortepiano sonatas. The true una corda pedal was only possible on the

125 Newman, Beethoven on Beethoven, 239. 
English fortepianos, because the hammers of the Viennese fortepianos "could never strike fewer than two strings but made up for this by being fitted with various muting devices."126 The function of the true una corda pedal allows the action to be shifted to the right; the hammer strikes two (due corde), and then one (una corda), of the three strings in succession with the pedal being gradually depressed.

An exemplary demonstration of the true una corda pedal function can be seen in the transition passage between the third and fourth movements of Opus 101. In the opening of the third movement, Beethoven indicates "Mit einer Saite" (on one string) for the first nineteen measures. At the end of the cadenza in measure 20, Beethoven marks "nach und nach mehrere Saiten" (more and more strings) producing a greater gradation of pianissimo.(Example 5). 127 At the return of the first movement's first theme in measure 21, Beethoven marks "Alle Saiten" (all strings) indicating the release of the una corda pedal (or tre corde).

(Example 6.)

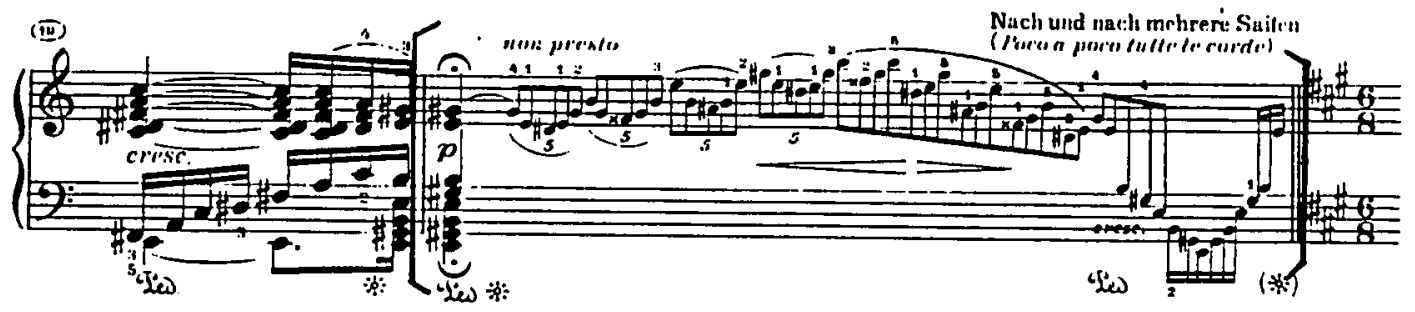

Example 5: Adagio, ma non troppo, con affetto, m. 20.

126 Melville, 50.

127 Grover, 134. 


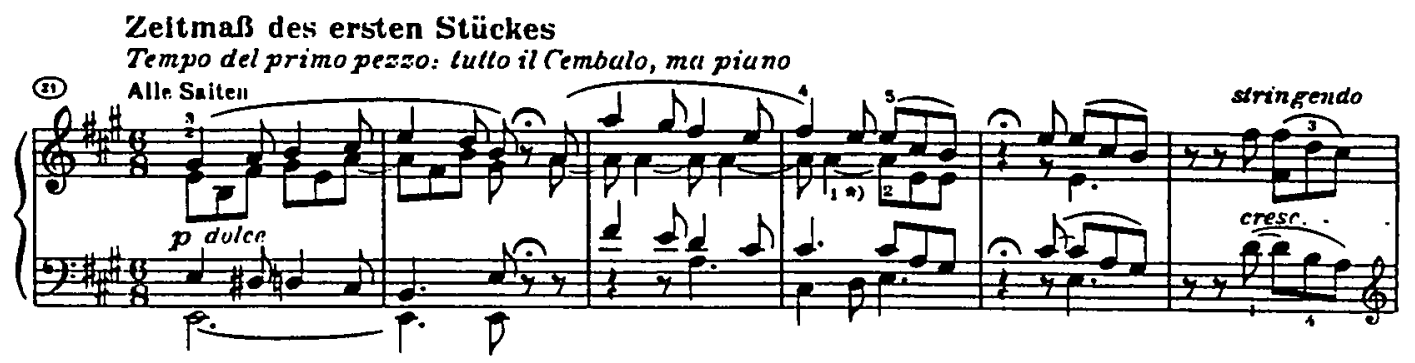

Example 6: Restatement of theAllegretto, ma non troppo (first theme), m. 21.

It is interesting to note that Beethoven wrote these una corda indications in Italian only in the autograph. In the first edition, the una corda markings appear in German-with the exception of "Mit einer Saite," which is accompanied by the superscription underneath in Italian "Sul una corda." With regard to the una corda markings in the restatement of the first theme of the first movement, Edwin Good remarks:

The effect that is wanted is to move slowly from an una corda timbre through two strings until at last, with the familiar strains of the earlier movement, the hammers are striking all three strings. It is a remarkable transition, not in loudness but in tone quality, a transition, moreover, that the modern piano is incapable of reproducing since it does not possess a true una corda stop. ${ }^{128}$

Beethoven only indicated the use of the damper pedal in three places in the finale movement of Opus 101. The first damper pedal marking appears in the second theme of the exposition, beginning on the second beat of measure 87, and a release before the downbeat of measure 89 . The fact that he marked this small damper-pedaled phrase with a slur indicates Beethoven's intention for legato playing with the aid of the pedal. This same damper pedal marking is

128 Edwin M. Good, Giraffes, Black Dragons, and other Pianos: A Technological History from Cristofori to the Modern Concert Grand (Stanford: Stanford University Press, 1982), 84. 
subsequently revealed in the second theme of the recapitulation (mm. 276-278). The only other damper pedal marking in the fourth movement is indicated in the last four measures of the development. From measure 228 to the downbeat of measure 232, Beethoven marked a long damper pedal marking during the dramatic, fortissimo ascent of the E-major arpeggiated triads rising from the EE in the bass. The most natural reason for Beethoven's use of the long damper pedal marking to triumphantly announce the return of the recapitulation with the sheer sound effect created by the depth and expansion of range, full dynamic intensity and sustaining power of the resonating strings.

The dynamic range of Beethoven's fortepianos also varies considerably from that of the modern grand piano. Because of the fortepiano's design, which is based on smaller hammers, lighter stringing and lower string tension than that of modern pianos, the overall sound is smaller; but the range of dynamics is as wide as the modern grand piano (Example 7). 129

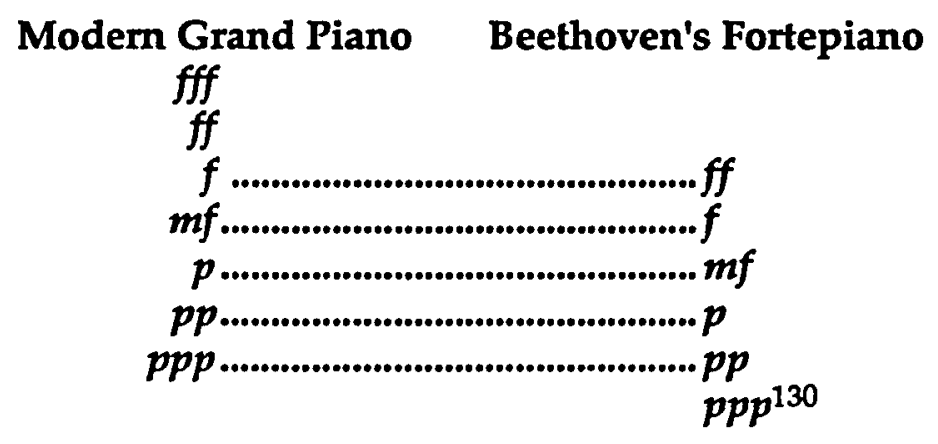

Example 7: Diagram of Piano and Fortepiano Dynamics.

129 Drake, Sonatas of Beethoven, 7.

130 Drake, Sonatas of Beethoven, 7. 
As the diagram suggests, "a crude but serviceable comparison can be formulated by imagining each general level of sound on today's instrument to be roughly the equivalent of one level louder on the fortepiano."131 Based on the capabilities of the modern grand piano, the twentieth-century perception of dynamic range is usually judged by how loud a sound can be produced. A performer who is more accustomed to the tremendously loud dynamics of the modern grand piano quickly discovers that employing too much force on the fortepiano is useless in attempting to reproduce a modern-day level of loudness. When playing Beethoven's music on a fortepiano, Melville discourages the performer's application of dynamic force:

The fact that none of the pianos-whether a Stein, Streicher, Walter, Schanz, Erard. Broadwood or Graf-would stand up to anything like this treatment is obvious proof that the contrasts between $p p p$ and ff have been stretched beyond any sensible limit. ${ }^{132}$

The loudest range of dynamics familiar to twentieth-century ears was not available on Beethoven's fortepianos. It is more important to consider the advantages of the softer dynamic range of Beethoven's fortepianos, rather than dismay over the disadvantage of having a limited range of loud levels.

Rosenblum proposes two alternatives for performing Beethoven's dynamics on the modern grand piano: first, "to play a modern instrument on its own terms, using its dynamic palette as the music suggests," and second, or "to scale down the dynamics of the modern instrument approximately" one level lower. ${ }^{133}$ In

131 Rosenblum, Performance Practices, 55.

132 Melville, 43.

133 Rosenblum, Performance Practices, 55. 
attempting to create a more historically-informed performance on the modern grand piano, the performer can use the dynamic range of the Beethoven's fortepianos as a guide for reference in interpreting his music. Rosenblum concludes that the "cause is not authenticity per se, but effectiveness of interpretation." 134

With respect to Beethoven's late period of writing, his last five fortepiano sonatas demonstrate more soft dynamic levels than his earlier sonatasincluding the more frequent used of the una corda pedal-to communicate the inner intensity of his lyrical and reflective style of expression. Rosenblum's studies show that in Beethoven's fortepiano sonatas " $f$ accounts for only 10 percent and $p$ for 18 percent of the dynamics, while $s f$ takes 30 percent and the term crescendo takes 11 percent." 135 Even within the four movements of Opus 101, Beethoven's dynamic scheme reveals soft first and third movements that alternate with loud second and fourth movements. In the first movement, Beethoven indicates soft dynamics for both the first and second themes of the exposition and the coda. Markings of espressivo e semplice (m. 25-26) and molto espressivo (m. 52-53) appear within the softer sections of the second theme and the retransition into the recapitulation, respectively. Beethoven's espressivo markings suggest his desire for meaningfully expressive playing within softer dynamic levels. With regard to Beethoven's combination of espressivo and semplice, Brendel comments that "it is highly illuminating to discover that espressivo and semplice are not mutually exclusive, as the general manner of espressivo playing

${ }^{134}$ Rosenblum, Pefformance Practices, 56.

135 Rosenblum, Performance Practices, 60. 
might lead one to believe." 136

Beethoven's frequent markings of crescendos in the first movement often lead to a diminuendo or piano marking. With the exception of a crescendo in the second theme, which reaches a climax with two rhythmically agogic sforzandos in measures 23-24-and subsequently again in the recapitulation, Beethoven indicates only a few loud dynamic markings. In the transition of the exposition, Beethoven marks a mezzo forte at measure 9; three forte marks, alternating with piano marks, leading to the climax of the development section in measures $42-50$; and the fortissimo marking in the second cadence-theme before the coda in measure 86. In performing the louder dynamic levels with the fortepiano's capabilities in mind, Rosenblum suggests that "the trick ... is to make a fortissimo sound as if it were being played as loudly as possible in order to suggest the excitement generated by an instrument extended to its limits." 137 The overall expression of the first movement is soft and lyrical, with occasional outbursts of passion.

The character of the second movement is more dynamically contrasting and unpredictable than the first movement. The dynamic range extends from pianissimo to fortissimo, including markings of $s f$ and $f p$. Within the first four measures of the first theme of the second movement, Beethoven indicates five different dynamic markings: $f$ (upbeat), sf (downbeat, $m 1), p$, crescendo, $f p$ (downbeat, m. 4). (Example 8.)

136 Brendel, 33-4.

137 Rosenblum, Performance Practices, 56. 


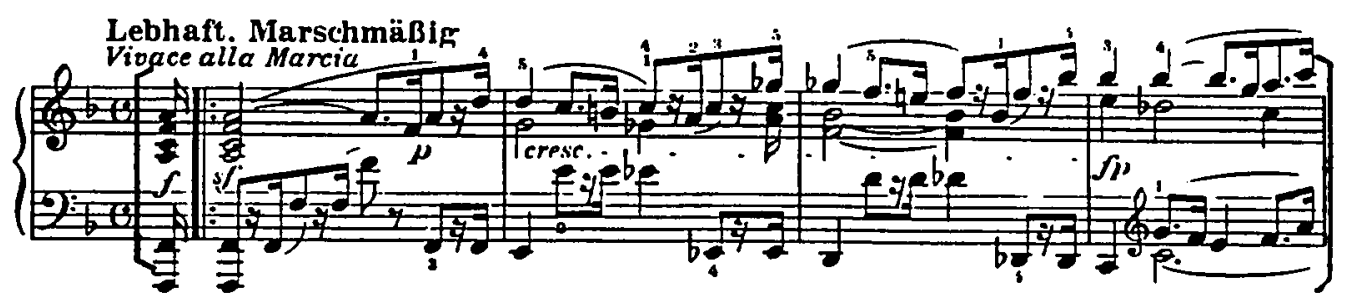

Example 8: Vioace alla Marcia, mm. 1-4.

In light of the limitations of the fortepiano's dynamic range, Beethoven's frequent usage of the $s f$ and $f p$ marking illustrates his resourcefulness in creating a more dramatic dynamic expression. ${ }^{138}$ One of Beethoven's most excessive uses of the sf marking in the second movement appears in the imitative stretto section in measures 40-41 to demarcate the subject entrances (Example 9). Newman notes that the sf markings are "dynamic accents that signal imitative entries in [the] polyphonic texture." 139

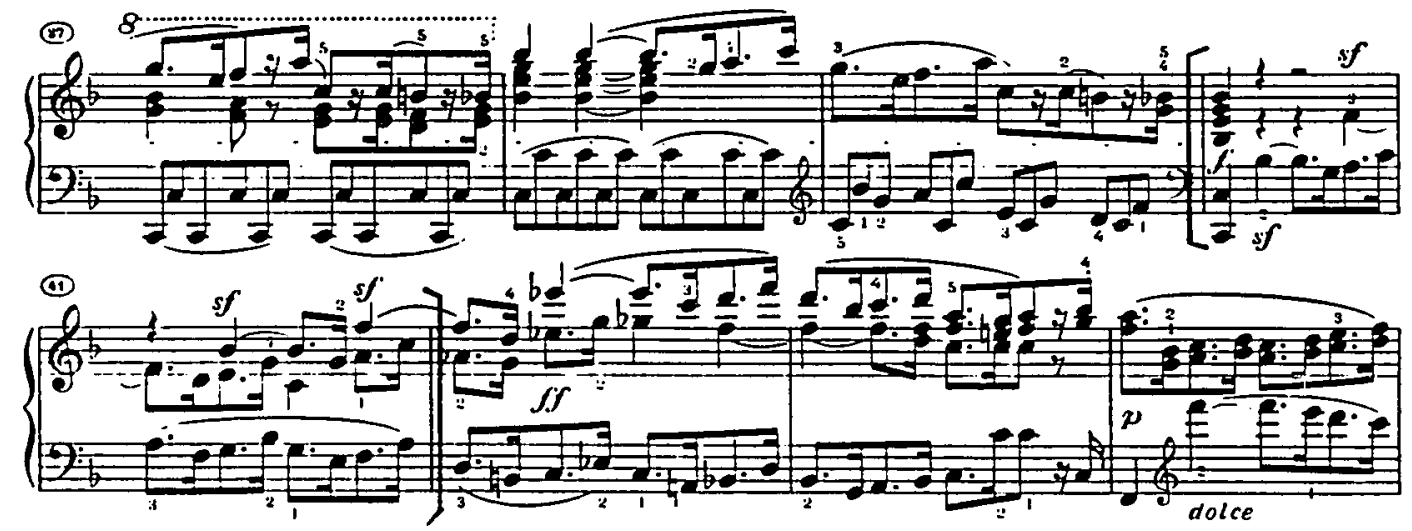

Example 9: Vivace alla Marcia, mm. 40-41.

138 Drake, Sonatas of Beethoven, 9-10.

139 Newman, Beethoven on Beethoven, 161. 
The three remaining $s f$ markings are all preceded by forte or fortissimo and followed by piano markings (m. 1 with preceding upbeat, $\mathrm{m} .19$ and $\mathrm{m} .50$ ). Because of the percussive nature of the modern grand piano, Brendel warns the performer not to implement "the most unthinkable treatment" of 'stabbing' the sforzandos in Beethoven's keyboard music. ${ }^{140}$ If the sforzandos are prepared with a forte or fortissimo marking, Brendel recommends that the performer "husband his strength in order to make the accent stand out above the general level of tone."141 Beethoven exploits the soft dynamic levels in some of the most expansive areas of the keyboard's range. In the blurred, damper pedal section at measures 30 and 33, Beethoven indicates piano and then pianissimo, respectively, located in two of the widest spacings between the hands (Example 3). In almost all of the other instances of wide spacings between the hands within the F major section of the second movement, he indicates a crescendo or various forte markings.

In the B-flat major Trio section of the Vivace alla Marcia Beethoven also exhibits the use of soft dynamics in the wide spacing of the hands in measures 87-90. Considering the unmuffled tone quality in the bass register of Beethoven's fortepiano, the clarity in distinguishing the repetition of the $C$ and $D$-flat motive in the bass voice (mm. 87-90) could possibly depict the sound of a distant drum roll. The drum roll changes from a half-step, pianissimo rumbling to the alternation of the low $C$ and bass c octave in measure 91 marked poco crescendo. In addition to the poco crescendo marking, Beethoven changes from four measures of a half-step, distant rumble followed by the more insistent drum roll expanded

140 Brendel, 31.

141 Brendel, 32. 
to the octave. The continuation of the octave drum roll-in addition to Beethoven's marking of piu crescendo in measure 93-builds to a forte in measure 94 and heralds the return of the principal theme. Again, the spacing between the hands is quite wide in measure 91 at the softest level of Beethoven's poco crescendo indication (Example 10).

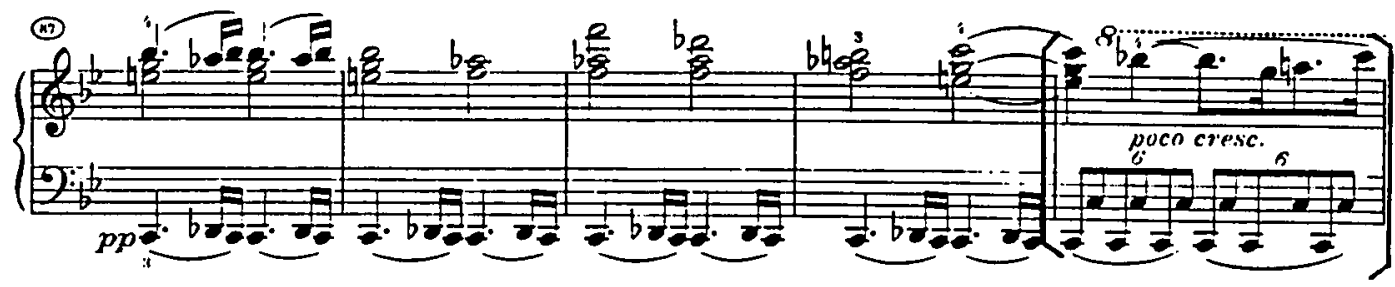

Example 10: Vivace alla Marcia, (trio), mm. 91.

According to the autograph of the third movement, Beethoven did not indicate any dynamic markings for the first nineteen measures. But in Steiner's first edition the abbreviated word for crescendo appears in measure 19, followed by a piano marking in measure 20. Both markings appear in the Wallner/Henle edition (Example 11). 


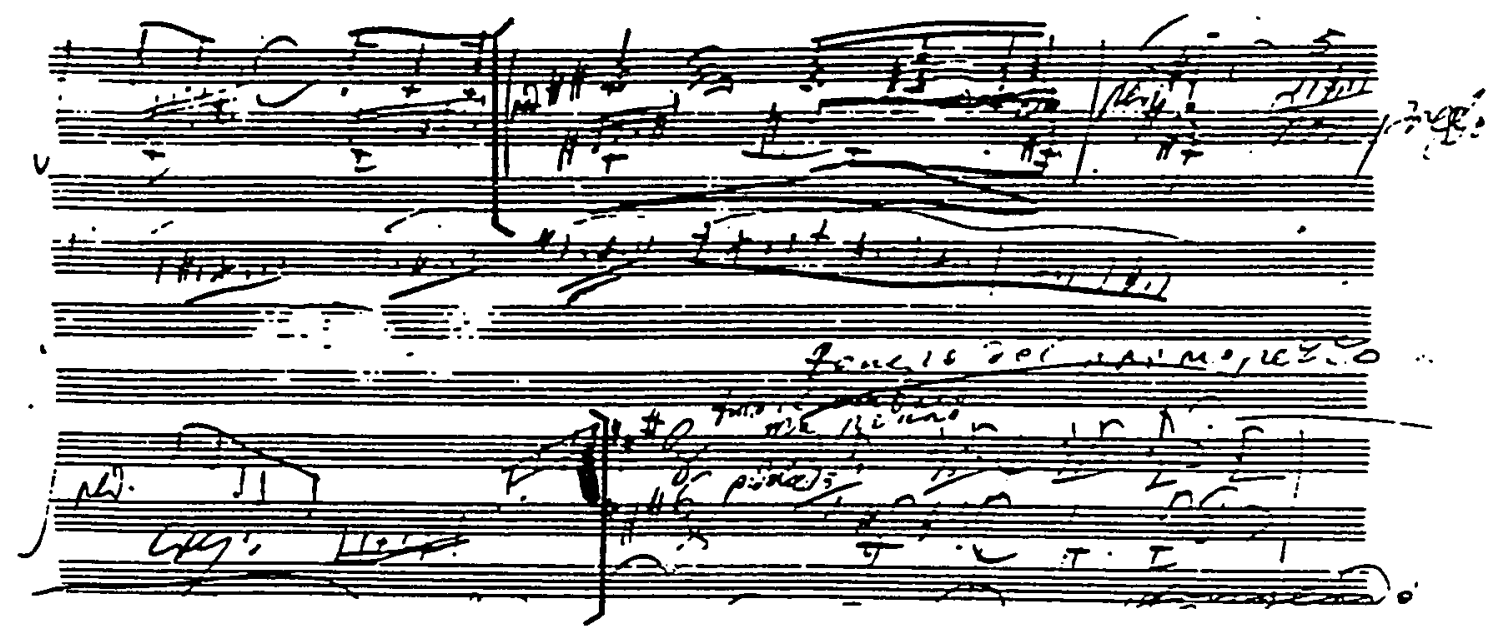

Autograph, mm. 19-20.

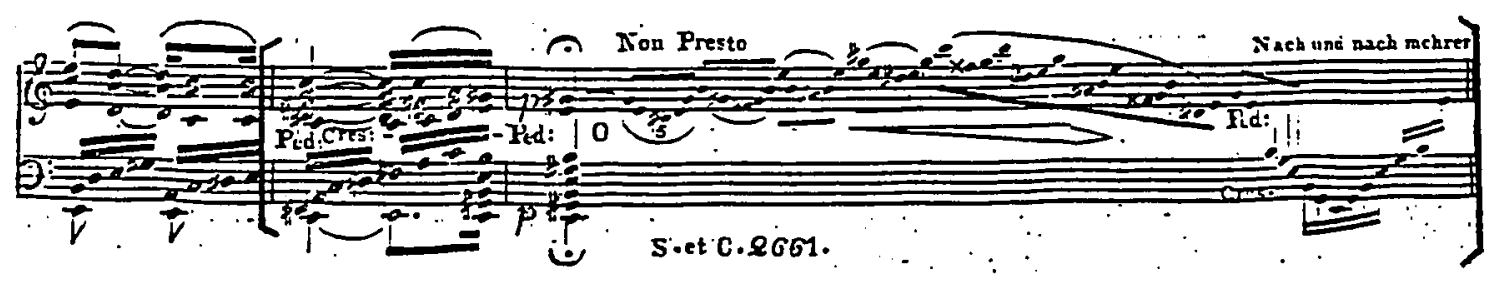

First Edition (Steiner), mm. 19-20.

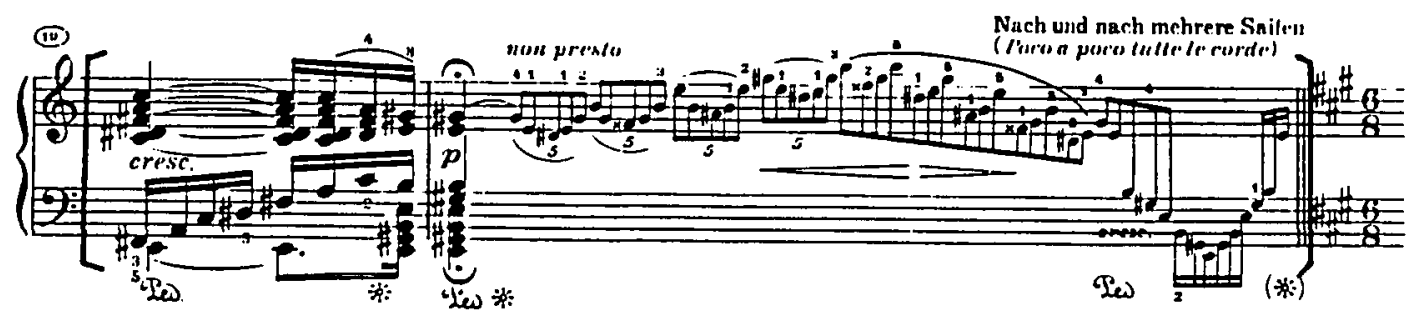

Henle Edition, mm. 19-20.

Example 11: Adagio, ma non troppo, con affetto, mm. 19-20. 
From a performance practice perspective, the most controversial dynamic consideration lies hidden in measure 5. Although neither the autograph nor the first edition show any dynamic marks in measure 5 , the Moscheles' edition contains a crescendo symbol from measure 5 through measure 6.142 Ignace Moscheles justified his crescendo indication based on his first account hearing of the Opus 101 sonata played by the famous Beethoven interpreter (during Beethoven's lifetime), the Baroness Dorothea von Ertmann (Example 12).

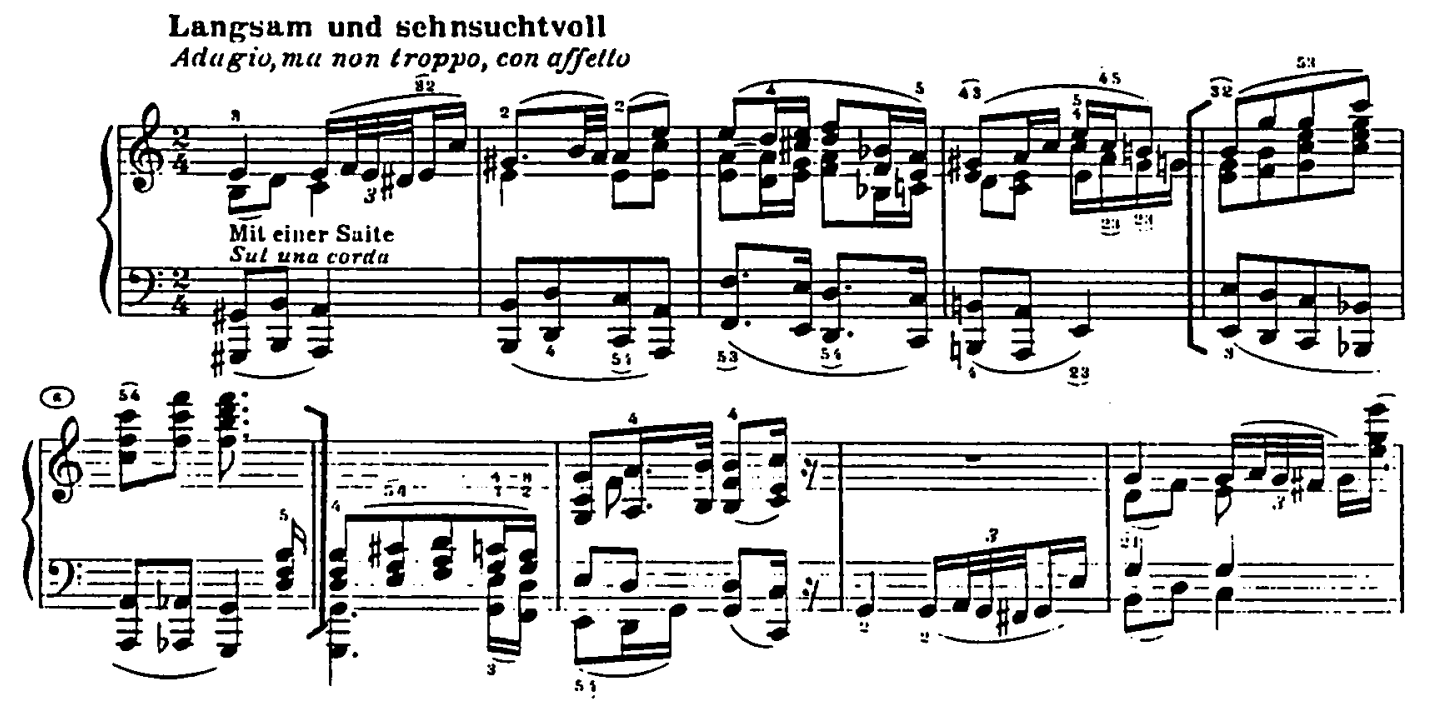

Example 12: Adagio, ma non troppo, con affetto, mm. 5-6.

The addition of the crescendo in measures 5 and 6 is understandable from a general performance practice application, because the movement of the notes outwards in contrary motion suggests a increase in sound. Several demonstrations of Beethoven's soft dynamics indicated in widely spaced expansions between the hands are evident in the first movement (mm. 24-33, 76-

142 Drake, Sonatas of Beethoven, 96. 
84, 100-103), the second movement (mm. 30-35, 87-92), and in the fourth movement (mm. 106-109, 239-243, 295-298, 305-313, 347-358). The crux of the argument is based on the fact that Beethoven did not indicate a crescendo; as Miriam Sheer remarks "Beethoven was meticulous in his use of dynamic markings."143

The $\mathrm{E}$ major key area of the cadenza in measure 20 functions as the dominant preparation for the entrance of the tonic A major return of the principal theme of the first movement; the inflected dynamics within the cadenza, and the final crescendo, suggest a triumphant climax. Beethoven indicated piano and dolce at the unexpected return of the principal theme of the first movement in measure 21. The dynamic markings in measure 21 generally reflect those in measure 1 of the first movement; the dolce marking is both dynamically and expressively descriptive. Brendel believes that Beethoven's interpretation of the word dolce

has its own emotional climate: my translation is 'tenderly committed'. Dolce tells the player: 'Identify yourself with this phrase; do not control it from outside.' It begs for loving attention and flinches from mechanical coldness. ${ }^{144}$

Beginning in measure 25, fragments of the principal theme of the first movement ascend by sequence and increase with a crescendo to a forte climax in measure 28, marked Presto. In this instance, the anticipation of the crescendo in measure 26 reaches a dynamically heightened climax in measure 28 . The tempo

143 Miriam Sheer, "The Structural Functions of Dynamics in Beethoven's Instrumental Works," The Beethoven Newsletter 5 (1990): 53.

144 Brendel, 33. 
change from first movement to Presto and the E major dominant-seventh chord predicts the outcome of an eventual resolution on A major; Beethoven indicated a diminuendo marking immediately following the forte sign (m. 28).

Two chromatically ascending trills, marked piano, lead to a trill on $\mathrm{E}$ (dominant), marked with a crescendo at the end of measure 28. According to Wallner in the Henle edition, Band II, of Beethoven's sonatas, the appoggiatura preceding the trill on E only appears in the Steiner first edition and not in the autograph. 145 The E trill links the Presto to the fourth movement; the fourth movement begins with a four-measure introduction consisting of bouncing root position, dominant-seventh chords (successive root position chords being a rarity for Beethoven) marked forte. The forte marking in measure 29 appears in the autograph, but not in the first edition. In her article on "The Structural Functions of Dynamics in Beethoven's Instrumental Works," Miriam Sheer discusses the unifying aspects of Beethoven's dynamic marking within the structure of some of his works. 146 Although she does not cite Beethoven's Fortepiano Sonata, Opus 101 , in her article, several quotes seem to apply to the dynamics in the connecting material between the third and fourth movements of the sonata:

The manipulation of tonal areas, while perhaps a stronger unifying force, is not as easily perceived, especially by non-musicians; changes in dynamics, however, have a direct and immediate impact on all listeners. ${ }^{147}$

145 B. A. Wallner, ed., Beethoven Klaviersonaten: Band I (München-Duisburg: G. Henle Verlag, 1972), 218.

146 Sheer, 62 .

147 Sheer, 62. 
The three E major dominant preparations (mm. 20, 28, 29-32) propel forward toward the ultimate resolution of the A major chord (m. 33), initiating the first theme of the fourth movement. Sheer observes that Beethoven judiciously used the graduated dynamics of crescendo and diminuendo "to link one section to the next."148 In linking the material between measures 20-32, Beethoven marked a crescendo before, and a diminuendo after, the three $\mathrm{E}$ major sections which precede the fourth movement. From the beginning of the third movement to the beginning of the first theme of the fourth movement, the only loud dynamic mark Beethoven indicated was a forte in measure 28 (excluding the crescendo in measure 20). Beethoven's use of loud dynamics projects and heightens the dominant anticipation of the fourth movement in the tonic; the loud dynamics also act as a unifying element, which not only link the third to the fourth movement, but unify the entire sonata. As Sheer contends, "a single dynamic level can link passages to create a larger structural unit (especially in fast movements) simply by being sustained for a certain length of time."149 The sforzando indicated on the downbeat of measure 33 functions as a metric accent for dynamic impact as well as "helping to outline the structure ... [which] marks the arrival at the tonic harmony and the start of a new section in the finale of Op. 101."150

A majority of Beethoven's dynamic markings in the fourth movement illustrate extreme changes from loud to soft and vice versa. A particularly

\footnotetext{
148 Sheer, 63.

149 Sheer, 62.

150 Newman, Beethoven on Beethoven, 151.
} 
dramatic example of Beethoven's extreme changes in dynamics, occurs in measures 87-90-and subsequently again in the development from measures 276279 , in which he abruptly indicates pianissimo, forte and piano within the range of four measures (Example 13).

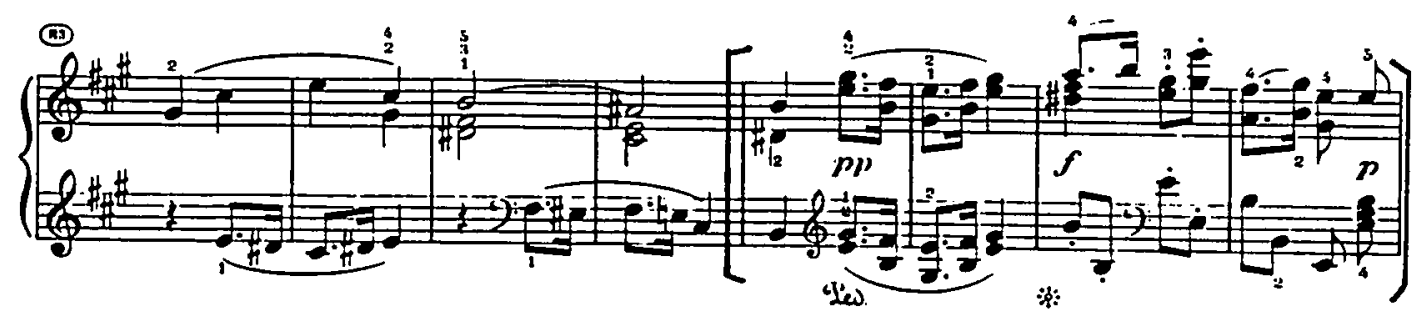

Example 13: Allegro, mm. 87-90.

Beethoven uses the dynamic accentuation of the sforzandos to set off the entrances of his contrapuntal material in the fourth movement: throughout the exposition, in the last half of the fugal development, and only in the first three measures of the recapitulation. In measures 149-154 of the fugal development, Newman comments that Beethoven exhibits a form of rhythmic ambiguity within the contrapuntal texture which distorts the rhythmic and dynamic flow:

In this episode the feminine cadence of each incise peaks clearly enough after a bar line, but the imitation of each soprano incise by the alto and tenor two beats later naturally diffuses any singleness of rhythmic grouping or dynamic direction in the total texture. ${ }^{151}$

Beginning in measure 239-only eight measures into the recapitulationBeethoven detoured from the course of the exposition; he inverted the subject, spaced the hands far apart, and aligned the two hands to simultaneously play the

151 Newman, Beethoven on Beethooen, 183. 
subject moving in contrary motion with imitations in the alto voice. Beethoven also changed the mood of the inverted section by indicating dolce poco espressivo. According to Drake, the "dolce describes the character [of the mood], while poco espressivo is an indication to hold back the tempo a little."152 With a different opinion, Brendel suggests that:

dolce and espressivo emit different emotional signals. The heartfelt gentleness of dolce generally keeps away from the minor keys. Dolce is soothing, or conveys tender rapture. However luminous it may be, it shines with an inner light, whereas espressivo distinctly addresses the outer world. Whereas the two appear together (as dolce poco espressivo in Op. 101), the dolce is to be given additional weight. For that is what espressivo demands: a perceptible increase in emotional emphasis over the foregoing passage. ${ }^{153}$

Drake and Brendel's analyses regarding Beethoven's meaning of dolce poco espressivo are primarily descriptions of expression rather than dynamics; the performer should consider the expressive definitions as well as the dynamic marking of piano to understand Beethoven's complete meaning of the section.

In the fourth movement some discrepancies in dynamic markings appear between the autograph and the Steiner edition: the first and second endings before the development (rii. 113), throughout the development (mm. 123, 155, 197, 201-202, 206, 210, and 214) and in the coda (mm. 305 and 324) The dynamic discrepancies are not diametrically contradictory. The most powerful dynamic markings appear in the final climax of the development. Beethoven initiated the tremendous build-up of dynamic intensity at the stretto section in measure 208.

152 Drake, Sonatas of Beethoven, 70.

153 Brendel, 34. 
In measure 214 Beethoven indicated a crescendo leading to the insistent sforzandos, which alternate from the soprano to the bass voices for four measures. From measures 220-223, Beethoven marked the sforzandos on the agogic beats. The climax is reached on the second beat of measure 223, marked fortissimo, along with Beethoven's EE inclusion in the bass voice. Beethoven's marked fortissimo again in measure 228 for the ascending E major chords, which alternate between the hands.

In contrast to the intensely loud dynamics of the development's final climax, Beethoven only marked two small segments of the coda with loud dynamic marks (with the exception of the crescendo marking in measure 324, which is only indicated in the autograph and not the first edition): he marked fortissimo in measure 313 and fortissimo in measures 359-361. Beethoven indicated pianissimo five times in the coda (mm. 303, 317, 339, 352 and 354) as well as piano dolce in measure 305, sempre piano in measure 306 , and piano in measures 317 and 347.

With regard to the fortissimo marking at measure 313 , Tovey claims that Beethoven "asks the same angry question as at bars [123-124], with the same pause for reply. Two bars later the question is quietly repeated in the minor, with the same pause."154 In the final fifteen measures of the coda, Beethoven marked soft dynamics for the low measured trill in the bass voice, which resembles the sound of a distant drum roll. Could this be a reminiscence of the drum roll figure from the second movement? Beethoven marked both of the

154 Donald Tovey, A Companion to Beethooen's Pianoforte Sonatas: Bar to Bar Analysis (London: Associated Board of Royal Schools of Music, 1931), 226. 
drum rolls with soft dynamic markings and spaced the hands far apart. The dynamic expression of the drum rolls constitutes a structurally unifying factor in the sonata. Beethoven concludes the coda in Tempo I in measures 355-358 with three measures of exuberantly fortissimo full-voiced chords in A major-with the final chord in a strong root position, no less!

Newman comments that "articulation in music has been compared with some justification to facial expressions in acting." 155 More frequently than any great composer before him, Beethoven consistently and extensively marked his music with phrase marks and slurs. In Opus 101 Beethoven displayed a variety of articulation markings involving the "new facial expressions" of the slur, demonstrating a characteristic representative of his late style. Articulation markings were certainly not a new feature in Beethoven's late sonatas; "he used far more of it than Czerny would admit in his incipits for Proper Performance, and in fact greatly enlarged the vocabulary of slur usage in his later works." 156 Instead of merely demonstrating where complete phrases begin and end, Beethoven's individual style of marking articulation appeared in the motivic or fragmentary sections. Beethoven indicated this style of articulation more frequently in his faster tempos, as evidenced in the first movement of Opus 101. Beethoven's autograph clearly shows his multiple articulation markings.

Particularly significant examples of Beethoven's unique articulation appear in the first movement and are not apparent in the subsequent

155 Newman, Beethoven on Beethooen, 121.

156 George R. Barth, "The Fortepianist as Orator: Beethoven and the Transformation of the Declamatory Style" (Ph.D. diss., Cornell University, 1988), 106. 
movements. The first unusual phrase mark begins in measure 5 and extends to the third beat of measure 6 , immediately preceding the fermata on the fourth beat of the deceptive cadence. George Barth defines this phrase mark as a "fresh arrival within the bar."157 Another characteristic articulation mark that reoccurs throughout the movement are sets of short slurs, which are articulated over the bar lines, such as those found in measures $9,10,61,62,100,101$. In measure 16, Beethoven indicated a double-layered slur ending with a staccato (Example 14).
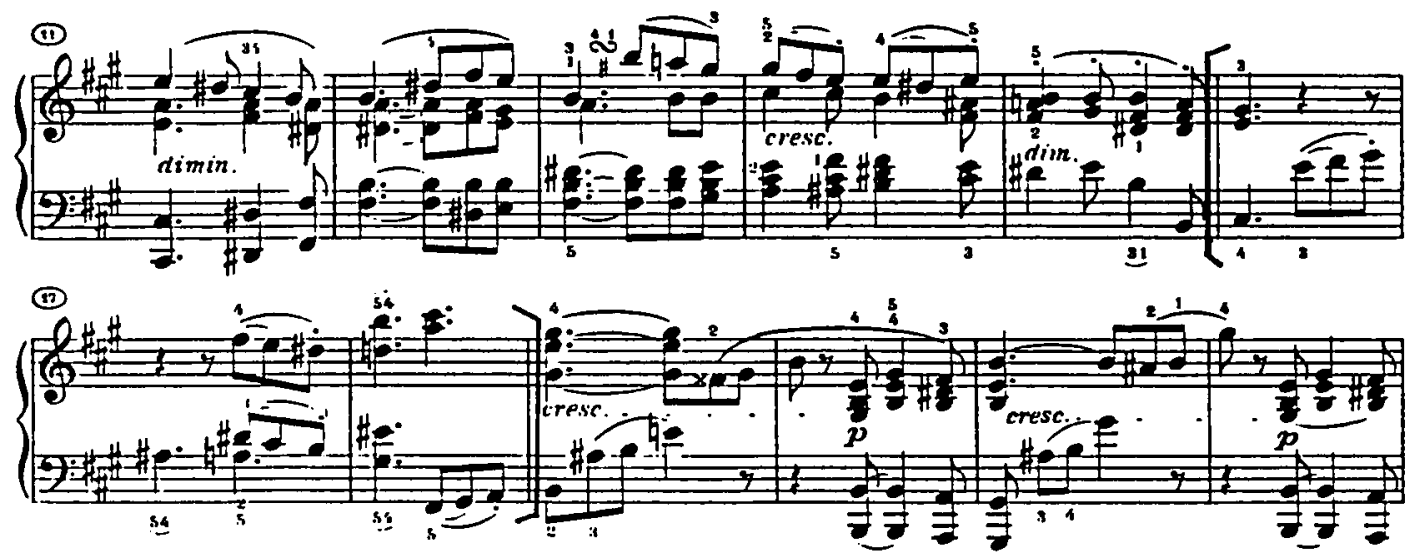

Example 14: Allegretto, ma non troppo, mm. 16-18.

This double layered slur appears again in measures $17,18,49$ (with sforzandos replacing the staccatos), 66, 68, 69, 70, 92 and 98 . Considering the fact that the first movement is only 102 measures long, the reoccurring frequency of the double-layered slur becomes a highly recognizable and characteristic feature of the articulation for this movement. Drake explains the subtlety of touch required to execute this special slur:

157 Barth, 125. 
[first] that the first note is the heaviest of the three and may be somewhat lengthened; [second] that the finger must be lifted from the second eighth; [third] that the third eighth, although it is detached from and played shorter and lighter than the second eighth, remains part of the three-note figure and must not be regarded as an upbeat to the following beat. 158

The final example of Beethoven's innovative use of the slur is demonstrated in measures 19-20. Beethoven indicated a slur from the fifth beat of measure 19 across the bar line and ending on the last beat of measure 20. The significance of the slur is that Beethoven marked an eighth rest on the second beat of measure 20. Newman's rationale for the slur extending over the rest is that Beethoven was "psychologically implying continuity even while the physical continuity is interrupted."159

Beethoven also used syncopated chords in the cadence-themes of the exposition and recapitulation with a dramatically accentuated displacement of the duple compound meter. In measures 29-34 Beethoven distorted the meter by placing ties across the bar lines to "give the impression of an accumulation of weight and tension" (Example 15).160 To begin the development section (mm. 3540), he continued the syncopated chords over the bar line in the treble over the first theme in the bass. The rhythmic displacement caused by the syncopated chords becomes an inherent feature of the development section from measures 33-48.

\footnotetext{
158 Drake, Sonatas of Beethoven, 139.

159 Newman, Beethooen on Beethooen, 134.

160 Drake, Sonatas of Beethoven, 115.
} 


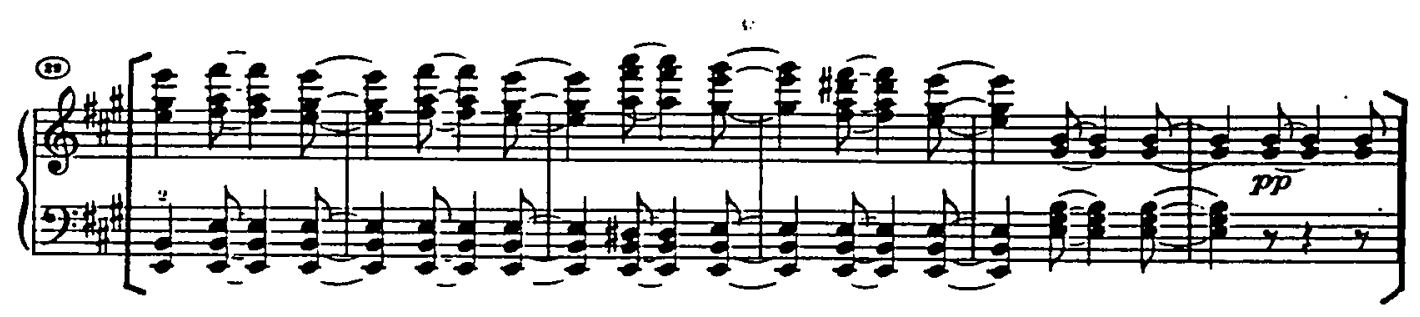

Example 15: Allegretto, ma non troppo, mm. 29-34.

The syncopated chords appear again in measures $81-88$, but this time, Beethoven indicated a crescendo and more thickly textured chords that start in measure 85. Beethoven reached the climax on the sixth beat of measure 86 marked fortissimo. The full sound of the fortissimo chord in measure 86 naturally begins to decay, while being suspended with additional ties over measures 87 and 88. The lilting gesture of the duple compound meter returns in measure 88 .

The primary ornaments that Beethoven used in the Opus 101 sonata are trills, pedal point, tremolos, turns, varied groupings of grace notes, and short and long appoggiaturas. Only scanty explanations by Beethoven himself, and brief comments by Beethoven's students on fingering and improvised embellishments, exist to aid the performer in the execution of ornaments. The performer can refer to Beethoven's original fingering or his written-out ornaments (partial or in full) to determine the proper execution of the ornament. According to Newman, "next to the choice and flexibility of tempo, the proper realization of his trills still seems to be the practice that pianists discuss most in his music."161

Of all the ornaments mentioned above, Beethoven used the trill with the most frequency in his scores. Beethoven utilized the short and long trill which he

161 Newman, Beethooen on Beethooen, 193. 
marked with the traditional trill symbols and written-out trills in the second and fourth movements of Opus 101. In the second movement, Beethoven's treatment of the trill functioned as

a kind of accent on key notes of the phrase ... and apparently came to be associated with a feeling of ecstasy and frequently appears in the more exuberant and Dionysian passages of his late works. ${ }^{162}$

To determine the correct starting note of the trill, the performer should observe Beethoven's fingerings, grace notes and notation as a guide. In the second movement two short trills appear on the agogic beats in measure 16 without terminations. The two trills in measure 18 also fall on the agogic beats and include Beethoven's written-out indication of termination notes after the trilled notes. Beethoven indicated an extended trill - with no termination indicationin measures 76 through 78 in the Trio of the second movement. The trill is located in the treble voice over the two-part canonic treatment of the tenor and bass. As in the Baroque tradition, Beethoven's long trills functions as an embellishment which extended the duration of a single note.

Since the tremolo is a distant cousin of the trill, it seems appropriate to discuss Beethoven's use of the tremolo. In the second movement, Beethoven indicated a written-out, measured tremolo in the bass voice in measures 36-38 and 91-94 suggesting a drum roll. The tremolo also functions as a pedal point which produces the $C$ dominant preparation that leads to the deceptive cadence in measure 40 . The first pedal point in the second movement actually appears before the tremolo-pedal point. In measure 30, Beethoven indicated a long

162 Charles F. Schroder, "Final Periods of Mozart, Beethoven, and Bartók" (Ph.D. diss., Graduate College of the State University of lowa, 1965), 203, quote from E. Newman. 
damper pedal marking starting with the D-flat in the bass. Because of the extended pedal marking, the sustaining D-flat note becomes a pedal point on the lowered sub-mediant for four measures.

The drum roll effect from the tremolo of the second movement surfaces again in the coda of the fourth movement (mm. 347-358), but as a measured trill in the bass voice. In the same manner in which the tremolo figure in the second movement also served as a pedal point, Beethoven added the EE to the measured trill in the fourth movement to create a pedal point in measures 350, 354, 356 and 358. The explanation for Beethoven's choice of measured trills and tremolos in the bass register is to project the clarity of the oscillating notes in conjunction with accompanying voice parts. ${ }^{163}$ It is interesting to note that Beethoven marked the two tremolo figures in the second movement and the measured trill in the fourth movement with soft dynamics; the soft dynamics suggest the increase of emotional intensity which, in all three instances, culminates with tremendously heightened dynamics and densely textured chords.

Between the third and fourth movements, the three ascending trills in measure 28 help to link the restatement of the principal theme of the first movement to the fourth movement. The first two trills function as embellishments, which chromatically rise to finally arrive at the trill on $\mathrm{E}$; the $\mathrm{E}$ trill extends for four measures, creating the dominant preparation for the $\mathrm{A}$ major tonic in measure 33. It is important to note that the appoggiatura attached to the $\mathrm{E}$ trill only appears in the first edition and not in the autograph.

Many short trills appear in the fugal development of the fourth

163 Newman, Beethoven on Beethoven, 204. 
movement. It is Newman's conjecture that the trills should begin on the principal note, due to the descending three notes which approach each trill figure; this manner of executing the trill helps "retain the subject's identity in the fugal finale."164 Breaking away from the Baroque tradition of playing trills, Beethoven modifies the execution of the trill within his contrapuntal setting to facilitate more continuity in the subject's line.

Beethoven used the turn figure in the first movement by indicating the traditional turn symbol; he integrated the turn figure into the notation of the theme in the third movement. Two turn figures appear in measures 13 and 65 of the first movement. Beethoven used the turns to ornamentally and melodically fill the gap between the octave span of the notes bordering the turn. The turns provide a beautifully lyrical quality to the tuneful segment of the theme.

In the third movement Beethoven's written-out turn figures become an integral part of the thematic framework (Example 16).

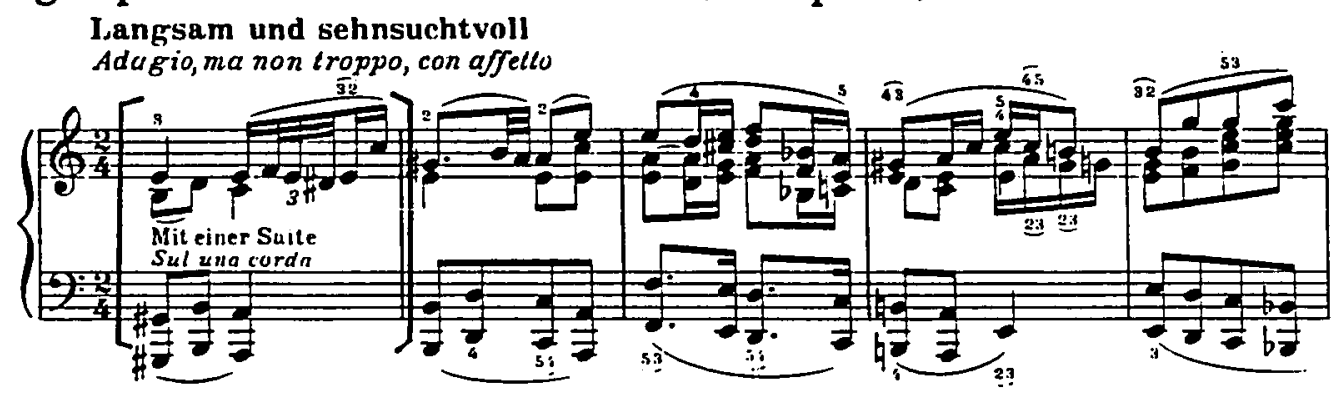

Example 16: Adagio, ma non troppo, con affetto, m. 1.

Beethoven takes the turn figure segment of the theme and creates a dialogue between the treble and bass voices in measures 12 and 13; the dialogue is followed by the further development of the turn figure segment in the treble over

164 Newman, Beethooen on Beethooen, 201. 
arpeggiated diminished-seventh chords in the bass. The grace notes which precede the downbeat of the bass notes (mm. 12-16) create a chromatically descending pedal point-also taking into consideration the down-stem eighth notes in measures 14-16-to the repetition of E dominant pedal notes in measures 17-20.

Beginning at measure 15, Beethoven displays four different ornament figures: a single grace note in the bass (which serves as an appoggiatura and a pedal point), the three-note grouping of appoggiaturas in the treble (which function like a rolled chord effect) and the written-out turn figure within the theme in the treble voice. Measure 16 possesses all four ornaments, with the exception of the three note grouping of grace notes (Example 17). With regard to the performance practice of measures 15 and 16, Drake recommends that:

Because the single and compound appoggiaturas in measure 15 and the single appoggiaturas in measure 16 of Op. 101, III, result in the main notes in each hand being played together, it would seem consistent to play the appoggiatura in the left hand in measures 12,13 and 14 ahead of the beat. 165

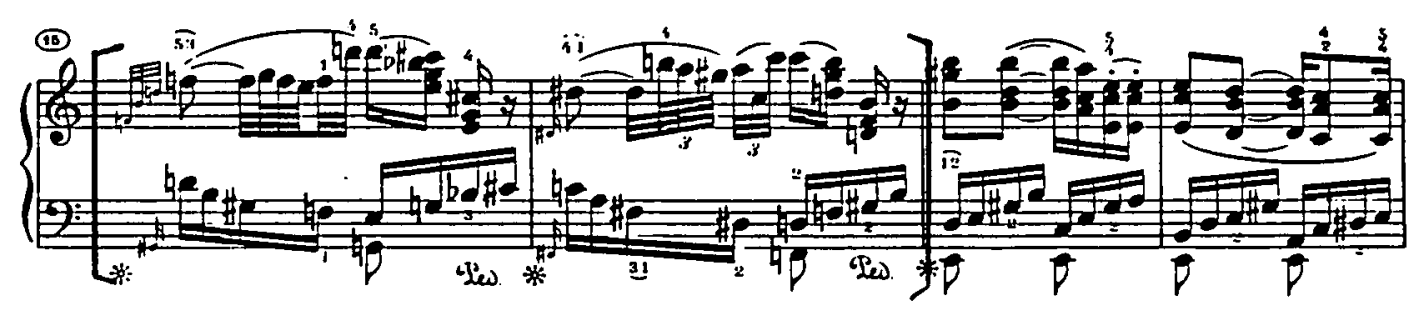

Example 17: Adagio, ma non troppo, con affetto, mm. 15-16.

Beethoven alternates his use of ornaments between the different movements of 
the sonata. In the first and third movements, he featured the turn figure as a lyrical gesture of expression and thematic content; the turn figure ultimately binds the two movements in a unifying manner with respect to the entire sonata. Beethoven reserves his use of trills-indicated either by symbols or written outand long pedal points for the second and fourth movements. 


\section{Chapter 5}

\section{Dedication to Baroness Dorothea von Ertmann}

Beethoven dedicated the Opus 101 sonata to his talented fortepiano student and patron, Baroness Dorothea von Ertmann. In a letter addressed to Tobias Haslinger in January of 1817, Beethoven insisted that the word "Hammerklavier" be printed in the inscription of the dedication, as follows:

Quite by chance I have hit on the following dedication:

$$
\text { 'Sonata }
$$

for the Pianoforte

or- - Hämmer-Klavier composed and dedicated to

the Baroness Dorothea Ertmann, née Graumann,

by L. v. Beethoven'

This is for the new sonata [Opus 101]. But should the title be already engraved, then I have the following two proposals to make, that is to say, either I shall pay for the new title, i.e. it will be engraved at my expense, or this title will be reserved for another new sonata which I shall compose [Opus 106]. And indeed to bring another sonata into the world, all that is necessary is that the L[ieutenan]t G[enera]l's or, better still, pleno titulo, the L[ieutenan]t G[eneraji's and First State Councillor's mines should be opened-The title must first be shown to a linguist.

Hammer-Klavier is certainly German and in any case it was also a German invention. Honour to whom honour is due-How is it that I have received no reports of the executions which have doubtless taken place?

Ever your best amicus ad amicum de amico.

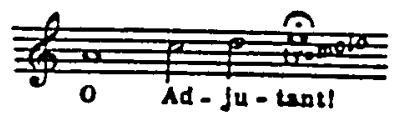

Please observe the strictest silence about the dedication, for I want it to be a surprise. 166

\footnotetext{
and Co. Ltd., 1961), 657, L. 742.
}

166 Emily Anderson, ed. and trans., The Letters of Beethoven, vol. II (London: MacMillan 
Besides being the wife of a colonel in the royal and imperial infantry regiment, Ertmann was respected as an accomplished musician and fortepianist in Vienna at the time. Ertmann's first encounter with Beethoven happened quite inadvertently. She was aware of Beethoven's reputation as a composer in Vienna: he was generally misunderstood and considered incomprehensible. Because she was curious about his fortepiano sonatas, Ertmann went to Haslinger's music shop to investigate Beethoven's sonatas for herself. Unbeknownst to her, Beethoven was standing in the corner of Haslinger's shop while Ertmann was playing his sonatas on the shop's fortepiano. After her playing, Beethoven approached Ertmann and expressed his great delight and satisfaction in her renditions of his sonatas. Ertmann was sincerely impressed with Beethoven as well as his sonatas and she began informal lessons with him which continued from 1803 to 1818.167

Even though she did not perform publicly, but usually in private concerts, Ertmann was considered one of the finest interpreters of Beethoven's music. More importantly, Beethoven admired her interpretation of his music the best. He endearingly called her "Dorothea-Cecilia" - ranking her musical prowess as the patron saint of music. Beethoven also appreciated her faithful adherence to his style of expression and interpretation, as opposed to the musical trend popularized by Hummel and his followers during the same time period. Along with a copy of Opus 101, Beethoven sent this letter to Ertmann on February 23, 1817:

167 Kenneth Drake, "A Study of the Beethoven Piano Sonatas in the Light of Evidence Provided by Beethoven's Pupils" (Ph.D. diss., University of Ilinois, 1970), 51-2. 
My Dear

And Beloved Dorothea

Caecilia!

You must have often misjudged me, for I must have seemed unpleasant to you. A good deal should be put down to my circumstances, particularly in former times when my Muse was less appreciated than now. You know the explanations given by the unbidden apostles who made shift with means very different from the Holy Gospel. Well, I did not wish to be reckoned among their number. Please accept now what was often intended for you and what may be to you a proof of my devotion both to your artistic aspirations and to your person-That I could not hear you play at Cz[erny]'s recently was due to an indisposition which at last seems to be yielding to my healthy constitution-I hope to hear from you soon how the Muses are faring at St. Pölten and whether you cherish any regard for your friend and admirer[.]

L. $\mathbf{v}$ Beethoven

My best compliments to your beloved husband and consort. 168

Ertmann's repertoire of Beethoven's compositions included the fortepiano sonatas, of Opuses 101; 27, No. 2; 31, No. 2; the "Kreutzer" sonata, Opus 47, for fortepiano and violin; the horn sonata, Opus 17; the cello sonata in A major, Opus 69; and the Fortepiano Trio in B flat major, Opus 97, ("Archduke") for fortepiano, violin and cello (which she performed with Schindler and Linke). Schindler claims that the reason Beethoven's sonatas remained in the Vienna repertory was due, in part, to Ertmann's frequent and charming performances. ${ }^{169}$

Beethoven's dedication of Opus 101 to Ertmann and her reputation as an esteemed Beethoven interpreter was well established in the musical circles of the time. Ertmann was admired by Reichardt and Mendelssohn for her poetic, expressive playing; she was especially respected for her playing of Beethoven's

168 Anderson, vol. II, 671-2, L. 764. 210.

169 Anton Felix Schindler, Beethoven As I Knew Him (New York: Schirmer Books, 1977), 
sonatas. After hearing Ertmann perform, Reichardt described her playing as

follows:

A tall figure and a beautiful soulful face heightened my expectation still more at first sight of the noble lady, and for all that I was taken by surprise as never before by the performance of a large Beethoven sonata. I have never seen, even in the greatest virtuosos, such strength together with the most intimate delicacy; in each fingertip a singing soul, and in both, equally dexterous, equally sure hands what strength, what authority over the whole instrument that must be to bring forth everything singing, speaking and playing which is sublime and beautiful in art! And it was not even a beautiful instrument, such as one otherwise frequently finds here; the great artist breathed her sensitive spirit into the instrument and forced it to do service which under no other hands it could have produced. 170

Mendelssohn made his first acquaintance with Ertmann in 1831 when Colonel von Ertmann and Dorothea were stationed in Milan. After hearing Ertmann play, Mendelssohn commented about her playing in a letter to his sister:

She plays the Beethoven things beautifully, although she has not studied for a long time, often exaggerates the expression a little and holds back a great deal and hurries then again; however, she plays single pieces gloriously, and I believe I have learned something from her. Once in a while, when she can no longer press out notes from within herself and then begins to sing with a voice which comes from the depths of her nature, then she reminds me of you, Fanny, although naturally you are far superior to her. As I came to the end of the Adagio of the B-flat major Trio, she cried out: "That is impossible to play, it is so beautiful," and that is really the truth about that passage. ${ }^{171}$

It is a well accepted fact that Schindler misrepresented Beethoven by fabricating and deleting aspects about the composer in his biography. But not all

170 Alfred C. Kalischer, Beethover und seine Zeitgenossen, vol. III, quote trans. by Drake (Berlin and Leipzig: Schuster and Loeffler, 1909-1910), 108.

171 Kalischer, vol. IV, quote trans. by Drake, 46. 
of Schindler's is incorrect or distorted. In his biography, Schindler exuberantly praised Ertmann's playing of Beethoven's music:

She grasped intuitively even the most hidden subtleties of Beethoven's works with as much sureness as if they had been written out before her eyes. This sensitive musician used the same insight with respect to nuances of tempo in a way that cannot be described in words. She knew how to give each phrase the motion of its particular spirit, how to move artistically from one phrase to the next, so that the whole seemed a motivated unity. ${ }^{172}$

Czerny is said to have approved of Ertmann's tastefully lyrical playing but condemned her freedom of tempo, especially in the third movement of Opus 101. Being a long-time student of Beethoven's, Czerny reminds the performer to play in strict time unless Beethoven indicated otherwise. In the following excerpt from his memoirs, Czerny recounts that:

Of the ladies of that era (1800-1820), Baroness Ertmann played Beethoven's works the best. She and her husband, Baron Colonel Ertmann, were among his [Beethoven's] most intimate friends, and she presumably his pupil, for she played his works (with great physical strength) utterly in his spirit. ${ }^{173}$

Ertmann was not only one of Beethoven's patrons and students but also a special friend. When Ertmann's child died, Beethoven supposedly comforted her by playing the fortepiano during a period of her grief. The first and third movements of Opus 101 have been described as melodies full of lyricism and longing, respectively. Is it possible that Beethoven played those melodies for

172 Schindler, 210.

173 Carl Czerny, On the Proper Performance of all Beethoven's Works for Piano, edited and with a commentary by Paul Badura-Skoda (Wien: Universal Edition, 1970), 8. 
Ertmann to comfort her sense of loss? Possibly, but there is no confirmed documentation. Beethoven's intention for dedication of Opus 101 to Ertmann was two-fold. Beethoven was asking for her forgiveness concerning a misunderstanding between them and offered an engraved copy of the sonata as "proof of my devotion both to your artistic aspirations and to your person." 174

174 Anderson, vol. II, 671, L. 764. 
Chapter 6

Beethoven's Tempo Indications in Opus 101

An innovative change that appeared during the time of the late sonatas was Beethoven's two-fold usage of the German language. First, he insisted on finding a German term for "fortepiano"; second, he indicated tempo markings in German, coupled with the traditional Italian in the Sonata, Opus 101 (and portions of Opus 109). In revoking his Napoleonic fervor and nurturing his German nationalism, Beethoven felt compelled to change the instrument's Italian name, pianoforte, to German, Hammerklavier-attributing honor to the German nation. Beethoven assumed that the fortepiano was a German invention. Thayer remarks on Beethoven's passionate insistence to convert to German: "With characteristic impetuosity, Beethoven decided to begin the reform at once, although it seems to have involved the reengraving of the title page of the new Sonata [Opus 101]." 175 In a letter to Steiner, Beethoven requested the change from pianoforte to Hammerklavier for his fortepiano sonatas:

After a personal examination of the case and after hearing the opinion of our council we are resolved and hereby resolve that from henceforth on all our works, on which the title is German, instead of pianoforte Hammerklavier shall be used. Hence our most excellent L[ieutenan]t G[enera]l and his Adjutant and also all others whom it may concern, are to comply with these orders immediately and see that they are carried out.

Instead of Pianoforte

Hammerklavier-

This is to be clearly understood once and for allissued etc., etc., 1973), 668 .

175 Elliot Forbes, ed., Thayer's Life of Beethooen (Princeton: Princeton University Press, 
by the G[eneralissim]o on January 23, 1817176

Unfortunately, Beethoven's request for "Hammerklavier" did not survive for long in his keyboard literature. As a result, the word Hammerklavier only appears in Opuses 101, 106, 109 and , surprisingly, not in Opuses 110 and 111. Only Opus 106 has become known as the "Hammerklavier" sonata.

Beethoven's practice of writing bilingual markings in his late sonatas was carried through into the Romantic period. In particular, Beethoven directly influenced Schumann and Wagner to utilize the German language for their musical markings of tempos and expression. Wagner genuinely admired Beethoven's devout loyalty to German nationalism. In his philosophical tribute to Beethoven, Wagner proclaims that Beethoven "spoke in the purest language to all men, the German spirit has through him redeemed the spirit of humanity from deep ignominy." 177 Wagner firmly believed that the indelible mark of Beethoven's German spirit in his music actually rescued music from being "degraded to a merely diverting art, to the height of its sublime calling, he has led us to understand the nature of that art."178

In his fervent attempt to define individual tempos, Beethoven began to indicate more detailed tempo descriptions in the headings for each of the sonata's movements. With regard to Beethoven's tempo markings in German and Italian, Rosenblum comments that "for some of the late works Beethoven

176 Emily Anderson, ed. and trans., The Letters of Beethoven, vol. II (London: MacMillan and Co. Ltd., 1961), 654, L. 737.

177 Richard Wagner, Beethoven, translated by E. Dannreuther (London: William Reeves, 1870), 41.

178 Wagner, 41. 
tried double headings, the descriptive German for 'the spirit of the composition' and the Italian tempo indication for the 'body' as he had written to Mosel."179 In Opus 101, Beethoven indicated all of the tempo markings of the movements in German, followed by the Italian. Beethoven's German terminology is much more descriptive of his tempo and expression intentions than the accompanying Italian markings.

The first movement is marked Etwas lebhaft, und mit der innigsten Empfindung, meaning "somewhat lively, and with the most heartfelt expression." 180 The Italian tempo marking is only Allegretto, ma non troppo. William Behrend's analysis of the tempo of the first movement suggests that Beethoven "gives himself up to his emotional mood, and sings a beautiful, gently mournful song, which despite the 'Allegretto' heading, affects the mind mostly like an undulation 'Andante."'181 Performers of this sonata would most likely agree with Behrend's assessment of Beethoven's tempo indication. The combination of the lyrical melody and the lilting ${ }_{8}^{6}$ meter can easily be robbed of its expressive nature if the first movement is too quickly executed.

Czerny most likely studied Opus 101 with Beethoven "or at least played under Beethoven's eye."182 Czerny encourages the performer to strive for

179 Sandra Rosenblum, Performance Practices in Classical Piano Music: Their Principles and Applications (Bloomington: Indiana University Press, 1988), 322. Hereafter: Rosenblum, Performance Practice.

180 Eric Blom, Beethoven's Pianoforte Sonatas Discussed (New York: E. P. Dutton and Co. Inc., 1938; reprint, New York: Da Capo Press, 1968), 195.

181 William Behrend, Ludwig van Beethoven's Pianoforte Sonatas, translated by Ingeborg Lund (London: Dent and Sons Ltd., 1927; reprint, New York: AMS Press, 1978), 159.

182 William S. Newman, Performance Practices in Beethoven's Piano Sonatas: An Introduction 
naturalness in playing. It is fascinating to discover the discrepancies in metronome markings concerning the appropriate Allegretto, ma non troppo tempo. In his Proper Performance edition of Beethoven's Opus 101, Czerny's performance practice recommendations are as follows:

The importance of this composition, which renders all outward embellishment superfluous, is best displayed by a very soft and sustained delivery, but rich in tone, and by a tranquil performance based on the total effect. It must not be played draggingly [sic], nor be disfigured by a fluctuating time. ${ }^{183}$

According to Badura-Skoda, Czerny was opposed to Ertmann's performance of the first movement because "for all its poetry, her playing is supposed to have been rather unsteady in tempo." 184 Czerny warns the performer not to succumb to the bewitching seduction of the tempo rubato when it is not indicated in the music: "the second by-path is, that we have almost entirely forgotten the strict keeping of time, as the tempo rubato (that is, the arbitrary retardation or quickening of the degree of movement) is now often employed even to caricature." 185

An example of Beethoven's indication of tempo flexibility appears in the principal theme of the first movement in measures 5,6 and 7. Newman proposes that flexibility of the tempo

(New York: W. W. Norton and Co., 1971), 29.

183 Carl Czerny, On the Proper Performance of all Beethoven's Works for Piano, edited and with a commentary by Paul Badura-Skoda (Wien: Universal Edition, 1970), 53. Hereafter: Czerny, Proper Performance.

184 Czerny, Proper Performance, 5.

185 Carl Czerny, Complete Theoretical and Practical Pianoforte School, Opus 500 , vol. III (London: Cocks and Company, 1839), 29. Hereafter: Czerny, Pianoforte School. 
reflects the prevailing rhythmic character ... [and] responds to changes in the harmonic rhythm, texture, articulation, ornamentation, and rhythmic progress. Moreover, it also manifests itself predominantly by stretching rather than compressing the ongoing rhythm (a point seldom mentioned). 186

The fermata falls on the agogic beat of the deceptive cadence in measure 6; the fermata seems to suspend the lilt of the ${ }_{8}^{6}$ meter and flow of the tempo.

According to Newman, Beethoven used the agogics to indicate

the more modern sense of local rubato or an actual flexibility of pulses... the conclusion here is that he did favor such agogic inflection, especially a lingering on the most expressive tones, in his later works, but also favored Classic restraint. 187

The preceding poco ritardando marking (m. 5) and the a tempo marking (m. 7), combined with the placement of the fermata (m. 6), clearly illustrates Beethoven's conscientious application of tempo-modifying devices to create a regulated flexibility of tempo-unlike the more ambiguous technique of playing with rubato.(Example 18).

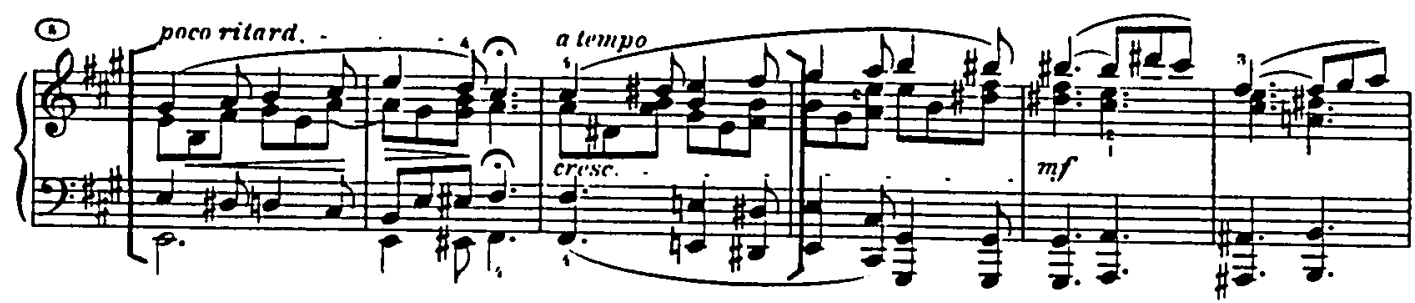

Example 18: Allegretto, ma non troppo, mm. 5-7.

In the first movement, Beethoven marked a fermata on the downbeat of

186 William S. Newman, Beethooen on Beethooen: Playing His Music His Way (New York: W. W. Norton and Co., 1988), 110. Hereafter: Newman, Beethooen on Beethooen.

187 Newman, Beethooen on Beethooen, 253-4. 
measure 52; the fermata immediately restricts the powerful thrust of the development's climax two measures earlier. The disruptive suspension of the tempo on the fermata suggests that maybe the previous developmental climax was just illusion and not reality. The extended five-measure ritardando at the close of the first movement produces an unwinding effect (where the hands move outwards in contrary motion). Czerny's suggestion for the performance of the extended ritardando is as follows:

It is particularly in ritardandos of considerable length, that there is wanted peculiarly well cultivated feelings, and much experience, in order to know how far we can venture to extend it without becoming tedious to the hearer. 188

Beethoven's use of an extended ritardando appears again at the end of the coda in the fourth movement, but will be followed by more considerably dramatic material.

In the second movement Beethoven substitutes the Classical slow movement with a new idea-a Vivace alla Marcia. This is in binary form (with a trio in the sub-dominant) of the traditional minuet, but the meter is ${ }_{4}^{4}$. For the tempo of the second movement, Beethoven indicated Lebhaft. Marschmässig, meaning to be played lively and in marching fashion. The Italian tempo marking is Vivace alla Marcia. Behrend interprets Beethoven's choice of the term "alla marcia" as a performance practice consideration for absolute precision in playing. ${ }^{189}$ When performing the second movement, Czerny suggests a "very lively, vehement and energetic" spirit with "the Trio, on the contrary, extremely

188 Czerny, Pianoforte School, 33.

189 Behrend, 160. 
soft, and also rather more tranquil." 190

The soft and slow third movement is a dramatic contrast from the military spirit and lively tempo of the second movement. Czerny's description of the third movement is "very legato and with intense feeling; always with the shifting pedal [una corda], and often also with the damper pedal."191 Beethoven indicated Langsam und sehnsuchtvoll for the tempo of the third movement, meaning to be played slowly and full of longing or yearning. The Italian tempo marking is Adagio, ma non troppo, con affetto, meaning not too slowly and with sensitivity. It is noteworthy here to recognize that Beethoven's German marking indicates a sense of "yearning" where as the Italian marking only indicates a sense of "sensitivity."

Besides the tempo and mood change from the second to the third movement, the third movement also functions as a prelude to the fourth movement. The third movement is connected to the fourth movement by three linking sections: a cadenza (m. 20), the restatement of the principal theme of the first movement (mm. 21-27), and an E major dominant preparation (m. 28) marked Presto, preceding the fourth movement. In one sense, the character and tempo of the third movement represent a twenty-measure prelude to the fourth movement. At the end of the third movement, Beethoven indicated a non presto cadenza at measure 20; Tovey describes it as a "themeless and timeless cadenza ris[ing] over the dominant chord." 192 The cadenza flows directly into

190 Czerny, Proper Performance, 53.

191 Czerny, Proper Performance, 53.

192 Donald Tovey, A Companion to Beethoven's Pianoforte Sonatas: Bar to Bar Analysis 
Beethoven's recall of the principal theme of the first movement.

Beethoven marked the seven-measure restatement of the principal theme of the first movement, Zeitmass des ersten Stückes, meaning the tempo of the first movement. The Italian tempo marking, Tempo del primo pezzo: tutto il Cembalo, ma piano, has approximately the same meaning as the German. Within the reiteration of the principal theme of the first movement, Beethoven intersperses pauses (indicated by fermatas and rests) which ultimately upset the temporal flow of the theme. In this demonstration of Beethoven's tempo modification, Drake contends that Beethoven's rhetorical pauses are "free-tempo devices."193 The first fermata in measure 22 separates the original question and answer phrase of the theme. The second fermata in measure 25 severs the previous answer phrase from the restatement of a fragment of the answer phrase. In measure 26, Beethoven repeats the thematic fragment up a step and marks a stringendo; Drake considers this to be another example of Beethoven's free-tempo devices.194 In chapter three of his section entitled "On Occasional Changes in the Time or Degree of Movement" in the Complete Theoretical and Practical Pianoforte School, Opus 500, Czerny comments on the use of accelerando and stringendo:

In such passages the hurrying onward and acceleration of the time is natural, and in its proper place.... But when these emotions are correctly perceived and caught up by the Player, still the principal affair lies in this, that in the application of them, nothing shall be overdone, and all these means of expression shall not be introduced to satiety; as otherwise the

(London: Associated Board of Royal Schools of Music, 1931), 221.

193 Kenneth Drake, "A Study of the Beethoven Piano Sonatas in the Light of Evidence Provided by Beethoven's Pupils" (Ph.D. diss., University of Mlinois, 1970), 105. Hereafter: Drake, diss..

194 Drake, diss., 108. 
most beautiful passages will appear distorted and unintelligible. 195 In measure 28, Beethoven marked fermatas on each of the three trills; the trills seem to hang in suspended animation following the rapidly descending flourish of the E major dominant, marked Presto (Example 19). The lingering, anticipatory nature of the trills (with fermatas) appears to neutralize the impact of Presto tempo. It is interesting to note that Beethoven utilizes the tempomodifying devices on all of the E major dominant preparations (mm. 20, 28 and the $\mathrm{E}$ trill in $\mathrm{m} .28$ ), which progress toward the tonic arrival of the fourth movement.

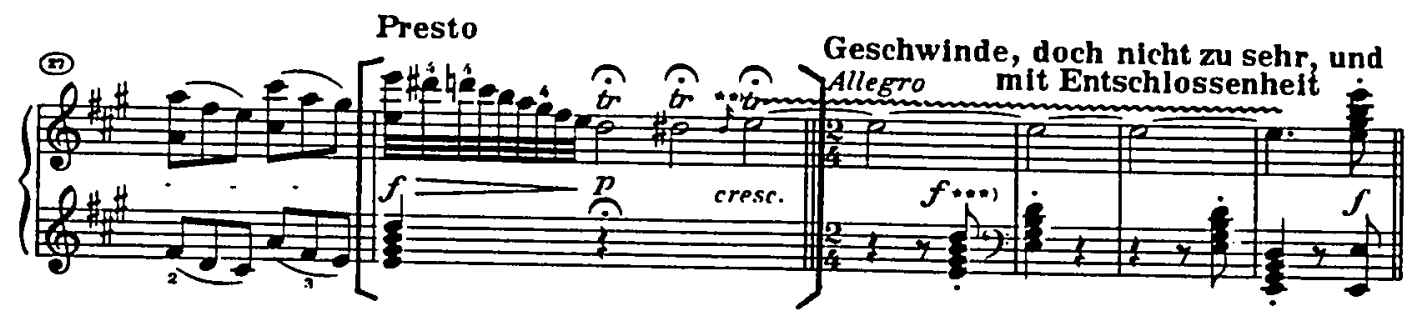

Example 19: Presto, m. 28.

The fermata placed on the full-voiced, E major chord in measure 20 (unaccompanied by a preceding ritardando) functions as a two-fold, tempomodifying device: it diffuses the rhythmic and temporal movement of the third movement and suspends the activity of rhythm and time to clear the musical palette for the freer exercise of the non presto cadenza. In measure 26 , the intensity of the stringendo ignites the fuse which explodes on the E dominantseventh chord on the downbeat of the Presto. The third trill in measure 28, is highlighted by its peak of the previous chromatic ascent. Beethoven's addition of an appoggiatura to the third trill, as well as the lengthy duration of the trill,

195 Czerny, Pianoforte School, 32. 
creates an almost timeless extension of the ringing $\mathrm{E}$ dominant to fanfare the upcoming tonic in the fourth movement.

The fourth movement begins with a feeling of youthful brilliance and rhythmic vitality. Beethoven's German tempo indication is marked Geschwinde, doch nicht zu sehr, und mit Entschlossenheit, meaning to play lively, however-not too much, and with determination. The Italian tempo marking is Allegro. In his Proper Performance edition of Beethoven's sonatas, Czerny succinctly states that "the Allegro [is] quick and resolute."196

In the first theme of the fourth movement, Beethoven indicates two successive fermatas in measure 40 , which suddenly halt the temporal as well as contrapuntal, flow of motion. Beethoven's placement of the successive fermatas is not unlike the placement of the fermata in the principal theme of the first movement. In both movements, Beethoven places the fermatas at the end of the third phrase, located six to eight measures into the theme. Beethoven's reiteration of the tempo-modifying device of the fermatas-in approximately the same location of the two movement's opening themes-suggests a unifying characteristic within the whole of the sonata. It seems ironic that Beethoven would facilitate a modification of tempo to unify a work, since he almost always advocated playing in strict time-or in his words "the right time."

Three measures before the entrance of the fugal development, Beethoven indicated a poco ritardando in measure 120 , followed by two chords marked with fermatas in measure 121 (the second chord to be played rolled). With the exception of the poco ritardando in measure 120, both sets of successive fermatas

196 Czerny, Proper Performance, 63. 
in the exposition appear at the end of an eight-measure phrase, and are followed by the loud entrance of the subject in octaves. Beethoven seemed to continue his use of repeating the tempo-modifying device of the fermata to demarcate the structural unification of the sonata.

Beethoven indicated no tempo flexibility or modifications in the fugal development section. In the recapitulation (m. 239) Beethoven indicated the same two fermatas on the chords as in the exposition. A single fermata on a chord is marked in measure 313, eleven measure after the beginning of the coda. To the listener, the fermata suggests that Beethoven might restate the fugal development; instead, Beethoven continues on with the coda.

Seven measures before the end of the coda, Beethoven indicates an extended ritardando from measures 355-358. The modification of the tempo suggests the motion of a clock winding down. Beethoven marked Tempo I for the last three measures of the coda to finalize the sonata with a feeling of hopeful resolution.

Scholars and performers are indebted to Czerny for his diligent and thorough recollections of Beethoven's teachings and performance practices, as Badura-Skoda comments:

It is one of music history's fortunate coincidences that Beethoven's pupil Carl Czerny was one of the greatest piano pedagogues. At a time when Beethoven's works were hardly cultivated any more, fashion having taken other directions, Czerny did much to ensure that the Beethoven tradition did not die out. He taught his pupils (among them the young Franz Liszt) to play Beethoven's works; he arranged concerts devoted exclusively to those works; and he made excellent two and four-hand piano transcriptions, some of them under Beethoven's supervision, of orchestral 
and chamber works, which were widely circulated in that form. ${ }^{197}$ Czerny's three documents relating his personal and musical relationship with Beethoven include: his memoirs, an edition of Beethoven's sonatas (published by Simrock around 1850) as well as other fortepiano pieces (with metronome markings and fingerings), and chapters II and III from volume IV of the Complete Theoretical and Practical Piano Forte School, Opus 500. Of particular significance regarding the study of Beethoven's sonatas, is chapter II, entitled On the Proper Performance of all Beethoven's Works for the Piano Solo. Only Czerny's metronome markings exist today in the Schenker (Universal Edition, Vienna) and Henle Edition, which superseded his Simrock edition. ${ }^{198}$

Even before beginning his lessons with Beethoven, Czerny was a great admirer of Beethoven's works. In his memoirs, Czerny recounts:

His [Krumpholz's] enthusiasm soon infected me and before long, I, in turn was a Beethoven worshipped like himself, learned all that Beethoven had written by heart, and, considering my years [about ten years old], played it with skill and enthusiasm. 199

With Krumpholz's recommendation and introduction, Czerny auditioned for Beethoven in 1801 and played Mozart's Concerto in C major, KV 503, followed by Beethoven's Pathètique Sonata, Opus 13. Beethoven recognized Czerny's musical aptitude and agreed to give him lessons:

The boy has talent; I will teach him myself, and I accept him as a pupil.

197 Czerny, Proper Performance, 1.

198 Czerny, Proper Performance, 1.

199 Oscar G. Sonneck, ed., Beethooen: Impressions by his Contemporaries (New York: Dover Publications, Inc., 1967), 25. 
Send him to me several times a week, but first of all see that he gets Emanuel Bach's treatise on the True Art of Keyboard Playing, which he must bring with him next time.200

During Czerny's first lessons, Beethoven focused primarily on the playing of scales in all keys, correct finger and hand positions, and particular emphasis on the use of the thumb. Beyond the technical aspects of playing, Beethoven concentrated on the art of touch, as recounted by Czerny:

Then he [Beethoven] went through the practice pieces in Bach's treatise with me, making me particularly aware of the Legato of which he had such an unrivalled command, and which all other pianists at that time considered unfeasible at the pianoforte; choppy and smartly detached playing was still in favour then (as it had been at Mozart's time).201

Rosenblum speculates that the influence for Beethoven's legato touch may have stemmed from his earlier training as an organist. ${ }^{202}$

Czerny's first-hand experiences with Beethoven and the composer's works, as well as his extraordinary memory and honorable intentions to painstakingly documenting Beethoven's teachings, credit Czerny as a reliable source for understanding and interpreting Beethoven's works. With regard to Czerny's sense of duty toward immortalizing Beethoven's teachings, Barth ascertains that:

When we consider the extent to which he [Czerny] devoted himself to pedagogy, this should come as no surprise: clearly he felt himself entrusted with the preservation of a tradition. ${ }^{203}$

200 Czerny, Proper Performance, 5.

201 Czerny, Proper Performance, 5.

202 Rosenblum, Performance Practices, 105. 
Badura-Skoda also confirms Czerny's reliability based on the great trust and friendship between the master and his pupil. Beethoven's affirmation of Czerny's character and musical ability was documented in a letter written when Czerny was only fourteen years old:

We, the undersigned, cannot deny young Carl Czerny our testimony to the effect that he had made at the pianoforte extraordinary progress far in advance of his 14 years; and that in consideration of this and of his admirable musical memory he deserves all possible support, all the more since his parents have used their resources for the training of their promising son.

Vienna, December 7, 1805. Ludwig van Beethoven.204 Two more examples of Beethoven's faith in Czerny are revealed in Beethoven's confidence to allow Czerny to premiere his Piano Concerto No. 5 in E-flat major, Opus 73, in Vienna; and entrusting Czerny with the duty of teaching KarlBeethoven's beloved nephew-to play the fortepiano.

Although Czerny won Beethoven's admiration and respect as a musician, it is a well-documented fact that Schindler disagreed with Czerny's interpretative analyses of Beethoven's works. Schindler proclaimed Czerny to be a distasteful virtuoso; and that he was more slanderously representative of the style of playing popularized by Hummel and his followers. To understand the opposition between these two close associates of Beethoven, it is important to remember that

Schindler's close association with Beethoven dates from the later years of the master's life, while Czerny's direct contact with Beethoven as pupil to

203 George Barth, "The Fortepianist as Orator: Beethoven and the Transformation of the Declamatory Style" (Ph.D. diss., Cornell University, 1988), 45.

204 Czerny, Proper Performance, 2. 
teacher had taken place some twenty years before. ${ }^{205}$

It was Beethoven's philosophy that tempo was an essential element of the character of his works; the "rate of movement had become a more organic part of [his] tightly integrated formal and expressive structure." 206 With the invention of the metronome around 1816 by Johann Nepomuk Mälzel, Beethoven was initially enthusiastic about the possibility of establishing guidelines to determine more precise tempos for his works. Beethoven felt it was necessary to standardize the meaning of his tempos with the aid of the metronome. Toward the end of the Classical period, "tempo was becoming less tied to traditional criteria-a combination of meter, tempo categories and note values-and, at the same time, increasingly individualized." 207 Due to mechanical difficulties with the metronome (resulting in inconsistencies of timing), Beethoven lost his faith in the usefulness of the metronome. According to Schindler, Beethoven is quoted as exclaiming, "No more metronome! Anyone who can feel the music right does not need it, and for anyone who can't, nothing is of any use."208

Of all his fortepiano sonatas, Beethoven only indicated metronome markings for the "Hammerklavier" sonata, Opus 106. According to Rosenblum, the metronome markings "have drawn skepticism and neglect on account of their speed."209 The significance of "authentic" Beethoven metronome markings

205 Czerny, Proper Performance, 3

206 Rosenblum, Performance Practices, 322.

207 Sandra Rosenblum, "Two Sets of Unexplored Metronome Marks for Beethoven's Piano Sonatas," Early Music 16 (1988): 59. Hereafter: Rosenblum, "Two sets."

208 Anton Felix Schindler, Beethoven As I Knew Him, edited by Donald MacArdle and trans. by Constance Jolly (New York: W. W. Norton and Co., 1972), 425-6. 
has almost become an obsessive pre-occupation with twentieth-century musicians. Because the ears of present day performer's have been distorted with the nineteenth-century definition of "the right tempo," Willy Hess concludes that it is

only in our own time, which may be characterized by excessive intellectualism, has there been a break with this tradition [to feel the right time], and it is also only in our time that strict adherence to Beethoven's metronome markings has been demanded. 210

Czerny was the first to document Beethoven's metronome markings in an edition of fortepiano sonatas published by Haslinger. In the end, Czerny produced probably four sets of metronome markings for Beethoven's sonatas: two sets for Haslinger's editions (the second set's author still unknown, but probably attributed to Czerny), one set for his own edition Proper Performance and one set for the Simrock edition. In Example 20, the metronome markings of the various editions are reproduced for purposes of comparison. Note the relative consistency in metronome markings of the first (with the possible exception of the Cramer), third and fourth movements. The second movement appears to have the most extreme range of metronome markings between the six editions.

209 Rosenblum, "Two Sets," 59.

210 Willy Hess, "The Right Tempo: Beethoven and the Metronome," The Beethooen Newsletter 3 (1988): 17. 


\begin{tabular}{|c|c|c|c|c|}
\hline Opus 101 & Allegretto & March & Adagio & Allegro \\
\hline & $\begin{array}{c}6 \\
8\end{array}$ & $\mathbf{C}$ & $\begin{array}{c}2 \\
4\end{array}$ & $\begin{array}{r}2 \\
4\end{array}$ \\
\hline $\begin{array}{c}\text { Haslinger: First State } \\
\text { (1828-c. 1833 or 1837) }\end{array}$ & 80 & 168 & 54 & 132 \\
\hline $\begin{array}{c}\text { Haslinger: Second State } \\
\text { (183?-1842) }\end{array}$ & 80 & 144 & 58 & 120 \\
\hline $\begin{array}{c}\text { Czerny: Proper Performance } \\
\text { (1846) }\end{array}$ & 72 & 152 & 60 & 132 \\
\hline $\begin{array}{c}\text { Czerny: Simrock } \\
\text { (1856-68) }\end{array}$ & 72 & 132 & 60 & 132 \\
\hline $\begin{array}{c}\text { Moscheles: Cramer } \\
\text { (date unknown) }\end{array}$ & 66 & 132 & 60 & 132 \\
\hline $\begin{array}{c}\text { Moscheles: Hallberger } \\
\text { (c. 1858)211 }\end{array}$ & 72 & 132 & 60 & 132 \\
\hline
\end{tabular}

Example 20: Metronome Markings for Opus 101.

Differences between Schindler and Czerny's interpretation of Beethoven's music included the necessity and accuracy of metronome marking. Czerny was a firm advocate of Beethoven's teachings to maintain a strict tempo in playing, unless the composer indicated otherwise. Based on Czerny's intimate musical relationship with Beethoven and his fortepianos works, Czerny's metronome markings are usually accepted as a reliable guide to help to clarify Beethoven's tempo indications. Although Schindler detested the mechanized beating of the metronome, he was emphatically aware of Beethoven's attention to tempo, as he stated: "When a work by Beethoven had been performed, his [Beethoven's] first question was always, 'How were the tempi?' Every other consideration seemed to be of secondary importance to him."212 Rosenblum's assessment of

\footnotetext{
211 Rosenblum, "Two Sets," 360.

212 Schindler, 423, $\ddagger$ footnote.
} 
Schindler's understanding regarding Beethoven's definition of tempo is that:

Schindler, who had much less sense for proper proportion, at least had the intelligence to realize that the key to understanding tempo in Beethoven lay not in metronomic truing-up, but in a deep understanding of gesture and the principles of rhetoric. ${ }^{213}$

Schindler criticized Czerny for being too rigid in his interpretation and use of the metronome markings. Schindler proclaimed that

the greatest importance to bringing everything out clearly, to seeing the phrases through, to breathing pauses, and to emphasis or lack of emphasis; these [were] all points with which Czerny [dealt] in too cursory a way. 214

Nottebohm assesses Czerny's recollection of Beethoven's tempos:

Although not of authentic validity, still these indications can lay claim to a certain confidence, especially for those works of which we know that Czerny either heard them played by Beethoven or studied [them] under his instruction .... Anyone who knew Czerny personally, who had the opportunity to observe his nature, which was above all directed toward the practical, will believe him capable of impressing firmly on his memory a tempo that he had heard, and will have noticed the certainty that he had in such outwardly tangible musical matters. 215

Schindler and Czerny were both personally and musically dedicated to the pursuit of preserving Beethoven's tempo indications. Barth suggests that "the stands of both Czerny and Schindler must be understood as representative .... In essence they need not be seen as contradictory, though each must be faulted

213 Rosenblum, Performance Practices, 104.

214 Czerny, Proper Performance, 3.

215 Rosenblum, Pefformance Practices, 329, quote from Gustav Nottebohm, Beethoveniana, (Leipzig: C. F. Peters, 1872), 136. 
for certain limitations." 216

The discrepancy in determining the accuracy of Czerny's memory regarding Beethoven's metronome markings, is revealed in the contradictions found between Czerny's three (or possibly four) sets of metronome markings for Beethoven's fortepiano sonatas. Even the metronome markings of the sonatas which Czerny claims to have studied under the watchful eye of Beethovenincluding Opuses 13; 14, Nos. 1 and 2; 26; 27, No. 2; 31, Nos. 2 and 3; 53; 57; 81a, and 101-fluctuate in metronomizations. Of the first sets of metronome markings published by Haslinger, Rosenblum speculates that the first

set of metronome marks apparently prepared by Czerny, probably around 1828, [were] published during the following years until sometime around 1833 or 1837; and the second set of indications, of unknown authorship, whose preparation and publication probably took place mainly from the mid-to late 1830s until 1842.217

Barth notes that in Czerny's edition of Beethoven's sonatas in On the Proper Performance of all Beethoven's works for the piano the metronome markings are the slowest of all the sets. ${ }^{218}$ In conjunction with Rosenblum's investigations of Czerny's metronome markings, Barth concludes

Yet by the time Czerny had completed his metronome indications for the Simrock edition eleven years later, he 'remembered' many tempos as having been considerably faster. Eighty percent of his markings differ from those in Proper Performance, one quarter of those significantly, and of the changed indications 82.5 percent are toward faster tempos, making

216 Barth, 103.

217 Rosenblum, "Two Sets," 61.

218 Barth, 50. 
Simrock faster than all but his earliest set for Haslinger. ${ }^{219}$

In his editions of Beethoven's sonatas, Moscheles' metronome markings were first published by Cramer (England) in 1838-1839 and then by Hallberger [Stuttgart] in 1858; dynamic markings, phrasing and pedaling were determined by Moscheles' recollection of performances by Beethoven and Ertmann. ${ }^{220}$ As stated previously, Moscheles was a devoted student of Beethoven. He was also significantly instrumental in publishing many of Beethoven's works. With respect to Moscheles' sincere but non-academic approach to his edition of Beethoven's sonatas, Alan Tyson claims that "there is no evidence that he [Moscheles] used or wanted to use autographs, or was at pains to discover the original editions." 221

In general, Moscheles' metronome markings in Hallberger edition are quite similar to Czerny's Simrock edition. Moscheles' attitude toward the metronome was more relaxed than Czerny's:

the musical world knows that the time by a metronome is but a slight guide for performers and conductors. Its object is to show the general time of a movement, particularly at its commencement; but it is not to be followed strictly throughout.222

Rosenblum's explanation of the metronome's function relates the closest to

219 Barth, 49, quote from Rosenblum, Performance Practices, 332, 333, 336 and chart 3.

220 Kenneth Drake, The Sonatas of Beethoven: As He Played and Taught Them (Cincinnati: MTNA, 1972: reprint, Bloomington: Indiana University Press, 1981), 23. (1964): 139.

221 Alan Tyson, "Moscheles and his 'Complete Edition' of Beethoven," Music Review 25

222 Ignace Moscheles, ed., The Life of Beethooen, vol. II (London: Henry Colbum, Publisher, 1841), 111n*. 
Beethoven's initial aspirations of maintaining a regulated tempo. She states:

Indeed, a metronome mark can only be a guide to a tempo span that preserves the character of the music and prevents the performer from straying too far from the composer's intentions. 223

Within the parameters of a given metronome marking there is room to breathe into the music with the natural tempo of inhaling and exhaling without disrupting the composer's tempo guidelines. Rosenblum concludes that:

Our habitual late-19th-century tempo sense may separate us from the tempos of the Classical era unless we make historically-informed choices. The goal is to find solutions that relate to the current information about a composer's tempo ideals, that satisfy the performer's musical instincts, and that move the audience."224

223 Rosenblum, "Two Sets," 60.

224 Rosenblum, "Two Sets," 70. 


\section{Chapter 7}

\section{Analysis}

In Opus 101 Beethoven preserved the traditional multi-movement form of the Classical sonata. The movements are in contrasting tempos but more diverse in mood and character than his previous sonatas. Beethoven's modification is one of concentration and economy of musical material. Charles Rosen remarks that "the works of Beethoven's last period, indeed, often represent a contraction or even a distillation of classical procedure rather than an expansion." 225 The individual movements of Opus 101 are relatively short in length, but are highly concentrated in content and expression. The unifying elements of counterpoint and fantasy-sonata characteristics within the movements interconnect the sonata as a whole. Malcolm Bilson's five categories of fantasy-sonata elements may be used to judge the validity of Opus 101 as a fantasy-sonata:

\begin{tabular}{|c|c|}
\hline Category A & $\begin{array}{l}\text { The rearranging of the external form of the } \\
\text { sonatas so as to evince an 'aesthetic program.' }\end{array}$ \\
\hline Category B & $\begin{array}{l}\text { The incorporation of rhapsodic characteristics } \\
\text { into the main thematic elements. }\end{array}$ \\
\hline Category C & Cadenzas or cadenza-like passages. \\
\hline Category D & $\begin{array}{l}\text { Use of improvisational or rhapsodic (mainly } \\
\text { unthematic) material at decisive or climactic } \\
\text { places in the construction of the movements. }\end{array}$ \\
\hline Category E & Simple extensions or ornamentations. ${ }^{226}$ \\
\hline
\end{tabular}

225 Charles Rosen, Sonata Forms, rev. ed. (New York: W. W. Norton, 1988), 356. Hereafter: Rosen, Sonata Forms.

226 Malcolm Bilson, "The Emergence of the Fantasy-Style in the Beethoven Piano Sonatas of the Early and Middle Periods," (Ph.D. diss., University of Illinois, 1968), 15. 
For the purpose of this study Category E will not be taken into consideration; Bilson contends that Category $\mathrm{E}$ had evolved into Category $\mathrm{C}$ by the time of Beethoven's late sonatas.227 A brief definition of the Bilson's first four categories is warranted to clarify the fantasy-sonata characteristics. Category A refers to

not merely a change in the number and/or order of movements, but comprises as well an intention on the part of the composer as to the specific placement of the psychological weight in the structure of the sonata as a whole. 228

Category $B$ refers to

main thematic elements demonstrating rhapsodic procedure ... [that] will include typically themes which are somehow incomplete, which thereby create an unresolved tension of particular expressive force, and propel the composition forward into its continuation. 229

Category $C$ is self-explanatory. Category $D$, in addition to its self-explanatory heading, "includes what may be termed digressions. Such digressions may show a marked climatic tendency, almost overshadowing the main material from which they represent the actual digression."230

Besides the fantasy-sonata, another source of inspiration for Beethoven's late works stemmed from his interest in simple melodies. The influence of the folk song on Beethoven's music was possibly generated by his instrumental arrangements of the Scottish folk songs for George Thomson. Through the
227 Bilson, 26.
228 Bilson, 17.
229 Bilson, 18.
230 Bilson, 23. 
process of arranging the folk songs, Beethoven discovered "how unconstrainedly irregular melodies can be treated with the help of harmony." 231 During his late period, Beethoven seemed to be searching for a more direct form of expressive communication in his writing. According to Rosen:

above all Beethoven stood almost alone in his time: as the underlying material in the works of all his contemporaries grew more complex and more chromatic, the basic motifs of Beethoven's music became simpler and more diatonic, very often the fundamental elements of the tonal language itself. ${ }^{232}$

The simplicity of the folk song character appealed to Beethoven; he did not hesitate to incorporate folk song ideas into his later works. Kerman states that "in the best early Romantic spirit, Beethoven was seeking a new basic level of human contact through basic song, as though without sophistication or artifice." 233

Although Beethoven composed Opus 101 in 1816 at the beginning of his late period, the lyrical nature of the sonata suggests more Romantic style characteristics of the 1830s. There are melodic suggestions of the forthcoming works of Mendelssohn and Schumann in Beethoven's lyrical writing. In the first movement of Opus 101, Behrend concludes that:

It is not accidental, then, that Mendelssohn's melodies and Schumann's form of expression are foretold in this movement-in the hovering

231 Friedrich Kerst and Henry Edward Krehbiel, eds., Beethooen: The Man and the Artist, as Revealed in His Own Words (New York: Dover Publications, Inc., 1964), 25.

232 Rosen, Sonata Forms, 356.

233 Joseph Kerman and Alan Tyson, The New Grove: Beethoven (New York: W. W. Norton, 1986), 122. Hereafter: Kerman-Tyson. 
syncopes so full of forebodings; in the close which seems to fade away into ethereal regions; though the Master had great 'control' of the emotional mood than any of his successors. 234

Inbetween the third and fourth movements of Opus 101, Beethoven recalled the principal theme of the first movement. Beethoven's idea of restating themes in other movements as a unifying factor implies more Romantic suggestions of nostalgic recollections; for example, Schumann recalled of a portion of Papillon, Opus 2, at the end of Carnival, Opus 9.

Beethoven was continually searching for "more fluid solutions to the problem of the form of the total sonata, in terms of weight, balance and mood of the various movements."235 At the beginning of his late period, Beethoven

no longer attempted to impart a symphonic breadth to his sonata style, but returned to the smaller dimensions of the Sonatas, op. 90 and op. 101, which were now infused alternately with a variety of rigorous polyphonic textures and an etherealized improvisatory tone. 236

Beethoven reached beyond the Classical architectural parameters and utilized counterpoint as a medium of expression. The characteristics of Beethoven's late style which include "syncopations, anticipations, individual use of the trill and extremes of pitch contrasted or combined" are all evident in his Opus 101 sonata. ${ }^{237}$ A distinctive feature in Beethoven's later works is his uncanny ability to combine great expressiveness with absolute simplicity. Cooper designates

234 William Behrend, Ludwig van Beethoven's Pianoforte Sonatas, translated by Ingeborg Lund (London: Dent and Sons Ltd., 1927; reprint, New York: AMS Press, 1978), 160.

235 Kerman-Tyson, 127.

236 Maynard Solomon, Beethoven (New York: Schirmer Books, 1977), 301.

237 Martin Cooper, Beethoven: The Last Decade, 1817-1827 (London: Oxford University Press, 1970), 146. 
Beethoven's Opus 101 sonata as

the first work that belongs quite unequivocally to Beethoven's 'third period' ... . [in that] it combines . . . great freedom of design and intimacy of feeling, which may find expression in forms that are irregular or fragmentary, with strict canonic and fugal episodes in the dramatic style with which Beethoven always now invested his contrapuntal music. ${ }^{238}$

Beethoven composed the Allegretto, ma non troppo in a rather condensed sonata-allegro form; there are no repeat signs indicated in the movement. Although Beethoven supposedly described this movement as a dream, the dreamlike fantasies are interspersed with outbursts of frustration. This could explain "why this small movement is not a ternary aria, but a miniature sonata conflict." 239 This first movement is also Beethoven's shortest opening movement (102 measures) of all of his fortepiano sonatas with opus numbers. The first movement opens with a lyrically sweeping melody which hovers over the dominant key of A major. Meilers contends that the lyrical aspect of the theme "is not so much self-contained song as a yearning for songfulness." 240

The suggestion of a floating feeling is expressed in the principal theme, which implies that the music has already been in progress before the listener tuned in to the first few notes. Kerman equates the Romantic gesture of Beethoven's principal theme as possessing "an almost Schumannesque effect."241

238 Cooper, 146.

239 Wilfred Mellers,Beethoven and the Voice of God (London: Farber and Farber Ltd., 1983), 147.

240 Mellers, 147.

${ }^{241}$ Kerman-Tyson, 127. 
The principal theme appears as a tender conversation between the question phrase (mm. 1-2) and the answer phrase (mm. 2-4); the first four measures begin and end on the dominant. Mellers poetically describes the character of the individual voice parts as follows:

[The tune] floats up the scale from the third and curls down from the high $E$ to $D$ and $B$. The alto part rocks like a lullaby, the tenor falls chromatically, the bass remains static on a dominant pedal. The fusion of the tenderly arching melody with the warmly spaced harmony makes the song at once sensuous and wistful;and the next two bars sigh in declension, for having leapt an octave from the upbeat, the melody falls in the havering cross-rhythms of the fourth bar. ${ }^{242}$

Although the sonata is in A major, Beethoven projects a sense of tonal ambiguity by evading the tonic. In the second statement of the principal theme (m. 5), Beethoven avoids closure on the tonic with a deceptive cadence in measure 6 (Example 21). Rosen comments that

the tonic is established by implication with an extraordinarily poetic effect of beginning in the middle, and only a firmness that is taken for granted without being emphasized could make possible the emotion that is built on it. 243

242 Mellers, 147.

243 Charles Rosen, The Classical Style: Haydn, Mozart, Beethooen (New York: W. W. Norton and Co., 1972), 68. 


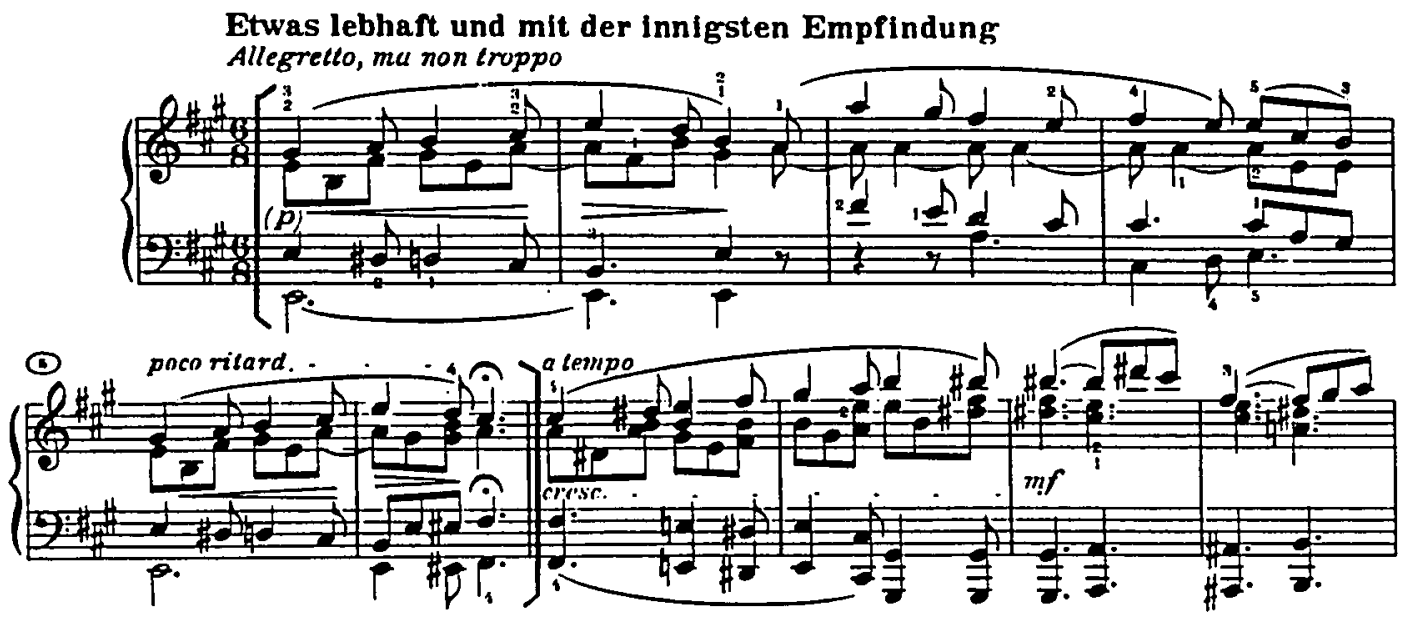

Example 21: Allegretto, ma non troppo, $\mathrm{mm} .1-6$.

The forward motion of the principal theme is thwarted by the fragmented and unresolved nature of the melodic phrases. The persistence of the bass pedal tones also inhibit the harmonic progression. According to Fritsch, the tonality of the first theme "is not so much stated as it is suggested."244 Beethoven's evasion of the tonic, displayed in the off-the-tonic opening and followed by the deceptive cadence, demonstrates the rhapsodic elements of Bilson's Category B. The anticipation of the Beethoven's arrival on the tonic is a characteristic feature of his late style. Wagner recognized Beethoven's avoidance of the tonic as a bona fide example of "endless melody." 245

In measure 7, Beethoven begins the transition with the principal thematic material in the dominant. With an anticipation of directional movement, the transition surges outward in contrary motion forging its way to a rather

\footnotetext{
244 Michael F. Fritsch, "Beethoven's Last Piano Sonatas as Fantasy Sonatas," (Ph.D. diss., Northwestern University, 1987), 45.

245 William S. Newman, The Sonata in Classical Era, 3d ed. (New York: W. W. Norton and Co., 1983), 527.
} 
inconclusive climax in measure 9; the climax peaks with a dominant to submediant harmonic progression. After the quasi-climax, the course of the transition wanders past an unsuspected A major chord (again in deceptive motion [m. 9]), drifts inward by contrary motion passing through another $\mathrm{A}$ major chord (m. 14), and finally dissolves into a deceptive cadence (mm. 15-16). The two A major chords are not substantial enough to establish the A major tonality. Four rhapsodic elements from Bilson's Category B are illustrated in the transition: a suggestion of expansion by means of recycling the first thematic material, the lack of strong points of arrival in A major, the meandering quality following the quasi-climax, and the closure on a deceptive cadence (retrospective of the first theme's deceptive cadence).

Many music scholars claim that the second theme begins in measure 16 in the dominant key; but Cooper argues that the theme "can really be perceived as a logical continuation of the first train of thought." 246 Because of the compressed format of the sonata and evasion of tonic in the first movement, it is difficult to delineate precisely the second theme. In Cooper's opinion

it is virtually impossible to label precisely a second subject. There seems equally good reason to begin this at bar 9 or 12 or 16; and this ambiguity is only a further proof of the movement's closely unified character. ${ }^{247}$

Nonetheless, for discussion here this melodic idea will be referred to as the second theme. The second theme is introduced alone by a rising motive in the bass (m. 16) and answered by the falling motive in the soprano (m. 17), which is

246 Charles Schroder, "Final Periods of Mozart, Beethoven, and Bartók" (Ph.D. diss., Graduate College of the State University of lowa, 1965), 199.

247 Cooper, 148. 
followed by free inversions of the four-note motive. Bekker comments on the prevailing dreamy quality of the

tender, gliding, quartet-like conduct of the parts, the free yet never restless harmonic flow, the prominence of light, sweet colours, [and] the absence of any marked dynamic contrasts. ${ }^{248}$

The emotional expression of these measures is one of ligthness, which is partly attributable to the minimal contour of the thematic material. Compared to the sweeping gesture of the first theme, measures 16 through 24 project even less forward motion by hesitatingly inching along with its four-note motive. Both the first theme (mm. 1-6) and the second theme (mm. 16-24) exhibit the undeniable fantasy element of elusiveness; this sensation creates the atmosphere of illusion, rather than the reality of music in time.

At the end of the second theme (m. 24), Beethoven marks a sudden dynamic outburst on a rapid arpeggiated ascent of the treble voice accompanied by a low octave in the bass voice; this rhapsodical flourish demonstrates Beethoven's characteristic late style of contrasting extreme ranges of pitch between the two hands (Example 22). In Mellers's opinion, the flourish exemplifies an "unBeethovenian lack of purposefulness [which] is part of the romantic flavour that appealed to Schumann." 249 The rhapsodical quality of the flourish in measure 24 symbolizes characteristics of the fantasy-sonata style in Bilson's Category D.

248 Paul Bekker, Beethoven, translated by M. M. Bozman (London: Dent and Sons Ltd., 1932), 131.

249 Mellers, 149. 


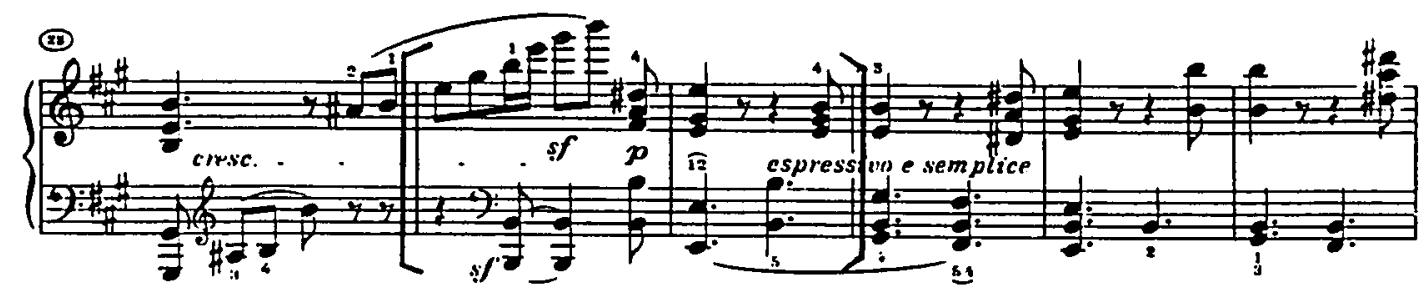

Example 22: Allegretto, ma non troppo, mm. 24-25.

An authentic cadence on the dominant (mm. 24-25) connects the second theme to the first cadence theme. Tovey specifies measures 25-32 as two "cadence themes"; the first cadence theme is a "2-bar tonic-and-dominant dialogue between bass and treble closing into self-repetition; secondly, a 4-bar phrase .. of syncopated chords [mm. 29-32]."250 The first cadence theme (mm. 25-28) seems to float along gently in replete celebration of the sonata's first authentic cadence. The gentle mood and lilting meter are disrupted in measure 29 by the displaced, accentuated beats of the syncopated chords (Example 23). The persistence of the syncopated chords impose a contrasting feeling of suspended weight and anticipatory tension compared to the lofty, evasiveness of the preceding theme.

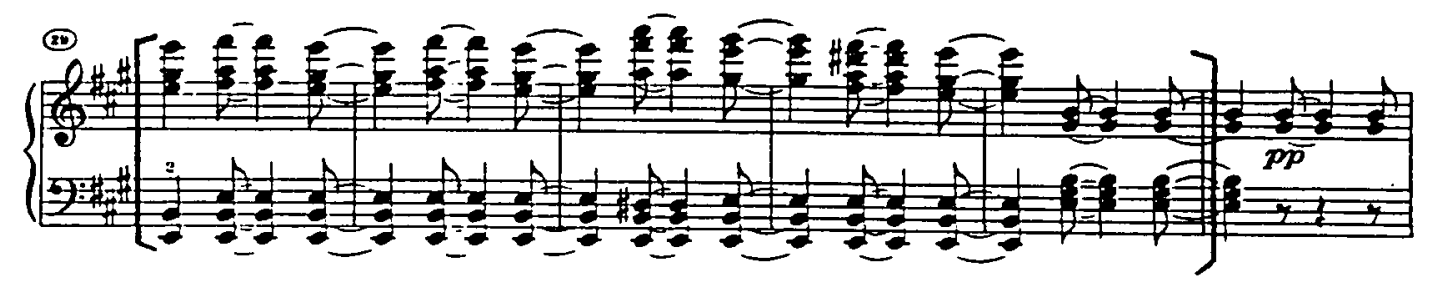

Example 23: Allegretto, ma non troppo, mm. 29-33.

250 Donald Tovey, A Companion to Beethooen's Pianoforte Sonatas: Bar to Bar Aralysis (London: Associated Board of Royal Schools of Music, 1931), 217. 
With regard to the rhythmic displacement of the second cadential theme, Fritsch contends that "the rendering of these segments in terms of the syncopation that became prominent already with a [a ${ }^{2}$, alto voice] at mm. 1-2 aids their indirect expression and furthers the organic unity of the movement." 251 The rhapsodic character of the cadential themes is an example of the fantasy elements represented in Bilson's Category D. Carr poetically describes the cadential themes as follows:

Softly persistent off-beat harmonic blocks and what might be the remembrance of a long-forgotten melodic impulse-barely moving, eloquently dumb-quickly erode any sense of the real meter, leaving as their gift an eerie sense of displacement and its companion emotion - the expectation of the unexpected. 252

In the brief development section (mm. 33-57), Beethoven begins by combining the syncopations from the second cadence theme with melodic fragments of the principal theme. With an almost obsessive intent, Beethoven permeates the development with his late style hallmark of using syncopations to alter rhythmic flow. Carr comments on the development of Beethoven's hybrid material: "to this contradictory and satisfying marriage is added violent dynamic change and, at its now fragmented climax, sforzandi on the same weak beats." 253 The question phrase of the thematic material begins in the bass on the dominant ( $\mathrm{m}$. 35) followed by its restatement (m. 38) in ascending sequence on the dominant of

251 Fritsch, 55.

252 Cassandra I. Carr, "Wit and Humor as a Dramatic Force in the Beethoven Sonatas" (Ph.D. diss., University of Washington, 1985), 241.

253 Carr, 241. 
F-sharp minor. With the upbeat to measure 41 , the forward motion of the development advances and retreats by alternating with wide and close spacings between the hands; Beethoven reserves his bolder statements for the wide spacings between the hands (marked forte), subsequently followed by the softer, echo-like effect demonstrated in the close spacings between the hands.

Beethoven's use of chromaticism also enhances the direction and tension of the development. In measure 41, the development begins in F-sharp minor and progresses by a step to the dominant of $\mathrm{D}$ major (mm. 43-46). The dominant harmonic progression moves more rapidly through the keys of B minor (mm. 4647), and C-sharp minor ( $\mathrm{mm} .49-52$ ). The climax section in measures $50-52$ is comprised of thematic segments in diminution; the climax displays the fantasy element of Bilson's Category D based on its "outburst" nature within a climactic passage. After the pause on the first inversion G-sharp dominant-seventh chord (m. 52), the molto espressivo section shifts from C-sharp minor to E major (mm. 5254) to prepare the A minor version of the principal theme starting in measure 55. The digression to the minor tonic is another fantasy feature of Bilson's Category D. In measures 52-57, the antiphonal-like dialogue continues in an ascending sequence; the melodic and harmonic material is reduced to a two-note figure, in contrast to the four-note phrases in measures 41-48.

The recapitulation begins in measure 58. Carr notes that "the same cleaving of the quietly wondrous to the insistently disruptive perpetuates the dreamlike quality of the sonata." 254 Even though Beethoven presents the second theme in the traditional tonic key, the feeling of A major is present, but not

254 Carr, 241. 
confirmed strongly until the A major, root position chord on the downbeat of measure 77. The preceding A major chords (m. 71-75) are in various inversions and hint at a tentative affirmation of the A major tonic key.

The coda begins in measure 88 immediately following Beethoven's extended and thickened texture of the syncopated chords over a tonic pedal in the bass. The great intensity created from the multiple combination of pitches in the densely textured chords is another feature of Beethoven's late style. Besides providing a point of closure for the sonata, an additional feature of the coda "is also to counterbalance the material used in the development."255 The development section emphasizes the principal theme ideas, while the coda unifies the entire sonata by featuring: a derivative of the second theme in the bass voice ( $\mathrm{mm} .88-91$ ), followed by a fragment of the second theme in the soprano voice (m. 92, mm. 98-102), and the syncopated chords of the second cadential theme from the exposition (mm. 95-98) In the last three measures of the coda, Beethoven illustrates his late characteristic of widely spacing the hands outward in contrary motion. This contrary motion gesture hints at the illusion that the hands are floating apart as the "dream" of the first movement disappears (Example 24). Carr summarizes the fantasy quality of the coda as follows:

An essentially disintegrative impulse characterizes the last eight measures: the muted weak-beat accentuations are followed by breathless moments of very loud silence indeed: a crescendo in the penultimate measure deflates without struggle to an etherealized ending; the musical voices pull apart to the widest distance of the movement, while the closing melody continues to rise, symbolically suggesting the departure of this dream

255 Noreen E. Fuchs, "The Treatment of the Coda in Beethoven's Sonatas for Pianoforte" (Master's Thesis, San Jose State University, 1979), 86. 
from the realm of audible music, not the ending of the dream itself. 256

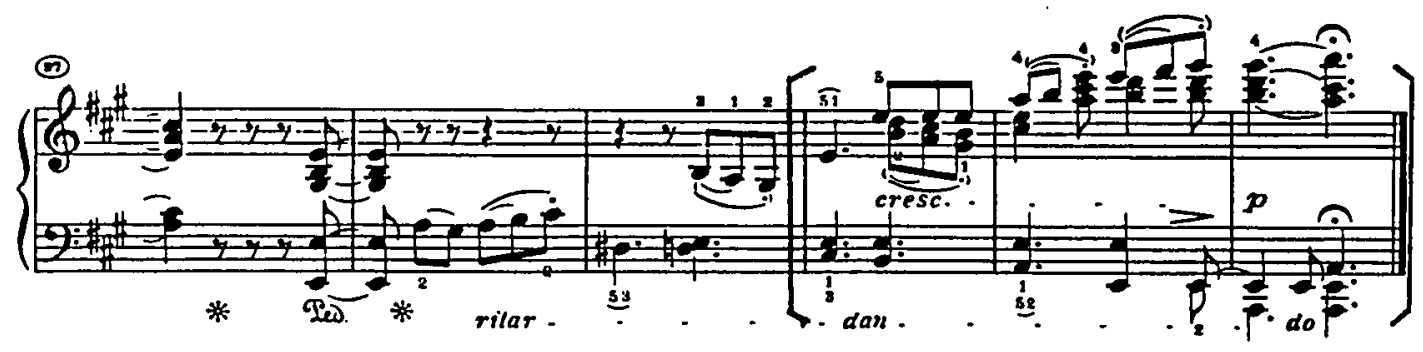

Example 24: Allegretto, ma non troppo, mm. 100-102.

As Tovey noted, from a structural standpoint, "the whole movement powerfully illustrates the vital difference between being on the dominant and in the dominant."257 Within this condensed sonata-allegro form, the fantasy elements blur the dividing lines between the exposition, development and recapitulation (and their sub-parts); the structure is "not obviously delineated through cadences as in the more formal earlier sonatas." 258 In the final analogy, the entire first movement is a fantasy beginning with a lyrical melody which seems to drift in from nowhere and neglects to touch the ground of musical reality by clearly establishing the tonic key. The rhapsodical outbursts provide a contrasting digression to the lyricism. The coda elevates the wafting fragments of the themes into thin air following the gesture of the weak-beat cadence.

Beethoven constructed the Vivace all Marcia in a modified minuet-trio form. Tovey describes the second movement's form as a "March, in elaborate

256 Carr, 242.

257 Tovey, 216.

258 Schroder, 199. 
melodic binary form; with [a] canonic Trio in [the] sub-dominant." 259 Beethoven's lively second movement in F major contrasts markedly to the preceding movement in its key relationship. Cooper remarks that the tonal progression of the second movement to the lowered sixth degree of the scale "was a favourite with Beethoven and always marks a dramatic change in mood." 260

Does the usual triumphant nature of a "march" indicate that Beethoven is returning to the heroic style of his middle period? Both Fischer and Elterlein disagree, and for different reasons. Fischer believes that Beethoven avoids the heroic element through the second movement's key relationships. ${ }^{261}$ Beethoven begins the second movement in $\mathrm{F}$ major, then continues in the middle strain (m. 12) in A major (major mediant), and proceeds to D-flat major (flatted submediant) in measure 30. Beethoven replaced the tonic-dominant progression of the traditional minuet form with his extreme use of chromaticism. Elterlein negates the heroic aspect based on Marx's idea that: "Actual deeds are not represented here, but the imagination of deeds which may happen, dreamed-of strokes of bold and lofty heroism." 262 Marx's quote also supports the fantasy aspect of the second movement.

Unlike the suggestions of metaphysical fantasy in the first movement, "the

259 Tovey, 218.

260 Cooper, 150.

261 Edwin Fischer, Beethooen's Pianoforte Sonatas: A Guide for Students and Amateurs, translated by Stanley Godman (London: Farber and Farber, 1959), 98.

262 Ernst von Elterlein, Beethooen's Pianoforte Sonatas: Explained for the Lovers of the Musical Art, translated by Emily Hill (London: William Reeves, 1898), 103. 
concussion of the opening bars [of the Vivace alla Marcia] announce to the nervous system rather than the intellect that something approaching completely lucid incomprehensibility has been let loose."263 The prominent features of the jerky, dotted rhythms, linear texture, wide leaps and abrupt intervals imply a sense of impatience and restlessness in the second movement. The most exploited late style characteristic in the second movement is Beethoven's extreme range of pitch and wide expansions between the two hands. Fritsch compared the generic march characteristics with those of Beethoven's Vivace alla Marcia from Opus 101 in a chart format (Example 25). Beethoven's digressions and modifications in the second movement are representative of the fantasy-sonata style: "the elaborate, unusual structure of this March and trio is conceived at once, as a perfect entity which makes use of the generic march and trio as a point of departure."264

"March" (generic)

melodically direct, simple

symmetrical phrase structure straightforward tonal expression homophonic

tuneful, innocuous
March from Op. 101 developmental, elaborate, fragmented, melodically evasive asymmetrical phrase structure modulatory; unstable tonal expression polyphonic wayward, aggressive, unsettled ${ }^{265}$

Example 25: March comparisons.

263 Carr, 243.

264 Fritsch, 64.

265 Fritsch, 63. 
In a letter written to Frederick Brunsvik, Beethoven quipped in a rather Shakespearean manner, "My kingdom is in the air; the notes whirl as the wind stirs them-so is the soul often in a whirl too"; Beethoven's quote could describe his use of fantasy elements within the second movement. 266 There is some truth to Beethoven's lofty quote illustrated in the second movement. Even though the second movement is brimming with the energy of the dotted rhythms, the power of the octaves and the extreme dynamics, a fair amount of the content is carried out in the middle to upper registers of the keyboard. Examples of activity in the lower registers are brief and then usually ascend out of the lower registers ( $\mathrm{mm}$. $1-4,12,45-50)$. Fischer notes that the character of the second movement should be considered "rather in the manner of a string quartet ... the independence of the parts leads to overlappings in the rhythm, which are not easy to negotiate within the fixed metre." 267

Beethoven exhibits an unusual amount of chromaticism in the second movement. Chromatic elements are apparent in the half-step descent of the bass line (mm. 1-4) to the dominant in C major (m. 4) in the first strain of the second movement (Example 26). Beethoven's use of chromaticism is a fantasy element of Bilson's Category A based on the divergent characteristics of the chromaticism away from the norm of simple melodies and straightforward tonal expression (Example 25).

\footnotetext{
266 Behrend, 160.

267 Fischer, 98.
} 


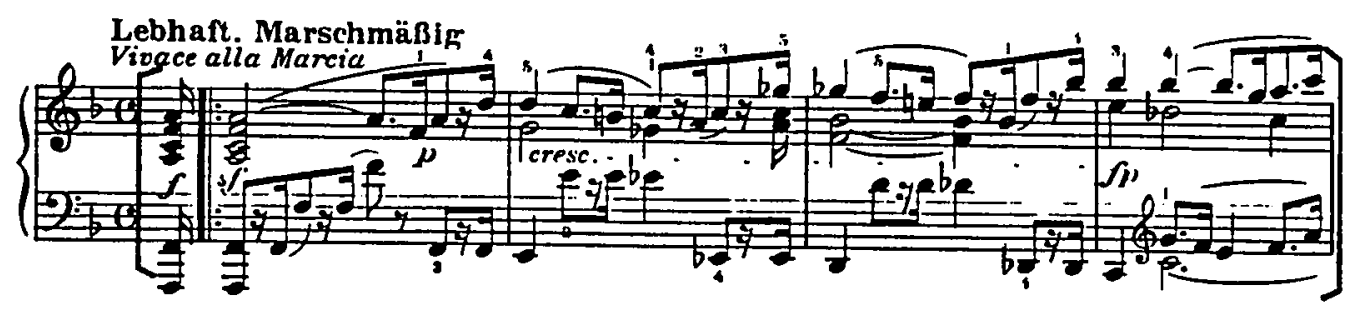

Example 26: Vioace alla Marcia, mm. 1-4.

Without preparation, the second strain of the second movement (m. 12) abruptly explodes on A major. Could the rhapsodic jolt of the A major be a fantasy element in retrospect to the evaded key of the first movement? If the answer is affirmative, then the premise for a factor of unification exists between the two movements. The polyphonic device of imitative sequences between the two hands permeates the second strain. Series of ascending imitative sequences (mm. 12-14) are followed by series of cascading fragments of the dotted rhythm pattern (mm. 14-18). (Example 27.) Carr descriptively characterizes this section as follows:

As the waterfall figure descends a second time, fantastical trills-neither ornamental nor structural, lacking a resolution-tone-push this intensely gestic march toward another oxymoronic state: human-physicality of unearthly nature. ${ }^{268}$ 

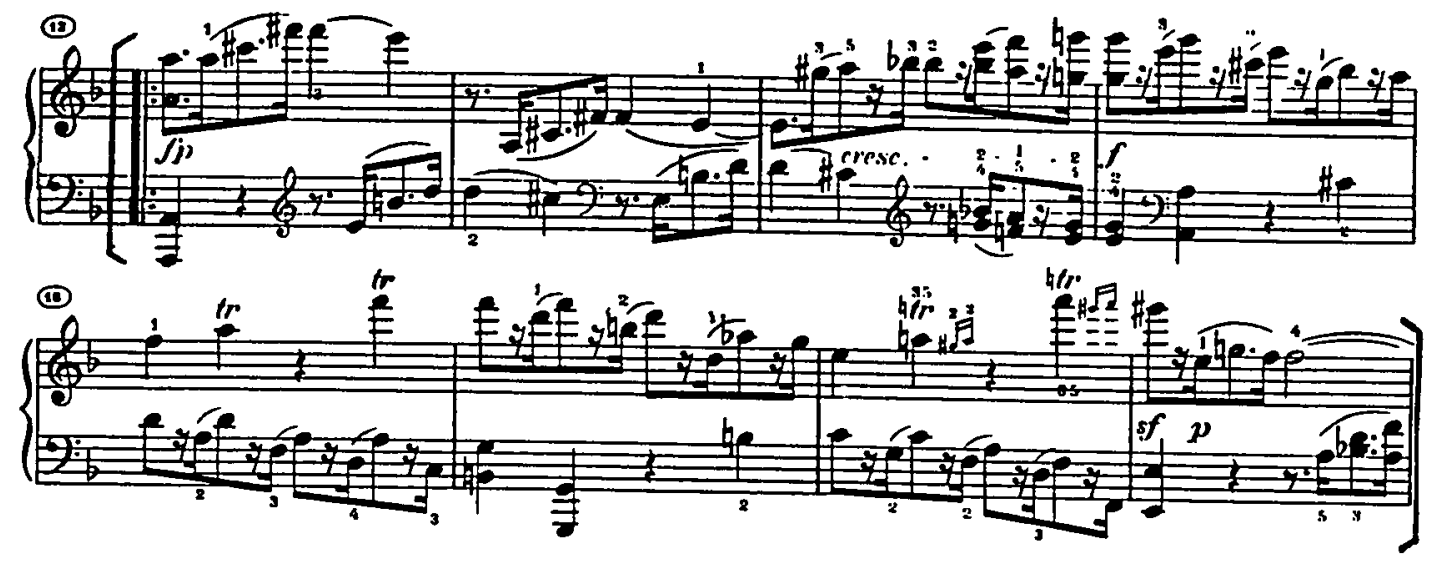

Example 27: Vivace alla Marcia, mm. 12-19.

A new set of imitative sequences begins at measure 19 followed by the reversed direction of the "waterfall figure" beginning in measure 26. An example of Beethoven's late style of using harmonic progressions to the flatted sub-mediant occurs in the second strain of the second movement. The harmonic progression begins with the D-flat suspension from measure 25 dovetailed with the key of F minor in measure 26; the F minor chord leads to the flatted-II chord in measure 27. With the aid of the Neapolitan sixth chord (m. 27), Beethoven shifts the G-flat minor chord of the previous measure to F minor (m. 28) which, in turn, leads to D-flat major (flatted sub-mediant) in measure 30. Another rising imitative sequence enters at measure 30 enhanced by the addition of a D-flat pedal point (mm. 30-33) created by Beethoven's extended damper pedal marking. Notice the wide spacing Beethoven places between the two hands (Example 28). 


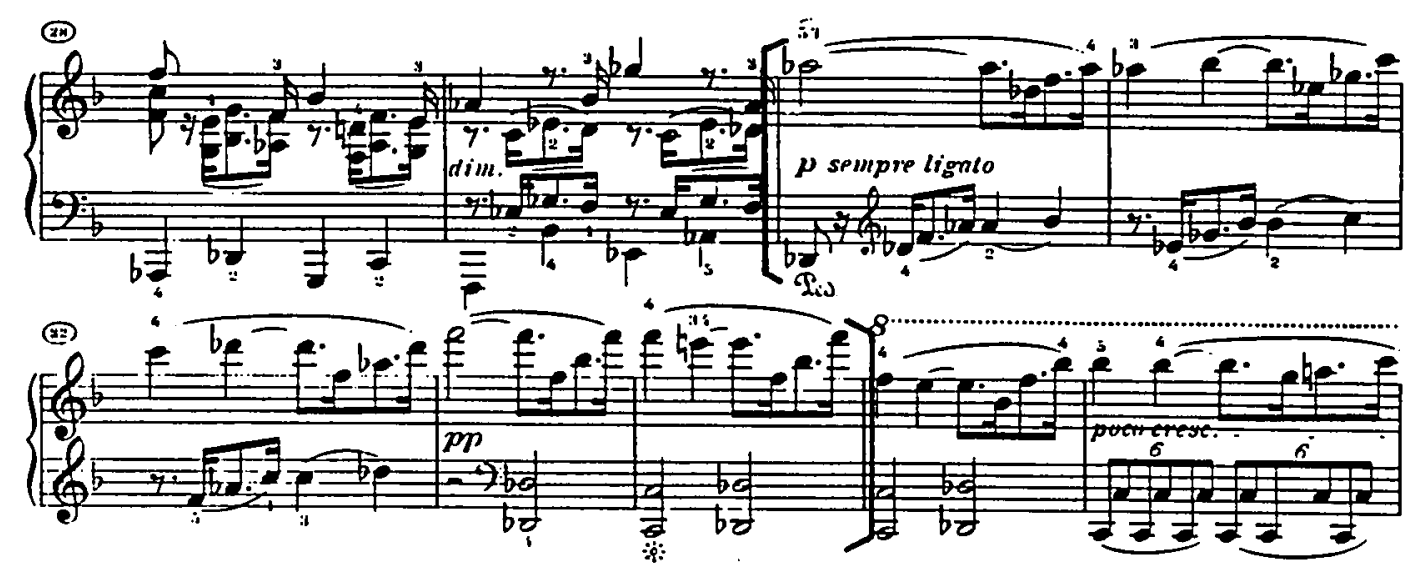

Example 28: Vivace alla Marcia, mm. 30-34.

A triumphant stretto at measure $\mathbf{4 0}$ intensifies the contrapuntal texture and powerfully closes the second strain of the March. For the first time in the March, Beethoven exhibits less chromaticism and, as a result, there is more harmonic stability. The fact that the dotted rhythms and "daring acrobatics" of the wide leaps and tessitura never arrive at a destination demonstrates the elaborations of ambiguity characterized in the fantasy style.

Following the dramatic exhibition of the stretto (mm. 40-43), Cooper comments that "it is characteristic of him that he immediately follows a tough, bare stretto by a playful passage in which the hands are crossed and the extreme rages of the instrument humorously contrasted."269 At the beginning of the third strain (m. 44-54), Beethoven gives the illusion of three hands playing three parts in three different registers of the keyboard (Example 29). This humorous contrast provides a sense of relief from the stretto section and suggests to the listener that the performer quite possibly has a third "ghost" hand helping to play the third

269 Cooper, 150. 
part. With regard to the rhapsodic quality displayed in the stretto, Carr notes that "whether in a spirit of drollery, mock heroics, or genuine remembrance of the latent power within the March figure, the subito forte third statement of the cadential figure completes the shockwaves that have made up the movement." 270

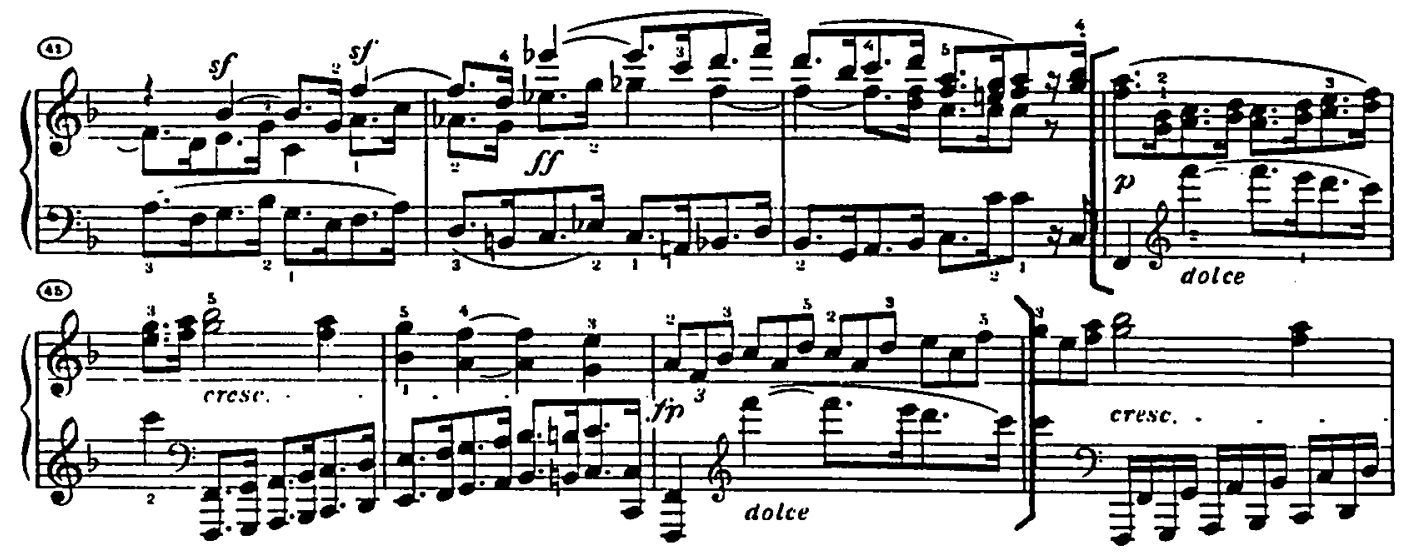

Example 29: Vivace alla Marcia, mm. 44-47.

The dramatic contrast in range and dynamics from the first section of the second movement to the Trio section can hardly go unnoticed. Reinecke remarks that "to the loud and decided ending of the principle division is placed in sharp contrast the delicate middle part in B flat major." 271 The trio begins at measure 55 in B -flat major with a fanfare-like motive which immediately blends into a two-part canonic texture at measure 58 (Example 30).

270 Carr, 247.

271 Carl Reinecke, The Beethoven Pianoforte Sonatas: Letters to a Lady, translated by E. M. Trevenen Dawson (London: Augener Ltd., [n.d.]), 98. 


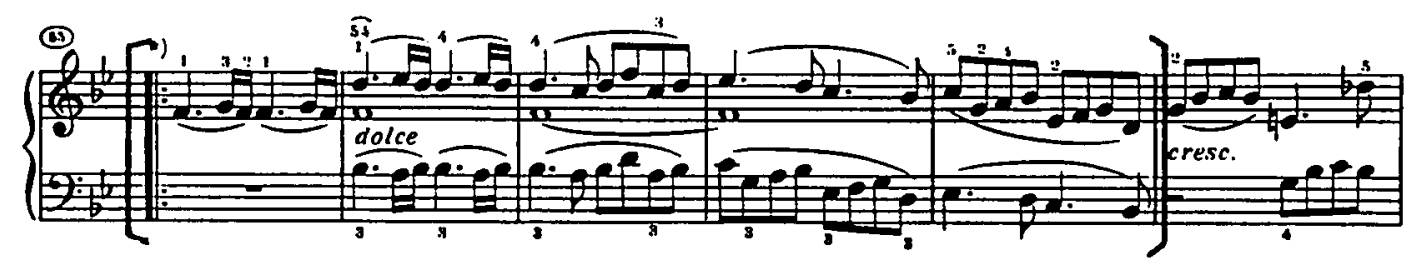

Example 30: Vioace alla Marcia, mm. 55-59.

Beethoven continues in strict canon with a repeat of the first ten measures. Recognizing Beethoven's rigid adherence to the contrapuntal technique of the canon, Blom states, "If he [Beethoven] intends to write in canon, then canon it must be, whatever the consequences." 272 The canon resumes in measure 65 without the imitation of the fanfare-like motive. As a result of Beethoven's strict treatment of the canon, the linear angularity creates some ambiguity in parts of the harmony. With the canonic imitation in the treble, (m. 66) a harmonic conflict exists between B-flat major in the bass voice and D minor in the treble voice. It is thought-provoking to wonder if the canon in the trio foretells of the fugue which is forthcoming in the development of the fourth movement. Although the rhythm of the canonic subject in the trio and fugal subject in the fourth movement is different, it is interesting to note that their intervallic contour is quite similar, especially in the use of a the tritone (Example 31). In his analysis of the contrapuntal bond between the second and fourth movements, Charles Schroder claims that "the somewhat tenuous nature of both the harmony and the counterpoint in this canonic section will finally find its

272 Eric Blom, Beethoven's Pianoforte Sonatas Discussed (New York: E. P. Dutton and Co., Inc., 1938; reprint, New York: Da Capo Press, 1968), 198. 
resolution in the partially fugal finale."273
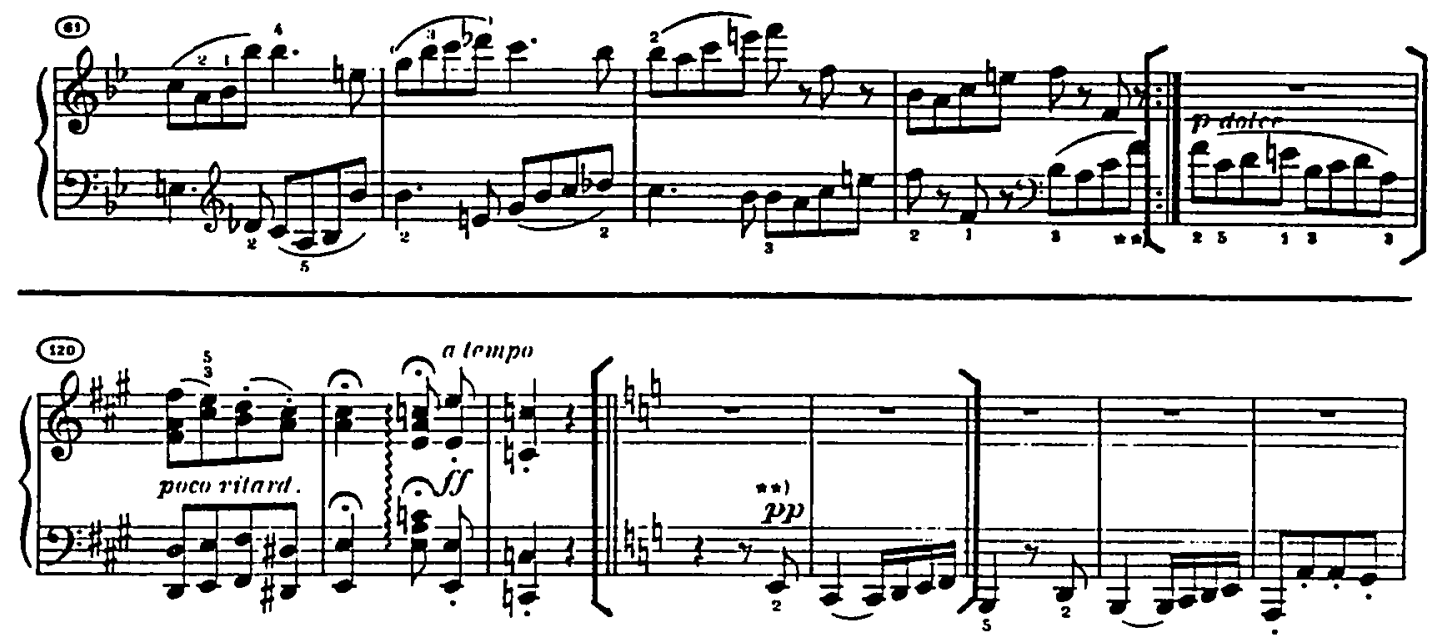

Example 31: Vivace alla Marcia, (trio), m. 65 and Allegro, mm. 123-124.

In measure 76 the canon ends and Beethoven appends a long trill in the treble voice. Still accompanied by the extended trill, the canon is resumed in the bass voice (m. 77) and then shifted to the tenor voice (m. 78). The trill lasts for three measures and then abruptly ends (m. 78 ) without any written-out termination or resolution. The spontaneous and improvisational character of the trill exemplifies the fantasy element referred to in Bilson's Category $D$. The fanfare-like motive returns, beginning on B-flat major and initiating the transition back to the second movement (mm. 84-94). At measure 91 the dotted rhythm of the second movement reappears in the treble voice under a $C$ dominant pedal; the $C$ pedal prepares the return of the second movement in $F$ major. Beethoven indicated Marcia da capo al fine senza repetizione (without repeats). Fritsch links the fantasy element to this transition material:

273 Schroder, 201. 
these measures are the completion of the identity relationship to the march, with $m$. 84-90 being related to $m$. 33-35, and $m$. 91-94 being equal to $m .36-69$. In relationship to the repetition of the march, they are a transition, from the spirit of the trio to that of the march. 274

The second movement demonstrates extreme contrasts in tempo, rhythm and character between the first and third movements. The elements of extreme contrasts within the second movement include: wide ranges of dynamics and pitch, extensive use of chromaticism, expansive leaps of the voices, and highly rhythmic drive of the first section of the second movement in contrast to the angular, canonic treatment of the trio. According to Fritsch, the second movement's

aggressive, arbitrary surface activity is unified by its functioning within one mindset. As a living organism the movement directs its own course. It remains unified because its expression is always within one personality. 275

With respect to Beethoven's unconventional polyphonic treatment, chromaticism and angular design within the minuet-trio dance form, the second movement most appropriately exemplifies the fantasy elements referred to in Bilson's Category A. Carr makes the following conclusions regarding the role of the second movement in the sonata:

While in no way preparing in a narrative or dramatic way for the third movement, the experience nonetheless ensures the breakdown of any intellectual sense of dramatic continuity or artistic (as it pertains to 'artifice') expectation. ${ }^{276}$

274 Fritsch, 88.

275 Fritsch, 65. 
The Adagio, ma non troppo, con affetto (only twenty measures long) is in $\frac{2}{4}$ meter and begins with a first inversion dominant chord of its home key of $A$ minor. Beethoven's preference for beginning on the dominant in the third movement reflects his treatment of the tonality of the thematic material in the first movement. Unlike the first movement, however, the third movement culminates on the dominant E major chord. Mellers delineates the differences between the song-like characteristics of the first and third movements:

So the first movement has been a 'dream-like song' and the second movement as earthly march that hints at, and in the trio weirdly and wonderfully attains, moments of transcendence. The collocation of the two movements makes it possible for Beethoven to 'start again': for what follows is indeed a song of longing (langsam und sehnsuchtsvoll is Beethoven's direction), though the longing is now no romantic dream. Yearning is sublimated into a late Beethoven hymn-aria. 277

Elterlein sees a unifying correlation between the lyrical transcendence of the first movement and the poignantly emotional yearnings of the third movement: "The feelings which we experience in the first movement take possession of the soul again [in the third movement]."278 The third movement is the bonding movement which unifies the entire sonata. Its songful, dreamlike characteristics remind the listener of the first movement. The third movement's deeply expressive contrast of repose from the restless Vivace alla Marcia, also serves as an introduction to the fourth movement.

Considering Beethoven's despairing outlook on life due to his ill health

276 Carr, 249.

277 Mellers, 154.

278 Elterlein, 104. 
and numerous misfortunes, one couid speculate that the third movement projects the utterance of Beethoven's longing for understanding and resolution. The continuous use of the chords in inversion, especially the opening dominant chords, enhances the sense of "a dull sorrow, a gentle complaining, and then again a painful yearning." 279 The whole mood of the third movement reveals "that there will be no answers, no summation, no solution." 280

The structure of the third movement is based on two, short motives introduced in the alto and soprano in measure 1 ; the movement continues with the derivations of those motives. The motive in the soprano voice includes a turn figure which is frequently imitated in a contrapuntal texture, and becomes an important melodic feature in the third movement (Example 32). ${ }^{281} \mathrm{~A}$ characteristic of Beethoven late style is captured in mm. 5-6 with the extreme range of pitches and wide expansion between the two hands. An example of a fantasy element appears in measure 4 with the improvisational manner of the alto and soprano outside of their designated motives.

279 Elterlein, 104.

280 Carr, 250-1.

281 Schroder, 203. 


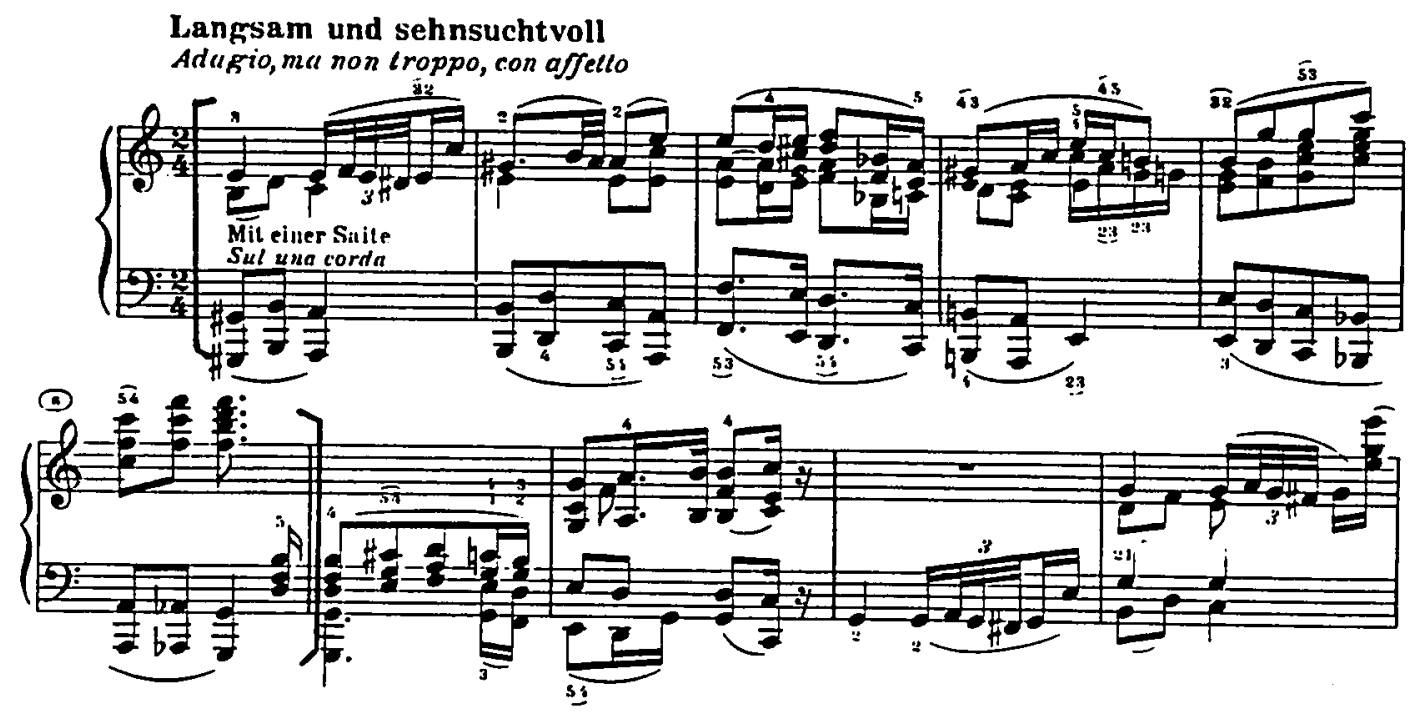

Example 32: Adagio, ma non troppo, con affetto, mm. 1-6.

Within the modulation to the relative major (mm. 1-8), Beethoven transforms the dominant $\mathrm{E}$ major chord by a chromatic alteration to the minor mediant of the new key (m. 4). Tovey notes this method of modulation is "now permanently established in Beethoven's style, of starting the modulations by changing the dominant chord in bar 4 from major to minor."282 After the weak C major cadence at measure 8 , the "turn figure" motive returns alone in the bass to begin the imitations in $\mathrm{C}$ major ( $\mathrm{mm}$. 9-13). In measure 10, the soprano answers the bass at the octave; the "turn figure" motive is developed into a dialogue between the soprano and the bass (mm. 9-13). The chromatic descent created by the alternation of the grace note pedal points with stem-down bass notes $(\mathrm{mm}$. 12-17) heightens the dialogue between the bass and soprano, which descend and ascend with arpeggiated diminished-seventh chords (Example 33).

282 Tovey, 221. 


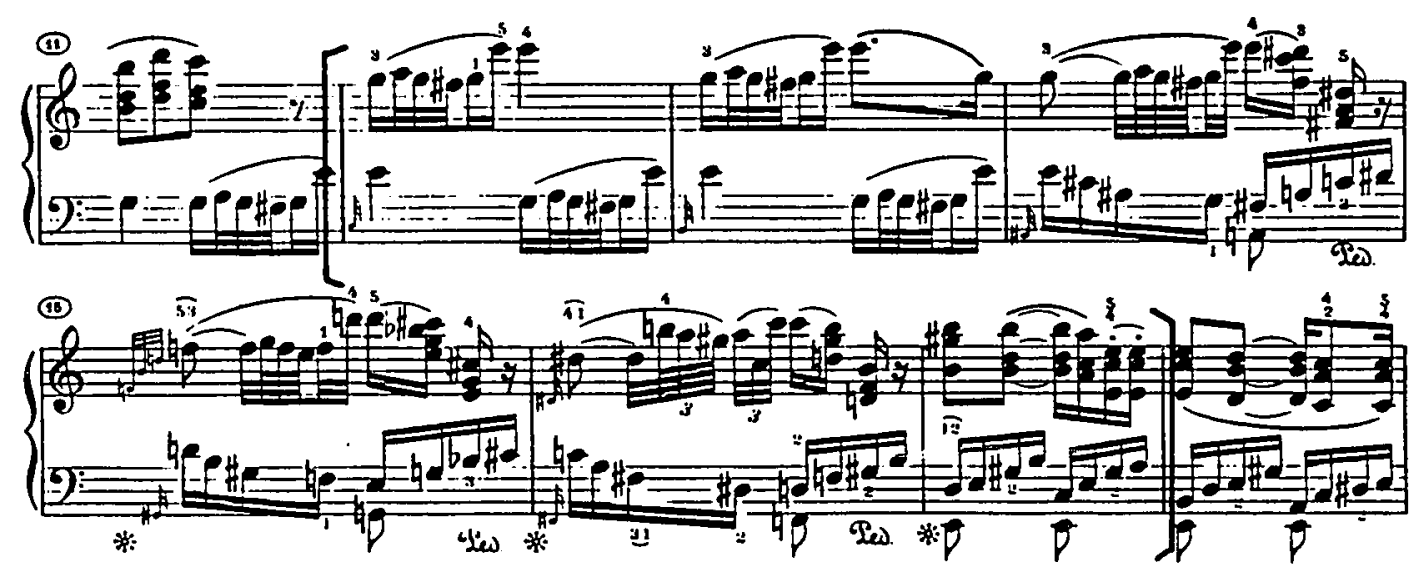

Example 33: Adagio, ma non troppo, con affetto, mm. 12-17.

Fritsch draws a parallel between Beethoven's attempt to establish the A major tonality in measures 17 and 18 of the third movement (with the aid of the $\mathrm{E}$ pedal points), as "reminiscent of the dissonance almost stabilized in $\mathrm{m} .9$ of the Allegretto." ${ }^{283}$ In measure 19, an extended vii $_{7} \circ / \mathrm{V}$ chord leads to the dominant; the harmonic motion is suspended on the dominant $\mathrm{E}$ major chord at measure 20. Immediately following the cadence, an improvisational and coloratura cadenza links the third movement to the restatement of the principal theme of the first movement. The fantasy element of the cadenza is aptly representative of Bilson's Category C.

Beethoven's technique of recalling the principal theme of the first movement before the fourth movement emphasizes his artistic determination to unify of the entire sonata. In Carr's opinion,

Beethoven seems confident of the symbolic power of his music, trusting

283 Fritsch, 95. 
that the entire range of realities created from the beginning of the work up to the point of the remembrance itself can be apprehended simultaneously by hearing one part of it. 284

The fantasy elements present in the restatement of the principal theme of the first movement is the restatement itself; this fantasy feature is represented in Bilson's Category A, which is based on the rearrangement or displacement of a movement's theme within another part of the sonata.

After the four measure restatement (mm. 21-24), fragments of the theme ascend in a sequence of thirds ( $\mathrm{mm} .25-27)$ to the Presto at measure 28 (Example 34). The trills that ascend by half-steps, accompanied by E dominant-seventh chords, serve as a dominant preparation for the entrance of the fourth movement in A major at measures 32-33. With regard to Beethoven's late style of the trill, Schroder observes that "the trills at this point [mm.28-32] serve in a sense to electrify the atmosphere and lead from a meditative and retrospective mood to one of exuberant energy." 285

284 Carr, 251.

285 Schroder, 204. 

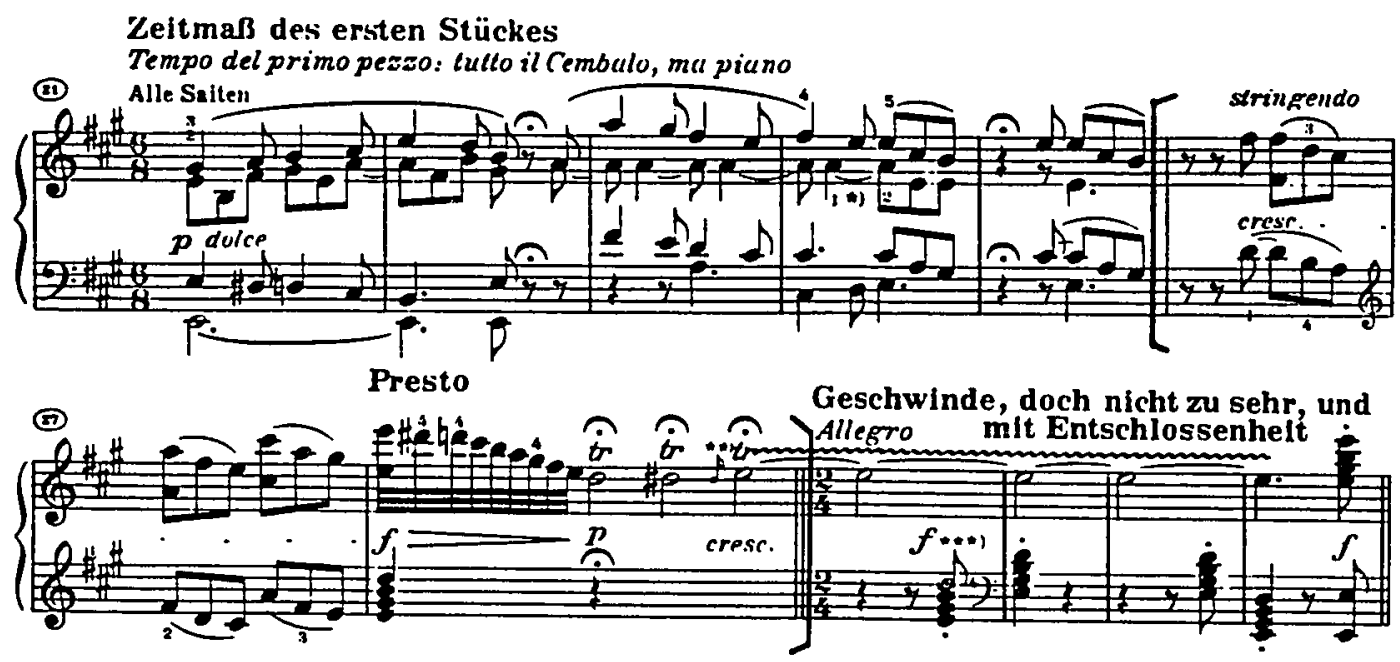

Example 34: Restatement, mm. 26-28.

It is interesting to note that Beethoven uses root position E dominantseventh chords (mm. 31-33) to project a firm, "earthly" foundation to enable the proceeding fourth movement to resolve the various ambiguities of the previous movements. Fischer summarizes the aesthetic features of the entire introduction by stating that the third movement "must never be allowed to touch the ground of reality, so that after the quotation from the first movement the worldliness and earthliness of the finale may be given full vent."286

The inherently ambiguous quality of the restatement directly affects and intensifies the decisive character of the fourth movement. The anticipation generated by the halting fermatas and rests of the restatement, as well as the emotionally heightened intensity of the chromatically ascending trills (with fermatas), clearly demonstrates Beethoven's late characteristic of anticipation. Carr describes the transition from the restatement section to the introduction

286 Fischer, 98. 
(mm. 29-32) and announcement (mm. 32-33) of the fourth movement as follows:

The chain of trills constitutes the vindication of those aesthetic expectations as the robust principle subject of the finale bursts out of the covering trills. Good humor, self-confident power and physical gesture all return through the ebullience of the canonic leap-and scramble figure. ${ }^{287}$

Beethoven structured the Allegro movement in the sonata-allegro form with the unusual substitution of a fugue as the development section. Otherwise, the fourth movement is the only movement in the sonata in which Beethoven adheres to the strictest treatment of the framework of the Classical form. Beethoven features an exposition with the customary thematic and transitional material (including a repeat sign at the end). In the development section, Beethoven develops a subject for the fugue based the thematic material of the exposition. The recapitulation restates the material of the exposition (with the exception of a short digression after the first eight-measure phrase) and returning to the tonic for the second theme. The fourth movement concludes with a coda which highlights elements of the exposition and the development.

The most significant fantasy feature (Category A) of the fourth movement is the fugal development section; Fritsch contends that the fugue functions as both an independent form and as a sonata development. ${ }^{288}$ Within the framework of the sonata-allegro form, Beethoven uses the contrapuntal devices of imitation, canon and the fugue to express his decisive feeling of resolution in the fourth movement. Beethoven's use of contrapuntal devices are not exclusively intended for structural purposes; Cockshoot infers that "it is clear at

287 Carr, 252.

288 Fritsch, 95. 
the outset of the finale that counterpoint is to govern its style."289

With great determination, Beethoven introduces the eight-measure principal theme of the exposition firmly in A major. The contrapuntal elements of the principal theme attack the fourth movement with great force exemplifying Beethoven's freedom and spontaneity (Example 35). The two chords at the end of the eight-measure theme end with fermatas (m. 40), a technique reminiscent of the fermata that Beethoven indicated at the end of the principal theme of the first movement (m. 6).

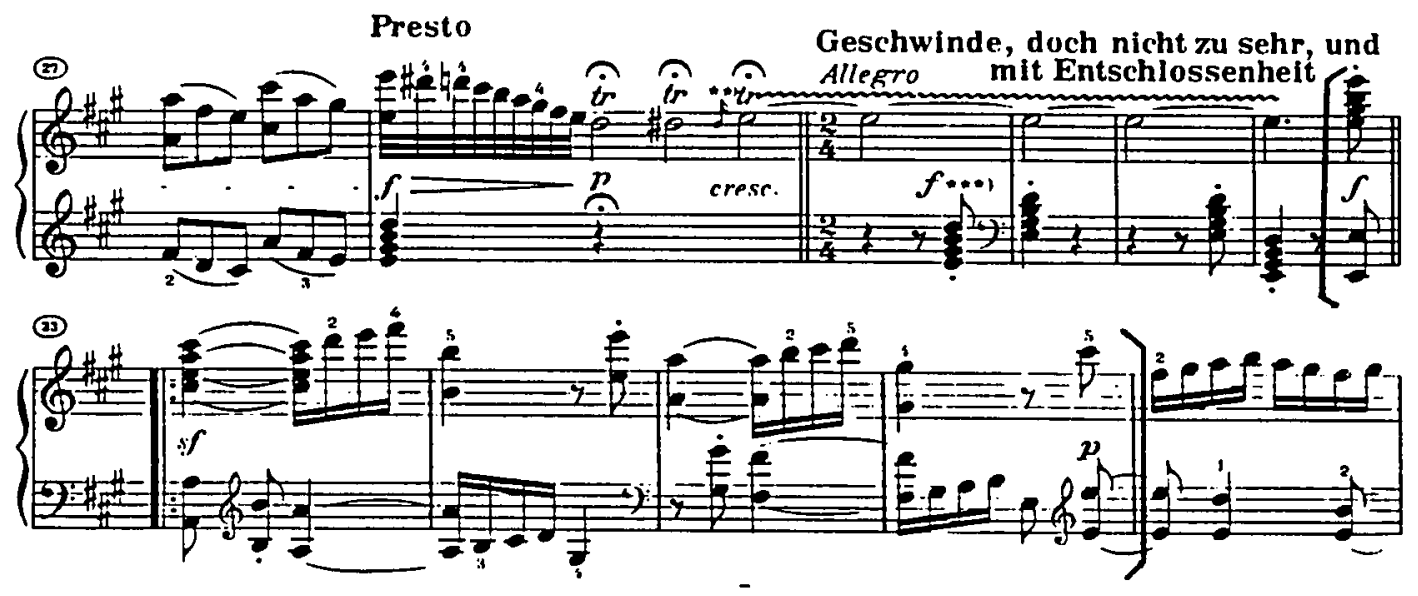

Example 35: Allegro, mm. 32-36.

Mellers suggests that "the pauses might, however, be frustration rather than emphasis: as is suggested when an attempted repeat in double counterpoint, with the right and left hands inverted, runs into trouble."200 The "trouble" is that the voices are in closer proximity to each other and the

289 John V. Cockshoot, The Fugue in Beethooen's Piano Music (London: Routledge and Kegan Paul, 1959), 50.

290 Mellers, 157. 
possibility of the voices ( and hands ) colliding is sensed. The upbeat to measure 41 begins the eight-measure theme in inverted double counterpoint beginning in the left hand (Example 36).

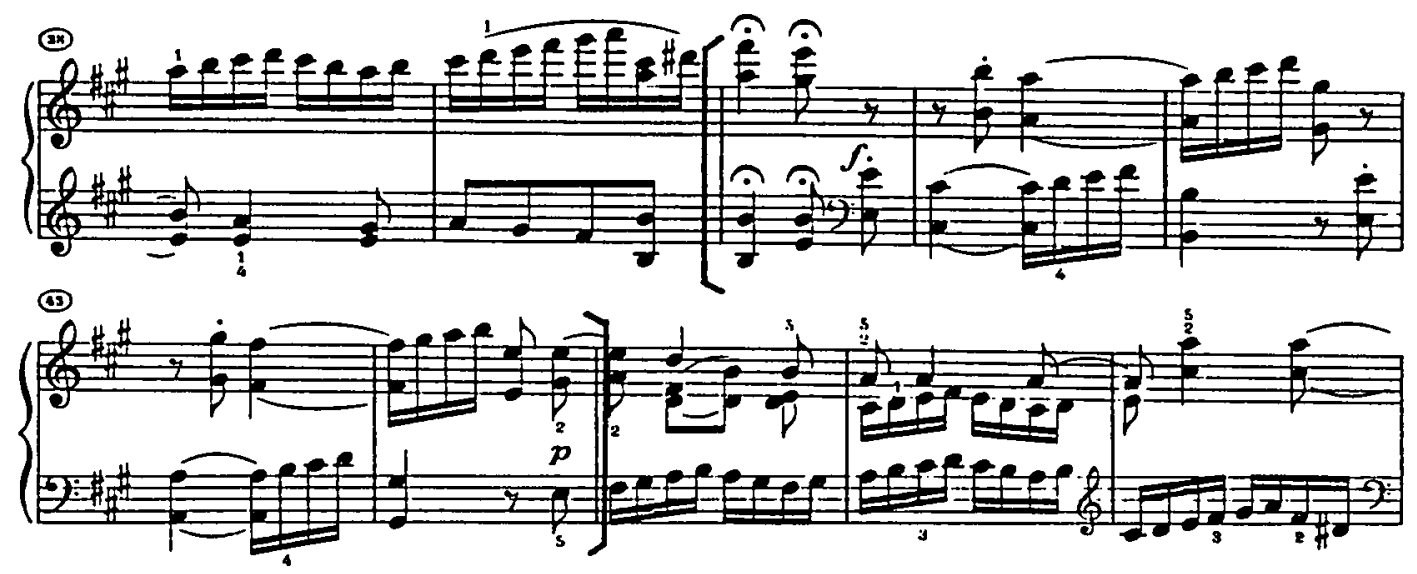

Example 36: Allegro, mm. 40-44.

Another eight-measure section (mm. 48-56) follows in which Beethoven exhibits a gentler treatment of the material derived from the first theme. Tovey calls this section a "new phrase on the dominant, like a middle strain."291 The return of the theme pounces forward in the deep bass voice (m. 56) and is imitated three octaves above in the soprano voice. After a four-measure theme (widely spaced between the hands), a four-measure quasi-canon follows in close imitation (mm. 60-64). The first transition ( $\mathrm{mm} .65-80$ ) is comprised of a repeated sixteenth-note motive heard first on the tonic and then on the dominant. The four-measure repeat at measure 69 , followed by the ascending quasi-sequence treatment of the motive, causes the motion of the transition to stagnate (Example 
37). Within the first transition (mm. 65-80), Beethoven seems to get

stuck on reiterated tonics and a four-note scale ... [which] the top part attempts to rise to lyrical song, recalling the alternating fifths and sixths prevalent in the first movement and adagio. But the song cannot grow; the effect is on the verge of risibility, like a stylus stuck in a record groove. 292
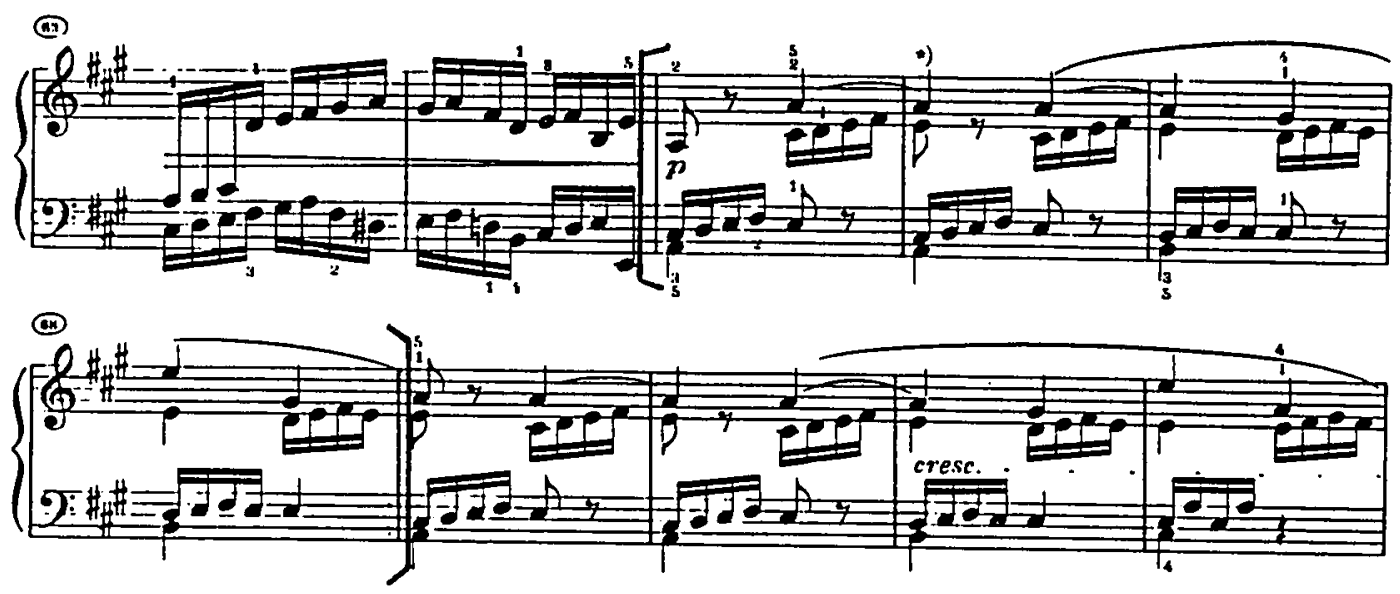

Example 37: Allegro, mm. 65-68.

Recalling the lyrical aspects of the first and third movements is another example of Beethoven's unifying functions as well as a fantasy characteristic. The second transition ( $\mathrm{mm} .81-90$ ) begins in the soprano on the weak beat with a dotted rhythm figure which is imitated first in the alto at measure 83 and then in the bass at measure 85 (Example 38).

292 Mellers, 157. 

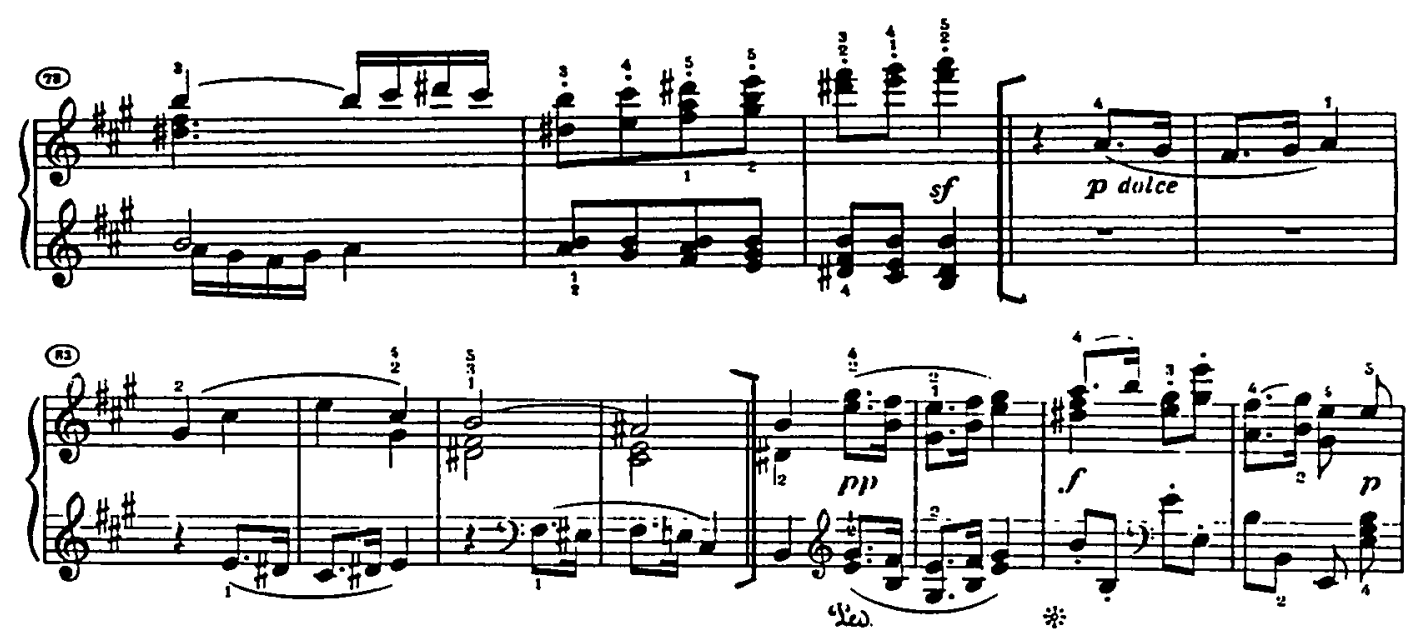

Example 38: Allegro, mm. 81-86.

Beethoven treats the following dotted rhythm figures in a chordal texture with a scherzando-like manner. Could the dotted rhythm figure-and especially the horn-call effect (mm. 87-88) - be a remembrance of the second movement? Dotted rhythms of this nature have not been present since the second movement. Beethoven resolves the ambiguities of the previous movements by means of unifying their characteristics in the fourth movement.

Beethoven treats the second theme (mm. 90-105) "like a polka, the imperious gesture reveal[ing] a facet of its character that would not have been guessed a mere ten measures before." 293 Once again a parallel can be drawn between the alternating ascending scalar passages accompanied by the syncopated gestures (mm. 98-106) and the third strain of the second movement (Example 39).

293 Carr, 253. 


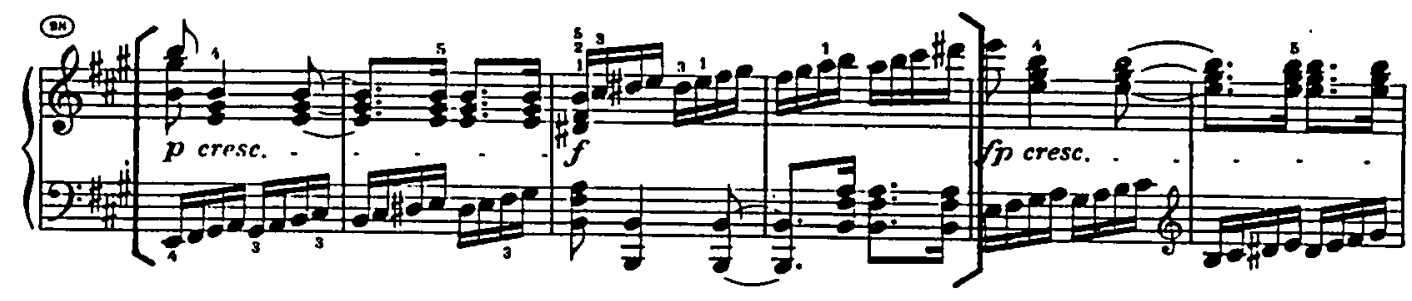

Example 39: Allegro, mm. 98-101.

Tovey's analyzes of measures $106-113$ as a cadence-theme that connects the exposition to the development. The four eighth-note motive (hereafter referred to as "motive $c t$ ") of the cadence-theme is extended into the first eight measures of the development section, which precedes the entrance of the fugue at measure 123. In measure 121, Tovey speculates that Beethoven "asks an angry question and pauses for a reply," represented by the double octaves hinting at the principal theme, only now in A minor.294 The two notes (E and C) of the "angry question" become the first two notes of the fugal development (Example 40). The fantasy element of the "angry question" refers to Category D based on the rhapsodic outburst of the displaced fragment of the first theme.

294 Tovey, 224. 


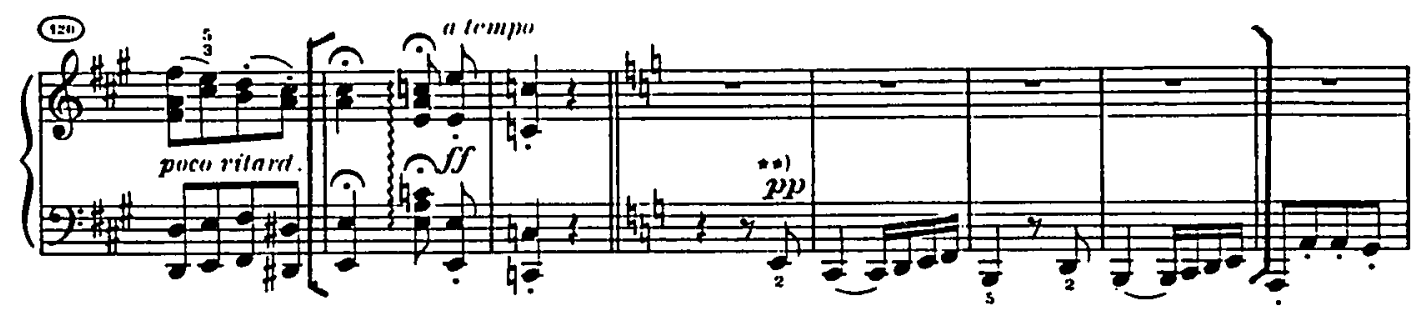

Example 40: Allegro, mm. 121-122 and mm. 123-126.

The development continues at measure 123 with a fugue; Tovey describes the development as a "fugue, with [a] modulating exposition, but centered on home-tonic minor" (Example 40).295 Cockshoot feels that it is only "natural that this development should be in the style of fugue in view of the contrapuntal nature of the movement." 296 Beethoven utilizes the fugue not solely as a structural tool but as a vehicle of expression. Cookshoot explains that Beethoven

never loses sight of the fact that this is the development section of a sonata and not an independent fugue, and he seeks to reconcile the dramatic style of the former with the intellectual style of the latter. ${ }^{297}$

Within the concise process of the fugue, Beethoven seems to communicate a clarification of his expressive intentions and unification of the preceding movement's contrapuntal devices.

The subject of the fugue begins in the bass voice following the key signature change to A minor. Cockshoot claims that Beethoven's fugue subject is "cleverly constructed and is ideally suited for fugal use. Its strongly contrasting

295 Tovey, 224.

296 Cockshoot, 51.

297 Cockshoot, 51. 
rhythms are very characteristic of many of Bach's subjects."298 The eightmeasure subject contains two motives: the first motive of the fugue traces the first motive of the principal theme of the exposition (followed in sequence down one step) and the second motive appears to be a derivative of "motive $c t$ " and finishes with a trill. The first motive has two figures: figure $a$ is the descending third and figure $b$ is the ascending sixteenth-note pattern. Cockshoot labels the second motive as $c .299$

The tenor voice answers the bass at measure 129 in $\mathrm{C}$ major; the tenor is accompanied by a countersubject (bass voice) based on an inverted version of $b$ begins on the first beat. The alto voice enters at measure 137 in $\mathrm{D}$ minor accompanied by the countersubject in the tenor and bass in thirds (mm. 137-141) and then in sixths (mm. 141-144). In measure 145, the soprano voice enters with the subject in A minor, accompanied by the countersubject in sixths by the inner voices. Canonic imitations of $c$ appear at measures 149-154; each voice pursues its contrapuntal course regardless of the angular design of the harmonies.

In measure 155, the subject reappears in the bass voice in $\mathrm{C}$ major, but rhythmically displaced by one beat. Above the bass subject, the soprano and alto voices display a compressed version of the subject's motive in new sequences. 300 The end of the fugue's exposition and the beginning of the first episode dovetail in measure 160. Cockshoot claims that the first episode begins on the second

298 Cockshoot, 62.

299 Cockshoot, 62.

${ }^{300}$ Tovey, 224. 
beat of measure 160 (in the soprano voice) and continues until measure 172.301 In the first episode the soprano voice begins with the second part of the $c$ motive; the alto and tenor voices follow in simultaneous imitation beginning in measure 163. The bass voice accompanies the upper three voices with a nominally free part following the outline of the fugue theme. ${ }^{302}$ In measure 168 , the tenor enters with the $a$ and $b$ figures of the subject on the dominant of A minor, accompanied by imitations of $b$ above and below in the bass and soprano voices.

Cockshoot labels measures 172-182 as the "middle section": "as is usual in a development section of a sonata movement, there is constant modification of existing material, and here the Subject is varied." 303 The upper voice enters with the subject in $\mathrm{C}$ major in measure 172, but the descent of a third from the second $b$ into $c(m .176)$ demonstrates a modification in the subject. Cockshoot explains that the modification of the subject

at 176 establishes the key of $C$ major more completely, which is the purpose of this entry. The Countersubject in the tenor supports this by omitting the $B$ flats and the bass reinforces the key with a gentle variation of $b$ down to the tonic. 304

In measure 176, the countersubject in the tenor abruptly ends to imitate the upper voice at the tenth; the bass enters in measure 177 to continue the canonic

301 Cockshoot, 65.

302 Cockshoot, 65.

303 Cockshoot, 65.

304 Cockshoot, 65. 
treatment of the upper voice and the tenor.

The second episode begins in measure 182 with ascending sequences of $a$ and $b$ (merged together as $a b$ ) which are rhythmically altered with reverse accents. Cockshoot remarks that

having carried on thus far in a manifestly fugal style, Beethoven finds that it is time now to adopt a freer style if the fugal manner of this Development section is not to make it outweigh the rest of the movement. Accordingly, he adjusts the balance between the sonata and fugal styles with a more pianistic section for neariy thirty bars until another entry appears (208). 305

An example of Beethoven's freer style is demonstrated in measure 186; the $a b$ motive is inverted and has freer endings in the tenor and bass voices. From measures 190-193, the bass voice leaps by tenths with the modified $a b$ motive in an ascending sequence underneath a chain of descending suspensions in the soprano voice. Beethoven developed the $b$ motive in continuously running sequences in the dominant key (mm. 193-208); Beethoven's pianistic style replaces the formal fugal style in that "contrapuntal complications are reduced to a minimum with constant parallel movement in thirds, sixths, and tenths." 306 From measures 201-208, the $a$ and $b$ motives are contracted and rhythmically displaced in the four voices; the $c$ motive is modified by the use of ties on the repeated notes.

Cockshoot identifies the last 24 measures of the development as the "final section."307 This final section (mm. 208-214) begins with a four-voice stretto; the

305 Cockshoot, 66.

306 Cockshoot, 67. 
voices of the stretto enter in the same order as the exposition of the fugue in A minor. A modification of the subject appears in the bass voice suspending a dominant pedal in mm. 211-212 and again in mm. 213-214. The four-voice stretto adds powerful tension to the development of the fugue. Beginning in measure 214 , all four voices follow in close imitations of $a, b$, and $c$. The climax appears in measure 223 enhanced by Beethoven's first use of EE (a new feature of the fortepiano at that time) in the bass voice; the following passage moves in double augmentation of $a$ and $b$ in the bass voice, while the upper voices descend in diminished-seventh chords through to measure 227. In measure 223-226, the extremely wide expansion of pitches and hands is characteristic of Beethoven's late style (Example 41).

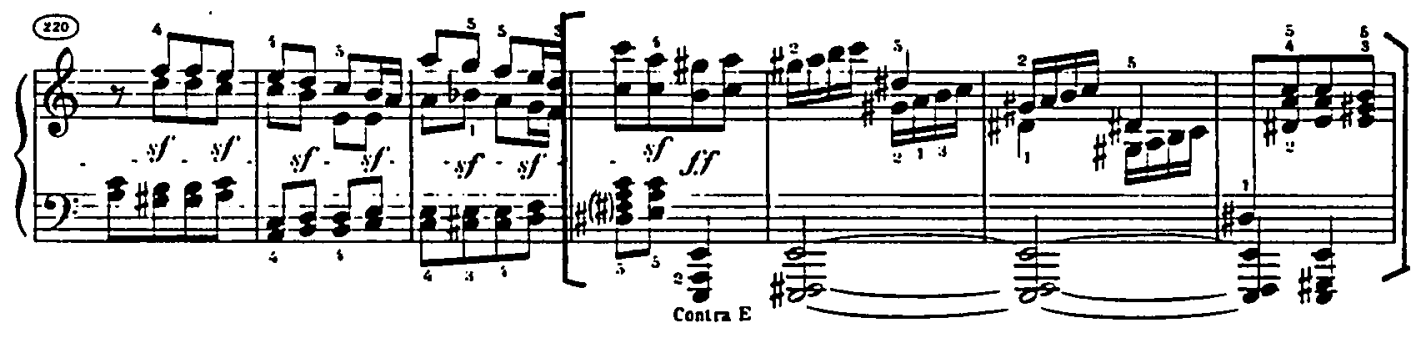

Example 41: Allegro, mm. 223-226.

At measure 228, the dominant preparation of the E major ascending arpeggios commences by "heralding the recapitulation in a mounting climax of joy." 308 The extremely rhapsodical nature of the EE passage in measures 223-227 (Category B) and the improvisational splendor of the cadenza-like passage in measures 228-231 exhibit characteristics of the fantasy-sonata (Example 42). Carr

307 Cockshoot, 68.

308 Cockshoot, 69. 
comments on Beethoven's negation of sublimity in the fugal development:

That the entire development of the finale is a fugue built of the first subject imparts yet more paradoxical facets to the enigmatic whole. To wit: As the sonata has more and more emphasized the shocking illogic necessary for the experience of trans-figured reality, the fugue represents the epitome of learned craftsmanship and of logic. As the sonata-through dream-trance and transmogrified physicality-has approached a state of disembodied energy, the fugue's very nature insists upon architecture and structure. ${ }^{309}$

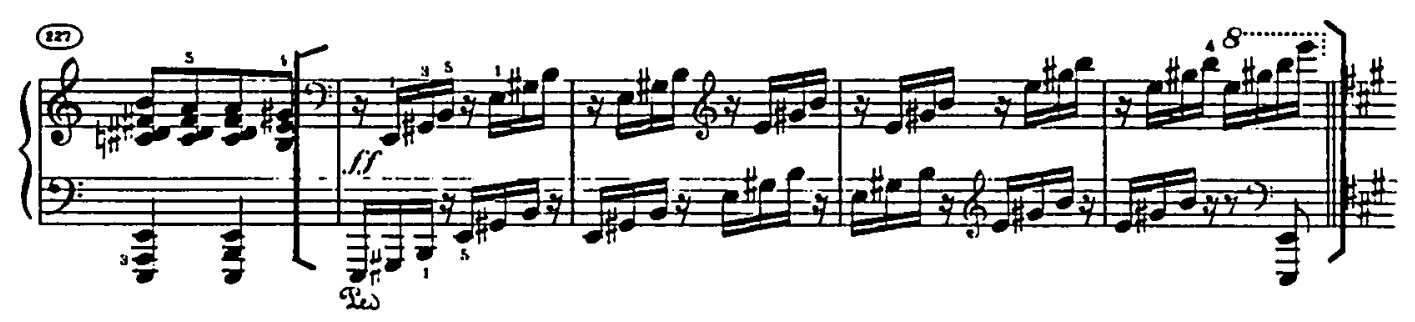

Example 42: Allegro, mm. 228-231.

In the recapitulation (beginning in $\mathrm{m} .232$ ) Beethoven follows the traditional plan of returning to the tonic, except for a turn aside which appears after the eight-measure theme (m. 239-240). Beethoven features the theme in the bass voice and the inverted theme in the soprano voice simultaneously with a repeated note dominant pedal in the tenor voice; the alto voice follows in contrary imitation to the soprano. (Beethoven's improvisational deviation from the recapitulation signifies the fantasy element represented in Bilson's Category D.). Quite characteristic of his late style, Beethoven spaces the voices of the theme widely apart in contrast to the traditionally close-knit technique of contrapuntal writing (Example 43).

${ }^{309}$ Carr, 255. 


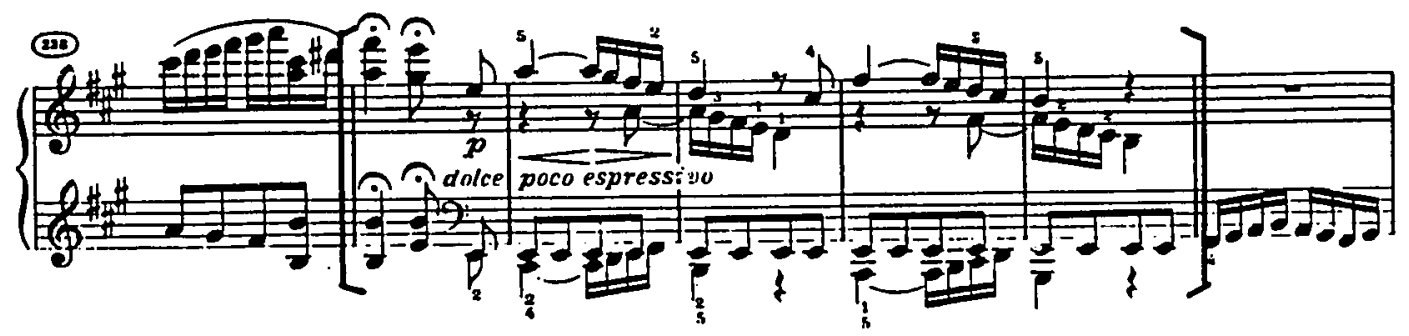

Example 43: Allegro, mm. 239-243.

The running sixteenth-note figure from the exposition remains unaltered in the recapitulation; the bass voice enters alone at measure 244, answered by the tenor voice (m. 245) and again answered by the upper voice (m. 247). The transition begins in measure 252 in the sub-dominant, which leads to the second theme in the tonic (m. 280). With rerard to the characteristics of Beethoven's late style in the fourth movement, Cooper states:

The style of the music [fourth movement], with its frequent interruptions and strong upbeat rhythms, the organic thirds and sixths which thicken the texture, and the dramatic insistence on extremes of pitch and even of conventional dissonance is not so much the contradiction as the complement of the suave, floating euphony of the first movement. ${ }^{310}$

The coda begins in measure 303 with the motive $c t$ derived from the exposition (m. 115). Tovey notes that $c t$ is repeated five times in the bass voice "making a tonic-and dominant swing" with the B-E-E-A-A pattern.311 Carr aptly characterizes the humor of the coda as follows: "The lightly hopping cadential figure which closes the recapitulation is made fun of in the first ten measures of the coda, a reincarnation of the 'stuck motive' device." 312 Beethoven hints at the

310 Cooper, 154.

311 Tovey, 226. 
suggestion of another fugue with the two double octaves in measures 313-314; but in measure 317-318, he seems to takes pity on the listener, "as though Beethoven had seen the look of despair on his audience's face" and continues to the end in a cheerful, exuberant spirit (Example 44).313 Fuchs describes the function of the coda as follows: "While maintaining the imitative, contrapuntal character of fugal writing, the coda-with its comparative calm-balances the remainder of the movement." ${ }^{\prime 314}$

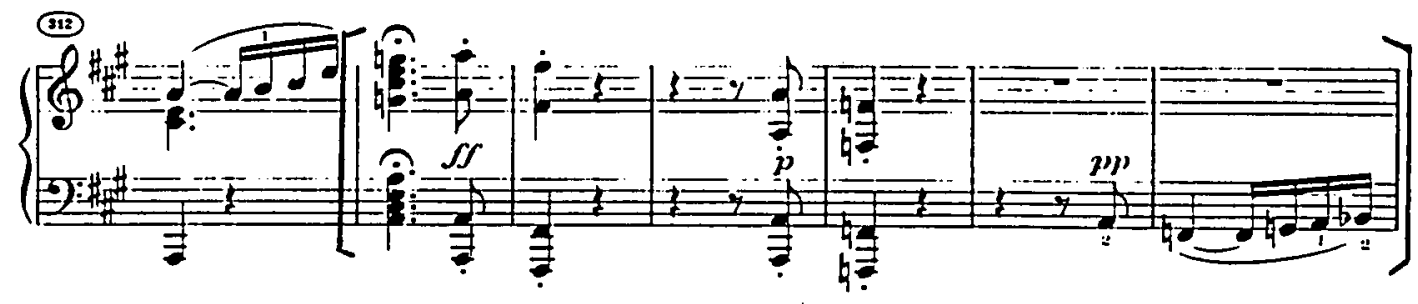

Example 44: Allegro, mm. 313-318.

Fritsch contends that the coda has three functions: first, an extension of the final cadence of the recapitulation (mm. 303-343); second, the section growing out of an allusion to the opening of the development (mm. 313-338); and finally, the closing cadential material for the fourth movement (mm. 338-361).315 The low trill beginning in measure 347 creates a drum roll effect not unlike the drum roll of the second movement, which suggests that Beethoven is still unifying the sonata by recalling segments of the other movement's themes. Notice the typical

$$
\begin{aligned}
& 312 \text { Carr, } 256 . \\
& 313 \text { Cooper, } 155 . \\
& 314 \text { Fuchs, 86-7. } \\
& 315 \text { Fritsch, } 119 .
\end{aligned}
$$


characteristics of Beethoven's late style illustrated in the wide spacings of the hands as well as his exploitation of the EE in measure 350 (Example 45).
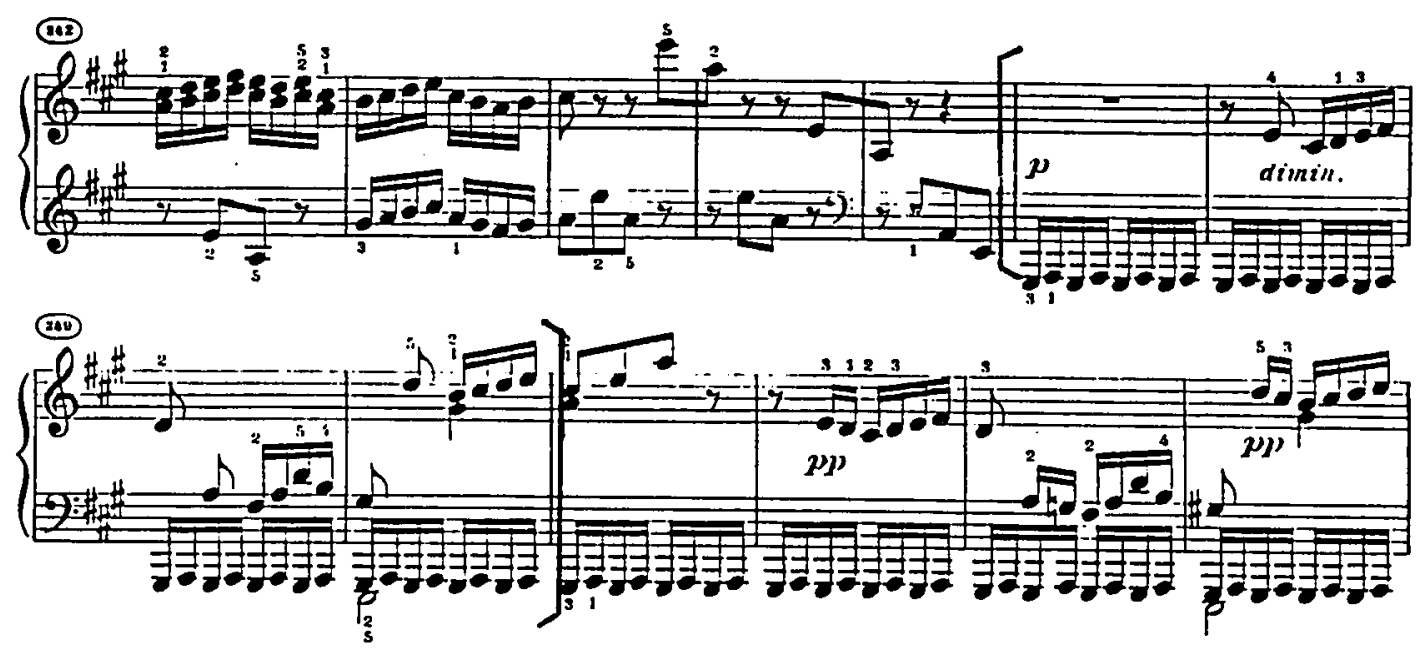

Example 45: Allegro, mm. 347-350.

From measures 355 to 358 Beethoven extends a ritardando which leads the listener to believe the ending will simply finish unwinding and stop. But Beethoven interrupts the ritardando by indicating "Tempo I" at measure 359 for the last three measures with a resolute and triumphant chordal ending signifying that, in Blom's words, "there is much happiness here, but it is not the soft abandonment to bliss of the first movement: it is gladness won by grim determination" (Example 46). ${ }^{316}$

316 Blom, 199. 


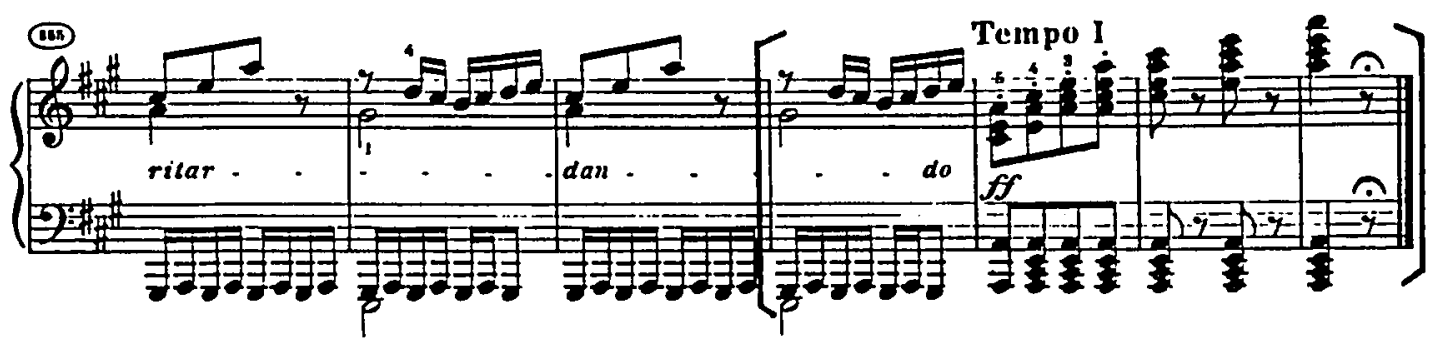

Example 46: Allegro, mm. 358-361. 


\section{Chapter 8}

Hermeneutic Interpretation of Opus 101

In chapter seven analytical parameters of Opus 101 were discussed in some detail. Occasionally hermeneutic interpretations of the sonata by other authors crept into the discussion. In this chapter a more general hermeneutic overview of the work is offered. To gain an understanding of musical hermeneutics, Ratz proposes that "only when we have examined the content of the music can we explore the possibilities of going beyond purely musical features to the interpretation of its meaning." 317 A genuine search for the essence of the human element deep within the heart of the sonata will illuminate Beethoven's hermeneutic import for the purposes of interpretation. According to Ratz:

we can say that music analysis renders the performer an indispensable service. Beyond that, however, there are also cases where-by the very fact that analysis has enabled us to penetrate to the very finest details of a musical structure-we discover features which compel us to search for a deeper meaning; unless at least some notion of that has been gained, performance is bound to remain superficial and will not penetrate into those depths where it was the composer's intention that the work should take us. 318

For historical reference, the discussion of the sonata's meaning will begin with the primary source. According to Schindler, Beethoven entitled the first and third movements of the sonata as "Impressions and Reveries; [and] they are to be

317 Erwin Ratz, "Analysis and Hermeneutics, and their Significance for the Interpretation of Beethoven," translated by Mary Whittal, Music Analysis 3 (1984): 244.

318 Ratz, 254. 
played in a free tempo." ${ }^{119}$ Because Schindler's accounts of Beethoven's life and works are sometimes questionable, it is important to note that Beethoven did not superscribe these titles in his autograph or first edition of the sonata. The titles are meant to "provide psychological suggestion, by means of which the impression that incited [Beethoven's] creative process could be shared with the performer."320 In profound contrast, Beethoven's German superscription for each movement intimate a much deeper significance of the sonata.

To support the human element of musical hermeneutics, Beethoven's personal life needs to be brought into this discussion. During his late period, Beethoven retreated within himself and became quite possessed with his composing. Exhaustion and disappointment drove Beethoven into seclusion. Even his late sonatas were composed with the intention to be played in private musical settings with only his friends in attendance. The aspect of Beethoven's privacy is reflected in the first and third movements of the sonata. The opening of the first movement alludes to the feeling that the lyrically floating melody appears to have materialized to a humanly audible level that allows the listener temporary exposure to Beethoven's innermost dream sequence of personal longings. The sublimity of Beethoven's yearnings in the first movement are transformed into the reverent utterances exhumed from the depth of his soul in the third movement.

The human experience of Beethoven's later years transcended his

319 Anton Felix Schindler, Beethoven As I Knew Him, edited by Donald MacArdle and translated by Constance Jolly (New York: W. W. Norton and Co., 1972), 209.

${ }^{320}$ Kenneth Drake, The Sonatas of Beethoven: As He Played and Taught Them (Cincinnati: MTNA, 1972; reprint, Bloomington: Indiana University Press, 1981), 6. 
conception of traditional Classical musical expression. In direct response to Beethoven's solitude and retrospection he re-molded the Classical sonata form to accommodate the aspirations and conflicts of his personal struggle for resolution. Through the vehicle of the sonata, Beethoven attempted to answer an existential question regarding the significance of his life. Earlier in his life, Beethoven placed a high value on marriage and family. To his disappointment, Beethoven was unsuccessful in both situation due to his distorted perception of women and his disillusionment with the concept of the family (influenced from his childhood upbringing). The first movement seems to express Beethoven's reflection of his earlier desires and conflicts associated with intimacy and fulfillment on a personal relationship level. Lofty dreams of romance and outbursts of passion that never reached fruition are also expressed in the first movement as a direct confession of Beethoven's personal experience. The dreamlike quality of the first movement can be sensed by Beethoven's fragmented presentation of the thematic material. The gentle lyricism in the first theme may reflect the pleasant memories of his past loves. Beethoven's "outbursts of passion" may be musically portrayed in the spontaneously rhapsodical interjections within the lyrical themes. The feeling of anticipation may be present in the syncopated chords which precede the development. The conflict of emotions describing desire and disappointment arise in the development with the persistent syncopations driving the first theme material to a sudden and unfulfilled climax. Beethoven's "lofty dreans of romance" fade away in the final measures of the coda; the thematic material moves in contrary motion outward and finalizes on a weakbeat cadence.

Beethoven's discernment of time during his late period altered in duration 
and metric proportions. Considering his failing health, Beethoven had no time to waste on brooding or self-pity over previously unfulfilled aspirations. In quite the opposite manner, Beethoven focuseri his time on the reflection of his past to gain the insight he needed to the resolve his understanding of the ambiguity of his existence. The solution to Beethoven's resolution hinged on the unification of his past events to validate his present significance.

Evidence of his economical use of time is demonstrated in his concise and contracted treatment of the sonata form. Not only are the movements of the sonata abbreviated in length, but Beethoven's themes within the movements are simple and diminutional, developing primarily from the derivatives of the thematic material. Beethoven assumes the risk of presenting fragmented themes which often begin and end without the motivation of intentional direction or establishment of the key (according to Classical standards). With regard to metrical time, Beethoven's use of syncopations and anticipations signal his evasiveness (Allegretto, ma non troppo), sarcasm and past heroic fervor (Vivace alla Marcia) and forcefulness (Allegro) in communicating his intensely subjective form of expression in the late period. From a hermeneutic standpoint, it was Beethoven's inclination to transcend the interpretation of the sonata beyond the irregularities of his methodology in construction and expression.

Beethoven demonstrates the polarity of extreme contrasts between the movements and the unification of interrelating the movements. The fantastical dreamlike transcendence of the first movement is markedly contrasted by the vigorous and impetuous physical nature of the second movement; and yet a clearer understanding of Beethoven's longings in the first movement are realized in the soulful yearnings of the third movement creating a bond of unity between 
the movements. The persistent rhythmic energy of the second movement is contrasted by the spiritual depth and rectitude of the third movement; and yet the contrapuntal devices exhibited in the second movement appear with greater magnitude and force in the fourth movement which ultimately unifies these two movements. Beethoven enhances the unification process by recalling the principal theme of the first movement, which not only links the the third to the fourth movement, but overtly depicts the cyclic quality of the sonata.

The extensive use of contrapuntal devices within the sonata-allegro form of the fourth movement demonstrates Beethoven's steadfast faith and investment in traditional Baroque counterpoint and the Classical sonata form. It is the marriage of counterpoint and the sonata-allegro form that strengthens Beethoven's power of conviction to resolve the conflicts within the sonata. Beethoven's fugal deveiopment in the fourth produces the sincerest attempts at unifying the entire sonata by means of logic and regimental procedure inherent in polyphonic writing.

The mirror image of Beethoven's progressive struggle for personal fulfillment and the resolution of his self-worth are reflected in the contrasting but interrelated movements of the sonata. An analogy can be drawn by attempting to identify the individual movements as stages of Beethoven's struggle for resolution. The first movement seems to represent fragments of Beethoven's inner fantasies about personal relationships based on the fragmented thematic material which displays lyrical and rhapsodical characteristics. The second movement projects the reality of his past allegiance for the heroic ideals of the Enlightenment based on his bold and revolutionary use of chromaticism and daring tonal progressions. The persistent dotted rhythms in the second 
movement and the simulation of a drum roll in the Trio symbolize the military aspects of the second movement. The third movement signifies Beethoven's yearning for spiritual redemption and forgiveness to unburden the conflicts of his heart and cleanse his soul. The musical projection of Beethoven's religious experience can be witnessed in the reverent expression within the hymn-like chordal texture of the third movement. In the middle section of the third movement, Beethoven combines the impassioned lyricism from the first movement with the contrapuntal technique of imitation from the second movement to create a unifying bond between the movements. The resolution of Beethoven's personal struggles is portrayed through the power of his polyphonic writing and the unification of the entire sonata within the fourth rnovement. The conflicts of tonal and harmonic ambiguity in the previous movements are resolved in the fourth movement (particularly demonstrated in the fugal development).

Beethoven arrived at his personal resolution through the retrospection of his life experiences. By releasing the frustration of his fantasies associated with personal relationships and his disillusionment with the heroic ideals, Beethoven came to a spiritual understanding that the resolution to his life experiences were intrinsically founded on the acceptance his failures and shortcomings and a renewal of his faith in God, humanity and himself. 


\section{BIBLIOGRAPHY}

Anderson, Emily., ed. and trans. The Letters of Beethoven. 3 vols. London: MacMillan and Co. Ltd., 1961.

Barth, George Robert. "The Fortepianist as Orator: Beethoven and the Transformation of the Declamatory Style." Ph.D. diss., Cornell University, 1988.

Behrend, William. Ludwig van Beethoven's Pianoforte Sonatas. Translated by Ingeborg Lund. London: Dent and Sons Ltd., 1927. Reprint. New York: AMS Press, 1978.

Bekker, Paul. Beethoven. Translated by M. M. Bozman. London: Dent and Sons Ltd., 1932.

Bilson, Malcolm. "The Emergence of the Fantasy-Style in the Beethoven Piano Sonatas of the Early and Middle Periods." Ph.D. diss., University of Illinois, 1968.

Blom, Eric. Beethoven's Pianoforte Sonatas Discussed. New York: E. P. Dutton and Co. Inc., 1938. Reprint. New York: Da Capo Press, 1968.

Brendel, Alfred. Musical Thoughts and Afterthoughts. Princeton: Princeton University Press, 1976.

Carr, Cassandra Irene. "Wit and Humor as a Dramatic Force in the Beethoven Sonatas." Ph.D. diss., University of Washington, 1985.

Cockshoot, John V. The Fugue in Beethoven's Piano Music. London: Routledge and Kegan Paul, 1959.

Cooper, Martin. Beethoven: The Last Decade, 1817-1827. London: Oxford University Press, 1970.

Crowson, Lamar. "The Expanding Keyboard Range and the Sonatas of Mozart and Beethoven." Clavier 27 (1988): 17-23.

Czerny, Carl. Complete Theoretical and Practical Pianoforte School, Opus 500. London: Cocks and Company, 1839. 
Czerny Carl. On the Proper Performance of all Beethoven's Works for Piano. Edited and with a commentary by Paul Badura-Skoda. Wien: Universal Edition, 1970.

Dorfmüller, Kurt. ed. "Supplement zum Thematisch-bibliographischen Verzeichnis von Kinsky-Halm." in Beitrage zur Beethoven-Bibliographie: Studien und Materialien zum Werkverzeichnis von Kinsky-Halm. Edited by Kurt Dorfmüller. München: G. Henle Verlag, 1978.

Drake, Kenneth. The Sonatas of Beethoven: As He Played and Taught Them. Cincinnati: MTNA, 1972. Reprint. Bloomington: Indiana University Press, 1981.

Drake Kenneth. "A Study of the Beethoven Piano Sonatas in the Light of Evidence Provided by Beethoven's Pupils." Ph.D. diss., University of Illinois, 1970.

Elterlein, Ernst von. Beethoven's Pianoforte Sonatas: Explained for the Lovers of the Musical Art. Translated by Emily Hill. London: William Reeves, 1898.

Fischer, Edwin. Beethoven's Pianoforte Sonatas: A Guide for Students and Amateurs. Translated by Stanley Godman. London: Farber and Farber, 1959.

Forbes, Elliot, ed. Thayer's Life of Beethoven. rev. 2d ed., Princeton: Princeton University Press, 1973.

Fritsch, Michael F. "Beethoven's Last Piano Sonatas as Fantasy Sonatas." Ph.D. diss., Northwestern University, 1987.

Fuchs, Noreen E. "The Treatment of the Coda in Beethoven's Sonatas for Pianoforte." Master's Thesis, San Jose State University, 1979.

Good, Edwin M. Giraffes, Black Dragons, and other Pianos: A Technological History from Cristofori to the Modern Concert Grand. Stanford: Stanford University Press, 1982.

Grove, George. Beethoven, Schubert, Mendelssohn. London: MacMillan and Co. Ltd., 1951.

Grover, David S. The Piano. New York: Charles Scribner's Sons, 1978.

Hess, Willy. "The Right Tempo: Beethoven and the Metronome." The Beethoven Newsletter 3 (1988): 16-17. 
Johnson, Douglas, Alan Tyson, and Robert Winter. The Beethoven Sketchbooks: History, Reconstruction, Inventory. Berkeley: University of California Press, 1985.

Kalischer, Alfred C. Beethoven und seine Zeitgenossen. Berlin and Leipzig: Schuster and Loeffler, 1909.

Kennemer, Hubert Clarence. "The Expansion of the Keyboard Range in the Solo Piano Sonatas of Beethoven." Ph.D. diss., University of Texas at Austin, 1970.

Kerman, Joseph, and Alan Tyson. The New Grove: Beethoven. New York: W. W. Norton and Co., 1986.

Kerst, Friedrich, and Henry Edward Krehbiel., eds. Beethoven: The Man and the Artist, as Revealed in His Own Words. New York: Dover Publications, Inc., 1964.

Kramer, Lawrence. Music as Cultural Practice, 1800-1900. Berkeley: University of California Press, 1990.

Loesser, Arthur. Men, Women and Pianos. New York: Simon and Schuster, 1954.

Mellers, Wilfred. Beethoven and the Voice of God. London: Farber and Farber Ltd. 1983.

Melville, Derek. "Beethoven's Pianos." In The Beethoven Reader, Edited by Denis Arnold and Nigel Fortune. New York: W. W. Norton and Co., 1971.

Meredith, William. "Robert Birchall and Ludwig van Beethoven: Beethoven's Letter of October 1, 1816, Reappears." The Beethoven Newsletter 1 (1986): 46.

Moscheles, Ignace., ed. The Life of Beethoven. London: Henry Colburn, Publisher, 1841.

Newman, William S. Beethoven on Beethoven: Playing His Piano Music His Way.New York, W. W. Norton, 1988.

Newman, William S. Performance Practices in Beethoven's Piano Sonatas: An Introduction. New York: W. W. Norton and Co., 1971.

Newman, William S. The Sonata in the Classical Era. 3d ed., New York: W. W. Norton and Co., 1983. 
Ratz, Erwin. "Analysis and Hermeneutics, and their Significance for the Interpretation of Beethoven." Translated by Mary Whitial.Music Analysis 3 (1984): 243-254.

Reinecke, Carl. The Beethoven Pianoforte Sonatas: Letters to a Lady. Translated by E. M. Trevenen Dawson. London: Augener Ltd., [n.d.].

Rosen, Charles. The Classical Style: Haydn, Mozart, Beethoven. New York: W. W. Norton and Co., 1972.

Rosen, Charles. Sonata Forms. rev. ed. New York: W. W. Norton, 1988.

Rosenblum, Sandra. Performance Practices in Classical Piano Music: Their Principles and Applications. Bloomington: Indiana University Press, 1988.

Rosenblum, Sandra. 'Two Sets of Unexplored Metronome Marks for Beethoven's Piano Sonatas." Early Music 16 (1988): 59-70.

Schindler, Anton Felix. Beethoven As I Knew Him. Edited by Donald W. MacArdle and translated by Constance Jolly. New York: W. W. Norton and Co., 1972.

Schroder, Charles Frederick. "Final Periods of Mozart, Beethoven, and Bartók." Ph.D. diss., Graduate College of the State University of Iowa, 1965.

Sheer, Miriam. "The Structural Functions of Dynamics in Beethoven's Instrumental Works." The Beethoven Newsletter 5 (1990): 53-66.

Solomon, Maynard. Beethoven. New York: Schirmer Books, 1977.

Sonneck, O[scar] G. ed. Beethoven: Impressions by his Contemporaries. New York: Dover Publication, Inc., 1967.

Sterba, Editha and Richard Sterba. Beethoven and His Nephew: A Psychoanalytical Study of Their Relationship. Translated by Willard R. Trask. New York: Schocken Books, 1971.

Tovey, Donald F. A Companion to Beethoven's Pianoforte Sonatas: Bar to Bar Analysis. London: Associated Board of the Royal Schools of Music, 1931.

Tyson, Alan. "Moscheles and his 'Complete Edition' of Beethoven." Music Review 25(1964): 136-41.

Wagner, Richard. Beethoven. Translated by E. Dannreuther. London: William Reeves, 1870. 
Wallner, B. A., ed. Beethoven Klaviersonaten: Band II. München-Duisburg: G. Henle Verlag, 1972.

Wegeler, Franz and Ferdinand Ries. Beethoven Remembered: The Biographical Notes of Franz Wegeler and Ferdinand Ries. Translated by Frederick Noonan. Arlington: Great Ocean Publishers, 1987. 